\title{
Banks, Liquidity Crises and Economic Growth*
}

\author{
Alejandro Gaytan \\ New York University \\ Romain Ranciere \\ New York University and CERAS \\ This Version: November, 2002 \\ First Draft: August, 2001
}

\begin{abstract}
How do the liquidity functions of banks affect investment and growth at different stages of economic development? How do financial fragility and the costs of banking crises evolve with the level of wealth of countries? We analyze these issues using an overlapping generations growth model where agents, who experience idiosyncratic liquidity shocks, can invest in a liquid storage technology or in a partially illiquid Cobb Douglas technology. By pooling liquidity risk, banks play a growth enhancing role in reducing inefficient liquidation of long term projects, but they may face liquidity crises associated with severe output losses. We show that middle income economies may find optimal to be exposed to liquidity crises, while poor and rich economies have more incentives to develop a fully covered banking system. Therefore, middle income economies could experience banking crises in the process of their development and, as they get richer, they eventually converge to a financially safe long run steady state. Finally, the model replicates the empirical fact of higher costs of banking crises for middle income economies.
\end{abstract}

KEYWORDS: OLG growth models, liquidity, financial intermediation, financial fragility, banking crises.

JEL Codes: E44, G21, O11

*We are grateful to Debraj Ray, Jess Benhabib, Boyan Jovanovic, Douglas Gale, Jason Cummins, Olivier Jeanne, Giovanni Della Riccia, Robert Townsend, for their comments and suggestions. All errors are ours. 


\section{Introduction.}

This paper investigates the relationship between the liquidity roles of banks, financial fragility and economic growth. It integrates the analysis of liquidity crises into the analysis of the long run growth effects of financial intermediation.

The development of a banking system to pool liquidity risk allows economies to achieve higher growth rates and higher long run level of wealth and consumption. We show that financial development is particularly important for the growth performance of middle-income economies.

However, a banking system may be vulnerable to liquidity crises with potentially large output and welfare consequences in the short run. We show that sufficiently rich economies can afford the cost of full coverage against the risk of liquidity crises, while middle income economies may find optimal to remain vulnerable in exchange for higher returns and welfare. This explains why middle income countries exhibit on average higher growth and higher frequency of banking crises.

A large number of empirical studies support the existence of a positive relationship between financial intermediation and growth. King and Levine [1995] and Beck, Levine and Loayza [2000] find a positive effect of the relative size of the banking sector, and several measures of financial development on per capita output growth. ${ }^{1}$ On the other hand, the banking crisis literature has pointed out the role of financial liberalization and the rapid increase in financial depth as good predictors of financial crisis. ${ }^{2}$ Loayza and Ranciere [2001] attempt to reconcile the apparent contradiction between those two strands of the literature. They show that a long-run positive relationship between financial intermediation and output growth can coexist for some countries with a negative short-run relationship, specially for those countries that have suffered financial crises episodes.

\footnotetext{
${ }^{1}$ Beck, Levine and Loayza (2000) use an external instruments approach to address the issue of joint endogeneity between financial development and growth.

${ }^{2}$ See for example Demirguc-Kunt and Degatriache [1998 and 2000]; Gourinchas, Landerretche and Valdes [1999]; Kaminsky and Reinhart, [1999].
} 
Table 1: Financial Development and Real Per Capita Income Growth(1975-1998)

\begin{tabular}{|c|c|c|c|c|}
\hline GrowthQuartile & Initial Income per capita ${ }^{1}$ & Final Income per capita & Growth(\%) & Financial Development $(\%)$ \\
\hline Q1 & 3443.75 & 5958.53 & 0.60 & 0.35 \\
\hline Q2 & 8833.43 & 11354.68 & 0.25 & 0.29 \\
\hline QB & 1513.17 & 1644.41 & 0.07 & 0.16 \\
\hline Q4 & 2181.37 & 1641.23 & -0.22 & 0.08 \\
\hline Average & 3992.93 & 5149.71 & 0.17 & 0.22 \\
\hline Number of Countries & 96.00 & & & \\
\hline
\end{tabular}

The empirical information on financial development and financial crises provide evidence that the costs and benefits of financial intermediation tend to differ with the level of wealth of the economy. Tables 1 and 2 summarize information on financial development, growth and financial crises. ${ }^{3}$ Tables 1 orders countries in quartiles according with the real per capita income growth over the period 1975-1998. For each group, it displays the mean of initial and final income per capita and the degree of variation in financial depth ${ }^{4}$. Table 1 confirms the positive relationship between growth performance and financial development. Moreover, those countries with a joint high performance of growth and financial development are typically middle-income economies who have "emerged" during the period. At the other end, in the fourth quartile, we find countries that have experienced declines in per capita income during the period along with poor financial development. This suggest that financial intermediation plays a crucial role in the growth performance of middleincome "emerging" economies.

Table 2 : Real Income Per Capita and Systemic Banking Crises ${ }^{3}$

\begin{tabular}{ccc}
\hline \hline Income Quartile & Number of systemic banking crisis ${ }^{4}$ & Partition of crises $^{\text {Q }}$ \\
\hline Q1 & 6 & $18.75 \%$ \\
Q2 & 9 & $28.13 \%$ \\
Q3 & 11 & $34.38 \%$ \\
Q4 & 6 & $18.75 \%$ \\
Total & 32 & $100.00 \%$ \\
\hline \hline${ }^{3}$ average 1975-1998 GDP per Capita Constant US\$ & \\
${ }^{4}$ source: Caprio and Klingebiel (1999) &
\end{tabular}

\footnotetext{
${ }^{3}$ There are 96 countries in the sample from 1975 to 1998. 32 of the countries in this sample experienced at least one systemic banking crises (Caprio-Klingebiel [1999]).

${ }^{4}$ Financial depth is measured by the ratio of liquid liabilities over GDP.
} 
Table 2, presents information on income per capita and banking crises. ${ }^{5}$ Countries are divided in quartiles according to their "level" of GDP per capita. The table shows that the highest frequency of banking crises is for middle-income economies. Moreover, emerging economies have not only experienced higher recurrence of banking crises but also more severe costs. Figure 1 plots the cumulative fiscal cost of banking crises (as percentage of GDP) for countries ranked according to their average per capita income. The severity of the banking crisis has been much higher for middle-income economies than for poor and rich economies.

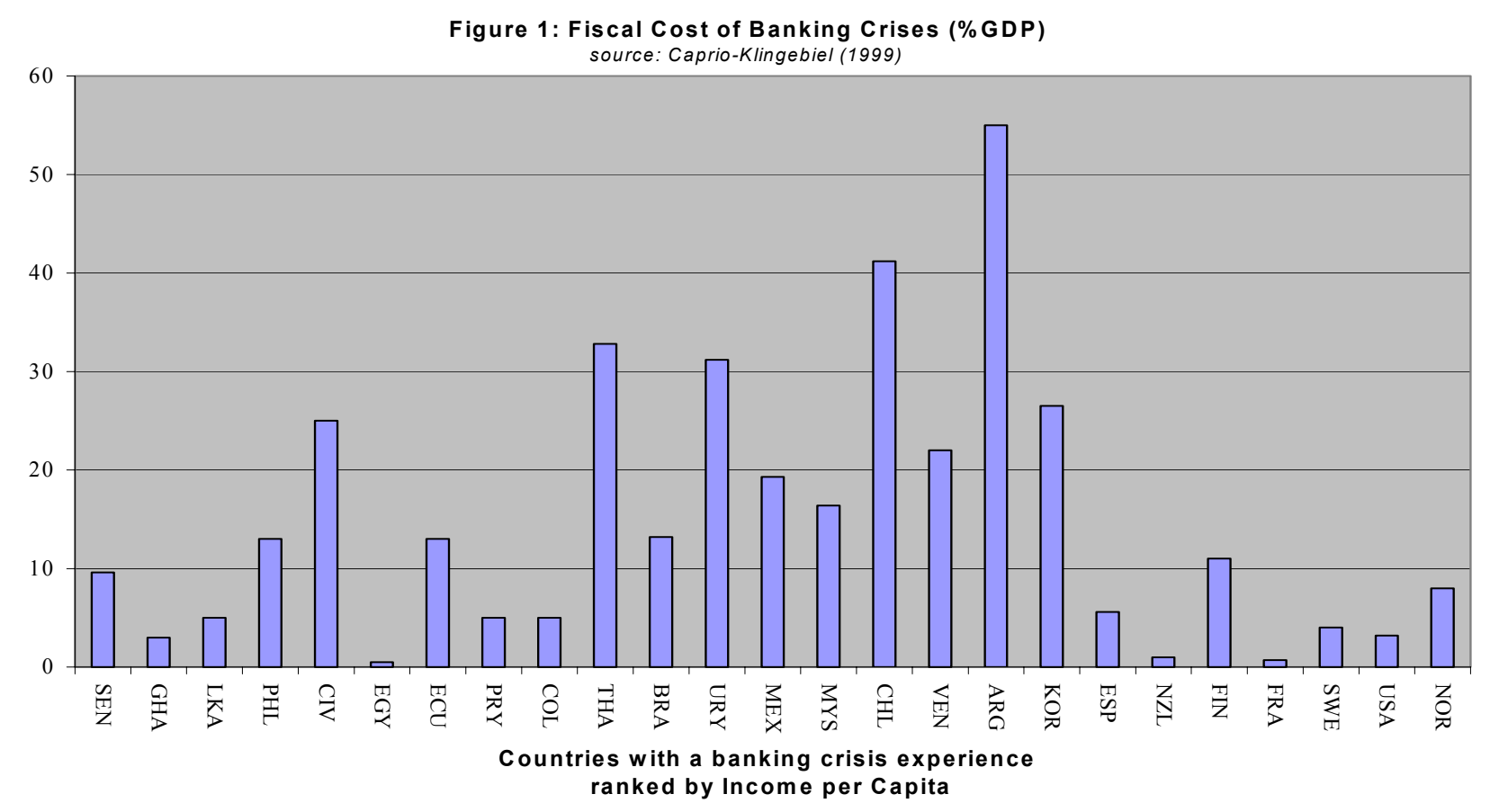

Financial intermediaries play several roles that can increase depositors' welfare and foster economic growth. This paper focuses only on allocating and liquidity functions of the banks, in particular: financial intermediaries (i) provide an efficient mechanism that channels investment capital into its higher returns; (ii) are efficient suppliers of liquidity (can transform illiquid assets into liquid liabilities); and (iii) provide liquidity insurance that eliminates idiosyncratic liquidity

\footnotetext{
${ }^{5}$ Caprio and Klingebiel define a systemic banking crisis as a situation where aggregate capital of the banking sector has been exhausted.
} 
risk. ${ }^{6}$ We study what are the costs and benefits of these liquidity functions on welfare and growth of the economy, and how they change in the process of economic development. This paper constitutes, to our knowledge, the first attempt to study the possibility and consequences of financial crises in a growth model with financial intermediaries.

We use an inter-temporal model of financial intermediaries to analyze the dynamics of wealth, capital and consumption. The model embeds a modified version of the Diamond and Dybvig [1983] model of liquidity provision (henceforth DD) ${ }^{7}$ into an overlapping generations model (Diamond [1965]). There are two technologies available, a short term storage technology, and a long term technology. In this paper, the long run technology uses a standard Cobb-Douglas production function with labor and capital as inputs. This technology constitutes the channel for growth over time and among generations.

As it has been noticed by Cooper and Ross [1998], the original Diamond-Dybvig solution does not consider the impact of the possibility of runs on the design of the optimal deposit contract or the bank's investment portfolio. In this paper we characterize the optimal deposit contract offered by a competitive bank when panic runs can occur with positive probability, and we show how this contract changes with the level of wealth of the economy. When panic crises are possible, an equilibrium selection mechanism is required. In this paper we consider the simplest mechanism: a sunspot; we assume that the bank can assign a fixed probability to the event of a panic run.

The possibility of bank run occurring with positive probability affects the design of the contract offered by the bank. It involves a decision between being covered, that is, invulnerable to panic runs; and taking the risk to be exposed to liquidity crises. Covered banking is possible at the cost of lower liquidity insurance, while exposed banking has the cost of possible crises episodes. The welfare implications of these two types of arrangements will depend on the probability with which crises can happen, and on the level of wealth of the economy.

The characterization of the optimal banking system constitutes the key result of this paper: for sufficiently high probabilities of crises, a covered banking system would be optimal for any level of wealth; for lower probabilities, poor and rich economies would opt for a covered banking system,

\footnotetext{
${ }^{6}$ Most of the existing literature on financial intermediation and growth focus on other functions of financial intermediation: Pooling of risk among different investment projects, specialization, adoption of new technologies, etc. See for example Greenwood and Jovanovic [1990], Saint Paul [1992] and Acemoglou and Zilibotti [1997].

${ }^{7}$ The modified version of the Diamond-Dybvig model emphasizes the distinction between liquidity insurance and liquidity provision in the role of banks.
} 
while middle income economies would chose an exposed banking system; finally, when the risk of runs is small enough, poor and middle income economies will choose to be exposed to liquidity crises. Nevertheless as long as the probability of runs is positive, there will be a level of wealth above which a covered banking system would be optimal.

The analysis of the optimal banking system has important implications for economic growth. Those economies that choose an exposed banking system take on the risk of short run output losses of crises to enjoy the higher liquidity insurance and possible higher returns. Nevertheless, as they get richer, they can eventually "escape" financial vulnerability and converge to a long run financially safe steady state.

The comparison of optimal banking and the benchmark of autarky yields two results. First, the optimal banking system always dominates autarky in terms of welfare of the current generation of depositors independently of the probability of runs. Second, even if at early stages of economic development, the provision of liquidity insurance imposes some growth costs, once the economy has crossed a certain wealth threshold, the development of a banking system has unambiguously positive growth consequences.

Finally, we show that the output losses suffered by an exposed system in case of a run, are more severe for middle income economies than for poor and rich economies replicating the empirical pattern on the costs of banking crises(see Figure 1).

Some previous literature has studied liquidity provision by financial intermediaries in an intertemporal framework. In particular, Bencivenga and Smith [1991, 1998], Qi [1994] and Fulghieri and Rovelli [1998] have studied the DD model in overlapping generations frameworks. Bencivenga and Smith [1991] investigate the relationship between financial intermediation and growth. However, their model is an endogenous growth model with constant returns to capital. With this assumption, the role of financial intermediation is no longer dependent on the level of wealth, and financial intermediation is always growth enhancing. Qi [1994] and Fulghieri and Rovelli [1998] focus is on intergenerational transfers and not on growth; their model has technologies with constant returns to capital and is an endowment economy without dynamics in wealth and no capital accumulation. ${ }^{8}$ Even when these authors recognize the presence and potential importance of a bank

\footnotetext{
${ }^{8}$ In our model, the use of a Cobb-Douglas technology, for the long asset, makes the returns to investment endogenous, and the banking solution- optimal investment and liquidation policy and liquidty insurance- dependent on the wealth of the economy.
} 
run equilibrium, none of these models incorporate financial crises in their analysis.

Our results of the mapping between the level of development and the vulnerability to crises have some similarities with Acemoglu and Zilibotti [1997]. In their model, uncertainty is suppressed above a certain level of wealth through full diversification, while in our model a sufficiently rich economy can afford the cost of full coverage against crises

Section 2 describes the general set up of the model: the structure of overlapping generations, the preferences, and the technologies available. Section 3 studies the optimal investment portfolio and growth under financial autarky. Section 4 characterizes the optimal banking system and studies the distortions generated by the possibility of crises and the dynamic implications of banking. Section 5 analyzes the consequences of a banking system, first by comparing the economy with a banking system with the economy under autarky, and then by analyzing the output cost of banking crisis. Finally, section 6 confronts our results to the empirical evidence, concludes and sets an agenda for future research.

\section{The Basic Model}

The economy consists of an infinite sequence of overlapping generations. In each period, a generation, composed by a continuum of ex-ante identical agents with unit mass, is born; there is no population growth.

Agents live for two periods. They have an endowment of one unit of labor during the first period of their lives, which they supply inelastically. Agents do not value consumption when they are young. During the second period of their life they are subject to a time preference shock. With probability $\pi$, an agent only values consumption when middle aged (the beginning of her second period), and becomes an early consumer. With probability $(1-\pi)$, she only values consumption when old (the end of her second period) and becomes a late consumer. The shock is stochastically independent across agents, and is private information to the agent. Therefore, preferences of an agent that belongs to generation $t$ are:

$$
\begin{aligned}
& U\left(c_{t}^{t}, c_{E}^{t}, c_{L}^{t}\right)=\Gamma u\left(c_{E}^{t}\right)+(1-\Gamma) u\left(c_{L}^{t}\right) \\
& \text { with }\left\{\begin{array}{llc}
\Gamma=1 & \text { with probability } & \pi \\
\Gamma=0 & \text { with probability } & (1-\pi)
\end{array}\right.
\end{aligned}
$$


where $c_{E}^{t}, c_{L}^{t} \geq 0$, are the levels of early and late consumption respectively at $t+1$ of an agent born at $t$, and $u(\cdot)$ belongs to the constant relative risk aversion class of utility functions: $u(c)=\frac{c^{1-\sigma}}{1-\sigma}$.

Risk averse agents would like to reduce the ex-ante gap between early and late consumption. We can measure the level of liquidity insurance attained by a financial arrangement by the ratio of consumptions $\left(\frac{c_{E}}{c_{L}}\right)$.

There is one good, used for consumption and investment. There are two technologies available. A storage technology, that uses the good as unique input and, for each unit invested at $t$, gives a return of one unit in any sub-period of $t+1$. There is also a long term technology with a CobbDouglas production function, which uses labor $l$ and capital $k$ as inputs. ${ }^{9}$ It is assumed that capital fully depreciates after being used in production. If the technology is left until full maturity (the end of the period), it gives the return:

$$
\digamma(k, l)=A k^{\beta} l^{1-\beta}
$$

Since the unit of labor is supplied inelastically, define the capital intensive production function by:

$$
f(k) \equiv \digamma(k, 1)=A k^{\beta}
$$

This production can be prematurely liquidated, with a liquidation cost. In this case the product generated is a fraction $0<\gamma<1$ of the full return at maturity, i.e., $\gamma f(k)$. Hence, the liquidation cost of the long term technology is expressed in terms of output and not in terms of capital. This assumption makes the relative marginal returns of a long project left until maturity and liquidated prematurely a constant $\left(\frac{f^{\prime}(k)}{\gamma f^{\prime}(k)} \equiv \frac{1}{\gamma}\right){ }^{10}$

An example helps to better illustrate this liquidation technology. We can think about this technology as a crop. It is irreversible in terms of the original capital invested (seeds). If it is left until full maturity, it yields the maximum size of crop; however, premature liquidation would yield

\footnotetext{
${ }^{9}$ To motivate the differences of the two technologies, we can think that the country is a small open economy with access to domestic production (the long technology) and to an international asset (the short technology) that has constant returns to investment (see Velasco and Chang [2000]).

${ }^{10}$ The results of the paper are robust to a broad range of specifications about concavity of the two technologies. In particular, the liquid technology may pay $g(x)$ units on both subperiods, for $x$ units invested, as long as there is a trade-off between liquidty and return (i.e., $f(\cdot)$ must be more concave than $g(\cdot)$ ). This assumption is justified because otherwise the liquid technology would dominate the long technology. The robustness analysis is available upon request.
} 
crop that is not fully grown. Finally, the amount of labor required both at the planting and at the harvest is the same, and it is independent of the timing of the harvest.

Define the return of holding the long asset as the function $h(k) \equiv \beta f(k)$. Hence, the marginal return of the long investment is $h^{\prime}(k)$ if the investment is maintained until full maturity, and $\gamma h^{\prime}(k)$ if it is liquidated prematurely. Let's define the two following capital levels:

$$
\begin{aligned}
\underline{k} \text { such that } \gamma h^{\prime}(\underline{k}) & =1 \\
\bar{k} \text { such that } h^{\prime}(\bar{k}) & =1
\end{aligned}
$$

Since labor is inelastically supplied, the long term asset presents diminishing returns to capital. Figure 2 describes the marginal returns of the technologies as functions of the level of investment. For low levels of capital $(k<\underline{k})$, the marginal return of the long term asset, even when it is prematurely liquidated, exceeds the marginal return of the storage technology $\left(\gamma h^{\prime}(k) \geq 1\right)$. Beyond some level of investment in the long asset $(k>\bar{k})$, its marginal return is lower than one $\left(h^{\prime}(k) \leq 1\right)$

Factor markets are competitive, so each input is paid its realized marginal product. However, the realized marginal product depends on the financial arrangement in place because it depends on the proportion of long term projects liquidated.

Wages received at the end of period $t$ represent the unique source of wealth for members of the generation. After receiving wages, agents realize make investment decisions before observing the realization of their liquidity shock. Since agents do not value consumption when young, the consumption-saving decision at $t$ is trivial, and they will invest their full wealth either directly in the two technologies (autarky) or as bank deposits (financial intermediation). ${ }^{11}$ It is assumed that there is an initial generation endowed with $w_{0}>0$ units of the consumption good.

In the two following sectiona we set up two financial arrangements: financial autarky and the competitive banking solution. Financial autarky is a benchmark to compare the welfare and growth costs and benefits of financial intermediation. In this case, agents have to insure themselves against future liquidity needs. In the second case we develop a general banking solution, where the financial intermediary provides liquidity and liquidity insurance to depositors. Under this arrangement, the idiosyncratic liquidity shock is private information to the agent, and the bank has to offer incentive compatible allocations. However, even when a truth revelation mechanism is in place,

\footnotetext{
${ }^{11}$ This is an importan difference from the OLG model of Diamond (1965). We abstract from the consumptionsaving decision to stress the choice among assets with different liquidity.
} 
panic bank runs are still possible, and the optimal demand deposit contract must consider the bank's expectations about the probability of a panic.

\section{Financial Autarky}

Under financial autarky, young agents make their investment decision between storing goods and investing in capital on their own. We adopt a simplifying assumption about the structure of the economy. We assume that each worker supplies her unit of labor to a continuum of representative firms with mass $m \in(0,1] .{ }^{12}$. With this assumption, young workers are paid a wage equal to the expected marginal product of labor $w_{t+1}=(1-\beta)[\pi \gamma+1-\pi] f\left(k_{t}\right)^{13}$ and, at the same time, the investors (old agents) receive the marginal product of their investment-liquidation decision $(\gamma \beta f(k)$ if early consumer and $\beta f(k)$ if late).

\subsection{The optimal individual investment decision}

In the absence of financial markets, agents cannot get insurance against idiosyncratic liquidity risk. Investment in capital is risky in the sense that its return will depend on the realization of the liquidity shock. Agents' investment choices will determine the level of consumption they will enjoy under each state of nature. At the end of their first period, for any given level of wealth $w>0$, a typical agent of generation $t$, chooses investment in the long technology $k$ to maximize:

$$
\begin{gathered}
\pi u\left(c_{E}\right)+(1-\pi) u\left(c_{L}\right) \\
\text { subject to } 0 \leq k \leq w
\end{gathered}
$$

where $c_{E}=w-k+\gamma h(k), c_{L}=w-k+h(k)$, and the difference between wealth and capital $(w-k)$, represents investment in the storage technology.

The following proposition characterizes the optimal solution for members of any given generation under financial autarky:

\footnotetext{
${ }^{12}$ This mass $m$ can be arbitrarily close to zero, however, it is equivalent to assume that every worker works for all firms.

${ }^{13}$ This assumption avoids the possibility of heterogeneity among consumers, that would unnecessarily complicate the dynamics of the model.
} 
Proposition 3.1

\begin{tabular}{||c|c|c|c|c|c||}
\hline \hline & $w$ & $\frac{u^{\prime}\left(c_{E}\right)}{u^{\prime}\left(c_{L}\right)}$ & $k$ & $c_{E}$ & $c_{L}$ \\
\hline $\boldsymbol{I}$ & $0<w \leq w^{*}$ & $\frac{1}{\gamma^{\sigma}}$ & $k=w$ & $\gamma h(w)$ & $h(w)$ \\
\hline $\boldsymbol{I I}$ & $w \geq w^{*}$ & $\frac{u^{\prime}\left(c_{E}\right)}{u^{\prime}\left(c_{L}\right)}=\frac{(1-\pi)\left(h^{\prime}(k)-1\right)}{\pi\left(1-\gamma h^{\prime}(k)\right)}$ & $k=k^{a}(w)$ & $w-k+\gamma h(k)$ & $w-k+h(k)$ \\
\hline
\end{tabular}

with $w^{*}$ defined by: $h^{\prime}\left(w^{*}\right)=\frac{\pi+(1-\pi) \gamma^{\sigma}}{\gamma \pi+(1-\pi) \gamma^{\sigma}}$

Proof. Gaytan-Ranciere (2002a).

The optimal solution under autarky is inefficient. The source of inefficiencies is that, in the absence of financial markets, each agent needs to insure herself against any liquidity need she may face. In poor economies self insured agents invest, as precautionary savings, their full wealth in capital beyond the point where it is efficient to do so. When the marginal return of the short asset exceeds the marginal liquidation value of the long asset, $\left(\gamma h^{\prime}(w)<1\right)$, it would be efficient to start investing a fraction of wealth in the short asset. However, $w^{*}>\underline{k}$ means that for any level of wealth between $\underline{k}$ and $w^{*}$ agents are over-investing in the long asset $(k=w)$, although $\gamma h^{\prime}(w)<1$.

For levels of wealth greater than the threshold $w^{*}$, a second inefficiency arises. Early consumers are forced to liquidate productive investments to cover their liquidity needs, while late consumers finance some of their consumption by using the less productive liquid investment. The impossibility of receiving insurance through financial markets generates an inefficient liquidation of the long investment. Therefore, when $w$ is very large investment in capital is bounded above by $k_{\max }$ $\left(h^{\prime}\left(k_{\max }\right)=\frac{1}{\pi \gamma+(1-\pi)}>1\right)$, while it is efficient to invest up to the higher level $\bar{k}\left(h^{\prime}(\bar{k})=1\right)^{14}$.

For low levels of wealth, when agents are investing only in the long technology, liquidity self insurance is constant $\left(\frac{c_{E}}{c_{L}}=\gamma\right)$. For higher levels of wealth, when agents are investing in both assets $\left(w>w^{*}\right)$, an increase in wealth reduces the gap between early and late consumption. Nevertheless, full liquidity risk insurance is not possible under financial autarky.

\subsection{The dynamics of wealth, capital and consumption under autarky}

We can now characterize the steady state of the economy and study the evolution of wages, capital and consumption towards this stationary equilibrium. Since capital fully depreciates after it is

\footnotetext{
${ }^{14}$ Notice that our analysis of the inefficiency of financial autarky echoes the literature on precautionary savings in presence of uninsured idiosyncratic risks and liquidity constraints (Aiyagari (1994), Jappelli and Pagano (1994), Calvet-Angeletos (2001)).
} 
used, the connection between the individual problem and the dynamics of the intertemporal model is given by wages of the next generation:

$$
\begin{aligned}
& w_{t}=F^{a}\left(w_{t-1}\right)=(1-\beta)(\pi \gamma+1-\pi) f\left(k\left(w_{t-1}\right)\right) \\
& k_{t}=k\left(w_{t-1}\right)=k_{\text {opt }}\left(w_{t-1}\right)
\end{aligned}
$$

The following proposition characterizes the dynamics of this economy :

Proposition 3.2 (convergence and the steady state) The economy converges towards a unique stable steady state $\bar{w}^{a}>0$ and $k\left(\bar{w}^{a}\right)$. The steady state is defined by $F^{b}\left(\bar{w}^{a}\right)=\bar{w}^{a}$

Proof. Gaytan-Ranciere (2002a)

Figure 6 presents the dynamics of wealth under autarky. Beyond the threshold $w^{*}$, the rate of growth decreases rapidly, overinvestment in the previous region has already exhausted the marginal returns on capital. A constant level of liquidation $\pi$, due to self insurance, becomes more and more costly in terms of growth. Finally, as both consumptions $\left(c_{E}, c_{L}\right)$ are monotonically increasing in wealth, their dynamics follow the dynamics of wealth.

\section{Intra-generational Risk Sharing: the Optimal Banking System}

All liquidity uncertainty in this economy pertains to the liquidity needs of individuals, and it is idiosyncratic. Therefore, welfare gains are possible via a mechanism of liquidity preference insurance. In addition, under financial autarky the mismatch between ex-post liquidity needs of the agents and the timing of highest returns of the assets, generates an inefficient allocation of aggregate resources. Financial intermediaries can provide welfare improvements by pooling liquidity needs and by finding an efficient balance between the agents' preference for insurance and the timing of the highest returns on the assets.

However, since liquidation is costly, if the value of the bank's assets at the early sub-period cannot cover a total withdraw on deposits, the bank is vulnerable to a panic run. A financial crisis driven by a panic appears as a coordination problem in which late consumers believe that the bank won't be able to service all deposits in the late sub-period, driving a total run on the bank at the beginning of $t+1$. The optimal deposit contract is influenced by the possibility of a financial panic. 
The bank faces a tension between improving welfare of depositors, by offering higher returns and liquidity insurance, and having a more vulnerable system. If the bank could assign a probability to the event of a financial panic, it could find the most efficient balance between these two objectives. Diamond and Dybvig (1983) does not consider the effect of the possibility of bank runs on the optimal risk sharing contract and the optimal portfolio of the bank. Nevertheless the DD solution is a benchmark because it is the best risk sharing possible if the liquidity shocks were observable. We will refer to the DD contract and investment portfolio as the first best or unconstrained optimal risk sharing solution.

In this section we develop the optimal risk sharing solution when the bank assigns a fixed probability to a financial panic. The unconstrained optimal risk sharing appears as a limiting case of the general problem (in the limit when the probability of a panic tends to zero). This benchmark is useful to determine the distortions generated by the existence of unobservable shocks and the existence of a positive probability of a financial panic. ${ }^{15}$

\subsection{Generation $t$ 's Optimal Risk-Sharing}

We consider a generational bank that pools resources and maximizes expected utility of current depositors. Since the t-bank pools labor income from the agents $w$, on the aggregate, all liquidity uncertainty disappears: by the law of large numbers, the bank knows that a proportion $\pi$ of agents will demand their deposits in the early sub-period, and a proportion $(1-\pi)$ in the late sub-period. Therefore it can offer a deposit contract that promises a fixed payment $c_{E}$ for the beginning of period $t+1$, and $c_{L}$ for the late sub-period of $t+1$. To provide the optimal risk sharing contract the financial intermediary chooses the investment portfolio $k$, and the optimal liquidation policy. Since the relative marginal returns of the assets vary with the level of wealth, it may be optimal to transfer resources between sub-periods: the bank can liquidate a proportion $\lambda$ of the long asset, to serve early consumers, and it can keep in storage an amount $i$ of the short asset, or "excess liquidity", for late consumption. This policy is aimed to form the most efficient match between liquidity needs of agents and the highest returns of the assets. Since the type of agent remains private information, a self-revelation mechanism is necessary to make the contract incentive compatible. Whenever the

\footnotetext{
${ }^{15}$ In our model all the ongoing projects are financed with investment of the older generation alive, therefore any risk sharing can only be done among members of the same generation. Qi [1994], Fulgueri and Rovelli [1998] and Bhattarcharya et.al. [1998] allow for overlapping investors, however, their focus is on optimal risk sharing between generations without reference to growth.
} 
contract offers higher consumption in the late sub-period $\left(c_{E} \leq c_{L}\right)$, patient agents have an incentive to wait until the full realization of the assets' returns.

\section{Existence of a Bank Run Equilibrium}

At the beginning of $t+1$ those agents that claim to be early consumers withdraw their deposits, and the bank is forced to liquidate any amount of assets required to satisfy that demand. The remaining assets are let to mature until the second sub-period to serve late consumers. The implication of the liquidation cost on the long technology is that the value of the bank's total portfolio at the early sub-period, $\left(c_{R} \equiv w-k+\gamma h(k)\right)$ is lower than the value if the technologies were left to mature as planned $(w-k+(\lambda \gamma+1-\lambda) h(k))$. When all consumers withdraw their deposits according with their true type, the bank faces a demand of $\pi c_{E}$ in the early sub-period. However if all late agents misrepresent their type and withdraw early, the bank has to meet a total demand for resources of $c_{E}$. Once late agents have learned their type they face the decision between waiting and receiving a share of the remaining assets in the late sub-period, or claim to be early and withdraw their resources from the bank. Whenever the bank has enough resources in the early period to satisfy any withdrawal, the dominant strategy for late consumers is to wait. Therefore, a run strategy can only be optimal if the value of all liabilities in the early sub-period exceed the liquidation value of the banks portfolio, that is if:

$$
c_{E}>c_{R} \equiv w-k+\gamma h(k)
$$

If (6) holds, and the contract is incentive compatible, there are two possible equilibria: a honest equilibrium where agents withdraw from the bank according with their true type, and a run equilibrium where all agents withdraw their deposits, pretending to be early consumers. In the run equilibrium the bank declares bankruptcy and distributes any remaining assets among claimants following a bankruptcy rule. Here we will assume as bankruptcy rule a pro-rata distribution of the assets. ${ }^{16}$ The pro-rata distribution divides equally the liquidation value of the bank's assets, among all claimants. Since it is not possible to distinguish who has misrepresented her type and who has

\footnotetext{
${ }^{16}$ There are two main bankrupcy rules: the sequential service rule, and the pro-rata distribution. Under the sequential service rule, the bank services all early withdrawals the promised pay-off $c_{E}$ up to exhaustion of its assets, and it closes afterwards. However, with isoelastic preferences there is an important drawback with this solution: for low risk aversion $(\sigma \leq 1)$ there are no crisis in a large range of wealth, rendering the problem uninteresting. For higher risk aversion this equilibrium can neither be supported as the solution of a mutual that maximizes welfare of all of its members, nor as the solution of a representative profit maximizing bank in a competitive system See Gaytan and Ranciere (2002b).
} 
withdrawn according with her real liquidity needs, it is optimal to assign the same consumption to any consumer that has withdrawn early. In the run equilibrium the bank will provide all consumers an equal share of its assets $c_{R}$.

\section{Equilibrium Selection Mechanism.}

A maximizing bank must necessarily realize that a contract for which (6) holds makes it vulnerable to panic runs, and this fact will affect the design of the contract. The question of how the equilibrium is selected when both equilibria are possible is crucial to determine how it affects the choice of the optimal contract. In the absence of additional uncertainty, it is not clear what drives expectations about the future solvency of the bank. In this paper we assume the most basic equilibrium selection mechanism: ${ }^{17}$ a sunspot. We assume that there is a publicly observable variable that influences the agents' level of "optimism" about the solvency of the bank. Suppose that with probability $q$ the variable takes values that lead to a pessimistic assessment about future solvency. Nevertheless, pessimistic expectations can lead to a financial crisis only when the bank is vulnerable.

\subsubsection{The Bank's Problem}

Let $\theta \in\{0,1\}$ be the state variable of a bank run. If $\theta=1$ late agents withdraw the deposits in the early sub-period, and if $\theta=0$ all agents make their withdrawals according with their type. Let $\eta$ be the probability of a bank run given the optimal contract and investment portfolio. If the contract makes the bank solvent under any circumstance in the early sub-period $\left(c_{E} \leq c_{R}\right)$ it is not optimal to run, even if all other late agents run $(\eta=0)$. On the other hand if $(6)$ holds the probability of a bank run is the probability of pessimistic expectations $(\eta=q)$.

At any period $t$, and for any given level of deposits (wealth $w>0$ ), a representative bank chooses $k, \lambda, i, c_{E}, c_{L}$ to maximize expected utility of a representative current depositor: ${ }^{18}$

\footnotetext{
${ }^{17}$ Several authors have studied bank runs as an equilibrium phenomenon (Postlwaite and Vives [1987], Jacklin and Bhattacharya [1988], Cooper and Ross [1998], Allen and Gale [1998], Golfajn and Valdes [1997]). These papers either assume an exogenous probability of crises, or neglect the possibility of panic-based runs. In a recent paper Goldstein and Pauzner [2001] tackle the problem of equilibrium selection and endogenize the probability of bank runs. Based on the ideas of global games developed by Carlsson and van Damme [1993], and Morris and Shin [1998] the authors show that the existence of aggregate uncertainty and imperfect and asymmetric private information, can select a unique equilibrium in the static DD model.

${ }^{18}$ The bank centralizes production and pays a wage to the following generation $\left(w^{\prime}\right)$ equal to the realized marginal product of labor $w^{\prime}=(1-\beta)(\lambda \gamma+1-\lambda) f(k)$.
} 


$$
\begin{aligned}
& V(\eta, w)=\max _{k, \lambda, i, c_{E}, c_{L}}(1-\eta)\left[\pi u\left(c_{E}\right)+(1-\pi) u\left(c_{L}\right)\right]+\eta u\left(c_{R}\right) \text { subject to: } \\
& \pi c_{E} \leq w-k-i+\lambda \gamma h(k) \leq w+\lambda \gamma h(k)+(1-\lambda) h(k) \\
&(1-\pi) c_{L}+\pi c_{E} \leq w-k+\lambda \leq c_{L} \\
& c_{E} \leq \leq \lambda \leq 1 \\
& 0 \leq k \leq w \\
& 0 \leq i \leq w-k \\
& c_{R}=w-k+\gamma h(k) \\
& \eta=\left\{\begin{array}{l}
\operatorname{Pr}\left(\theta=1 \mid k^{*}, \lambda^{*}, i^{*}, c_{E}^{*}, c_{L}^{*}\right)=0 \Leftrightarrow c_{E} \leq c_{R} \\
\operatorname{Pr}\left(\theta=1 \mid k^{*}, \lambda^{*}, i^{*}, c_{E}^{*}, c_{L}^{*}\right)=q \Leftrightarrow c_{E}>c_{R}
\end{array}\right.
\end{aligned}
$$

Equation 8 is the resource constraint at the early sub-period of $t+1$; for serving agents with early liquidity needs, the bank can liquidate the short asset $(w-k)$ and a proportion $\lambda$ of the long term technology. Equation 9 is the resource constraint at the late sub-period of $t+1$; the bank uses all its remaining assets to serve late consumers. Since agents still have access to the storage technology, the bank must offer a higher return to patient consumers (the incentive compatibility constraint 10). Finally, the probability of a bank run (equation 15) given the optimal contract is equal to the sunspot probability if the bank is vulnerable to a crisis, and zero otherwise.

The bank's problem can be decomposed into two decision problems that provide insights about the tensions and distortions of the optimal contract generated by the possibility of crises. The bank can offer two alternative types of contracts. Under the first type of contract "covered banking", the financial intermediary chooses a contract that makes it invulnerable to crisis $\left(c_{E} \leq c_{R} \Rightarrow \eta=0\right)$. The returns on deposits under this contract are independent of the realization of the sunspot. Under the second type of contract "exposed banking", the bank takes on the risk of having a run on its deposits $\left(c_{E}>c_{R} \Rightarrow \eta=q\right) .{ }^{19}$ For any given level of wealth, the bank determines first the optimal contract for each type and, in the second stage, it selects the type of contract that maximizes expected utility. ${ }^{20}$ This second decision is equivalent to choosing the probability with which crisis

\footnotetext{
${ }^{19}$ Using the terminology of Cooper and Ross (1998) "covered banking" correspond to "run preventive contracts" and "exposed banking" to "contracts with runs".

${ }^{20}$ It is important to notice that the "covered banking" contract may be optimal, and it is not impossed as prudential
} 
will occur $(\eta)$.

The optimal covered banking contract $O^{c}=\left\{k^{c}, \lambda^{c}, i^{c}, c^{c}, c^{c}\right\}$ solves the problem:

$$
\begin{gathered}
V^{c}(w)=\max _{k, \lambda, i, c_{E}, c_{L}} \pi u\left(c_{E}\right)+(1-\pi) u\left(c_{L}\right) \text { subject to: } \\
(8),(9),(11),(10),(12),(13), \text { and } \\
c_{E} \leq w-k+\gamma h(k)
\end{gathered}
$$

where (16) is the run preventive constraint..

The optimal exposed banking contract $O^{e}=\left\{k^{e}, \lambda^{e}, i^{e}, c^{e}, c^{e}\right\}$ solves the problem:

$$
V^{e}(q, w)=\max _{k, \lambda, i, c_{E}, c_{L}}(1-q)\left[\pi u\left(c_{E}\right)+(1-\pi) u\left(c_{L}\right)\right]+q u\left(c_{R}\right) \text { subject to: }
$$

$$
\text { (8), (9), (11), (10), (12),(13), and (14) }
$$

In the second stage of the problem, the bank chooses the contract that gives the larger expected utility, which is equivalent to choosing $\eta=\arg \max \{V(\eta, w)\}$ between the two contracts, where $V(\eta, w)=\operatorname{Max}\left\{V^{e}(q, w), V^{c}(w)\right\}$.

The analysis of the tensions and distortions generated by run proof contracts, under covered banking, and by a positive probability of a run, under exposed banking, require a the definition of an efficient benchmark. We consider the intra-generational first best solution, in which a planner (or bank) can observe the realization of the liquidity shock. This solution is equivalent to the limiting case of exposed banking when the probability $q$ tends to zero. ${ }^{21}$. Using this benchmark we can make assessments about the distortions of the two banking contracts in terms of technology (investment capital $k$ ), liquidity provision $(\lambda$ and $i)$ and liquidity insurance $\left(\frac{c_{E}}{c_{L}}\right)$.

\section{The General Shape of the Solutions.}

Before presenting the first best, covered and exposed contracts, it is possible to characterize the general shape of the solution. Technological considerations on the returns of the assets define four regions (A to $\mathbf{D})$ depending on the level of wealth for the three solutions. Although the thresholds that define these regions differ among the three contracts, we define the generic thresholds: $\underline{k}$, $\tilde{w}^{j}$, and $\hat{w}^{j}$ where $j=\{u, c, e\}$ is an index for the unconstrained or first best solution, the covered banking and exposed banking solutions respectively.

regulation of banks.

${ }^{21}$ The two contracts are equivalent because in the absence of aggregate uncertainty the incentive compatibility constraint is never violated. 


\section{Region A: No investment in short-term technology, no liquidity provision.}

For poor economies $(w \leq \underline{k})$ investing in capital dominates investing in the short asset because the marginal return even is higher if it is liquidated. Therefore all wealth is invested in the long technology $(k=w)$, and early consumption is served by liquidating a constant proportion of this asset $\left(\lambda^{j}\right.$ is constant). Notice that the optimal portfolio is the same as under autarky. Since the optimality of full investment in capital is a technological consideration, the optimal portfolio, and the threshold of the region is common to all solutions.

Region B: Constant level of investment in capital, reduction of early liquidation, increasing liquidity provision.

For $\underline{k} \leq w \leq \widetilde{w}^{j}$ the financial intermediary invests in both assets and provides extra liquidity. The defining characteristic of this region is that investment in capital is kept fixed at $\underline{k}$. All optimal solutions keep the marginal return of the long asset fixed at a high level, where its value, when liquidated prematurely, equals the marginal return of storing the good. ${ }^{22}$ Even for a constant level of the capital stock, output can grow because the bank is liquidating a decreasing proportion of the long asset ( $\lambda^{j}$ is decreasing in wealth). The bank starts using the liquid asset as a source of liquidity to pay out early consumers, reducing premature liquidation of the long asset. Late consumers are served using an increasing proportion of the fully matured output.

\section{Region C: No liquidation of long term investment, increasing investment in both assets.}

When wealth has crossed a certain threshold $\left(w \geq \widetilde{w}^{j}\right)$, the financial intermediary stops using the long asset to serve early consumers. All the long technology is left until full maturity $\left(\lambda^{j}=0\right)$ to serve late consumers, and investment in capital can increase again. If there is no crisis, early consumption is served only using the short asset $\left(c_{E}^{j}=\frac{w-k^{j}}{\pi}\right)$, and late consumption using the long term technology $\left(c_{L}^{j}=\frac{h\left(k^{j}\right)}{1-\pi}\right)$. Increasing investment in capital over this region implies that the marginal return of the asset used to serve late consumers decreases relative to the return of the asset used for early consumption.

\section{Region D: No liquidation of long term investment, and excess liquidity.}

For high levels of wealth $\left(w>\hat{w}^{j}\right)$ high investment in capital has exhausted the marginal return of the long asset, and it is optimal to transfer some returns of storage to serve late consumers $\left(i^{j} \geq 0\right)$. Over this region there is no early liquidation of the long technology $\left(\lambda^{j}=0\right)$.

\footnotetext{
${ }^{22}$ Two assets can be used to serve the same type of consumption only if their marginal returns are the same at the required moment of liquidation.
} 
A general expression for early and late consumption for all contracts and all regions is given by:

$$
c_{E}^{j}=\frac{w-k^{j}-i^{j}+\lambda^{j} \gamma h\left(k^{j}\right)}{\pi} \quad \text { and } \quad c_{L}^{j}=\frac{i^{j}+\left(1-\lambda^{j}\right) h\left(k^{j}\right)}{1-\pi}
$$

We present first the main features of the efficient benchmark (4.1.2). Then we characterize the optimal covered (4.1.3), and exposed banking (4.1.4) contracts. Section (4.1.5) presents then the optimal banking system as the bank's choice between these contracts.

\subsubsection{The Efficient Benchmark: Unconstrained Optimal Risk Sharing}

Gaytan and Ranciere (2002) characterize the unconstrained optimal risk sharing solution. The main implications for investment, liquidation policy and liquidity insurance are presented in the following table:

\begin{tabular}{||c|c|c|c|c|c||}
\hline \hline & $w$ & $k^{u}$ & $\lambda^{u}$ & $i^{u}$ & $\frac{c_{E}}{c_{L}}$ \\
\hline $\mathbf{A}$ & $0<w \leq \underline{k}$ & $w$ & $\lambda^{*}$ & 0 & $\gamma^{\frac{1}{\sigma}}$ \\
\hline $\mathbf{B}$ & $\underline{k} \leq w \leq \widetilde{w}^{u}$ & $\underline{k}$ & $\lambda^{u}(w)$ & 0 & $\gamma^{\frac{1}{\sigma}}$ \\
\hline $\mathbf{C}$ & $\widetilde{w}^{u} \leq w \leq \hat{w}^{u}$ & $k^{u}(w)$ & 0 & 0 & $h^{\prime}\left(k^{u}\right)^{-\frac{1}{\sigma}}$ \\
\hline $\mathbf{D}$ & $w \geq \hat{w}^{u}$ & $\bar{k}$ & 0 & $(1-\pi)(w-\bar{k})-h(\bar{k})$ & 1 \\
\hline \hline
\end{tabular}

where $\widetilde{w}^{u}, \hat{w}^{u}, \lambda^{*}, \lambda^{u}(w)$ are defined by: $:^{23}$ :

$$
\begin{aligned}
\widetilde{w}^{u} & =\underline{k}\left(1+\frac{\pi \gamma^{1 / \sigma}}{(1-\pi) \gamma \beta}\right) \\
\hat{w}^{u} & =\bar{k}\left(1+\frac{\pi}{\beta(1-\pi)}\right) \\
\lambda^{*} & =\frac{\pi \gamma^{\frac{1}{\sigma}}}{\pi \gamma^{\frac{1}{\sigma}}+(1-\pi) \gamma} \\
\lambda^{u}(w) & =\lambda^{*}-\left(1-\lambda^{*}\right) \beta \frac{w-\underline{k}}{\underline{k}}
\end{aligned}
$$

Efficiency of the unconstrained solution can be summarized by the following conditions:

\section{Technology efficiency:}

\footnotetext{
${ }^{23}$ The definition of the unconstrained threholds $\widetilde{w}^{u}$ and $\hat{w}^{u}$ is presented in the Appendix. $k^{u}(w)$ is a continuous, strictly increasing and concave function implicitly defined by (see Gaytan and Ranciere (2002)):

$$
\frac{u^{\prime}\left(c_{E}\right)}{u^{\prime}\left(c_{L}\right)}=h^{\prime}\left(k^{u}(w)\right)
$$
}


(i) There is full investment in capital whenever the early liquidation marginal return on capital exceeds the marginal return on storage $\left(k=w \Leftrightarrow \gamma h^{\prime}(k)>1\right)$;

(ii) whenever there is liquidation of the long technology, capital investment never exceeds $\underline{k}$ (if $\left.\lambda>0 \Rightarrow \gamma h^{\prime}(k) \geq 1\right)$

(iii) when wealth is large enough $\left(w \geq \hat{w}^{u}\right)$ the bank fully exploits the marginal return on capital $(k=\bar{k})$.

\section{Liquidity efficiency:}

(iv) There is never inefficient liquidation of the long technology (if $\gamma h^{\prime}(k) \geq 1 \Rightarrow \lambda>0$ );

(v) whenever the marginal return of capital at maturity exceeds the marginal return on storage there is no excess liquidity (if $h^{\prime}(k)>1 \Rightarrow i=0$ ).

\section{Efficient liquidity insurance:}

(vi) Whenever there is early liquidation of the long asset $(\lambda>0)$, liquidity insurance is kept constant at a level that equates the marginal rate of substitution with the marginal return of $\underline{k}\left(\right.$ if $\left.\lambda>0 \Rightarrow \frac{u^{\prime}\left(c_{E}\right)}{u^{\prime}\left(c_{L}\right)}=\frac{1}{\gamma}\right)$;

(vii) whenever $\gamma h^{\prime}(k)<1$, an increase in capital investment is optimally associated with an increase in liquidity insurance;

(viii) excess liquidity is held $(i>0)$ only to make an efficient transfer from the early to the late subperiod to provide perfect insurance (if $i>0 \Rightarrow \frac{c_{E}}{c_{L}}=1$ ).

An important question is whether a bank that offers a contract that replicates the first best solution is vulnerable or not to panic runs. If the first best solution is run proof, it must be the optimal contract chosen both under covered, and under exposed banking; and therefore, it must be the optimal banking solution. There is the following relationship between risk aversion and invulnerability of the first best solution.

\section{Proposition 4.1 (Optimal risk sharing and bank runs) (i) If $\sigma>1$ (high risk aversion),} the unconstrained risk sharing solution is vulnerable to crises $\left(c_{E}>c_{R}\right)$. 
(ii) If $\sigma \leq 1$ (low risk aversion), there exists a unique level of wealth $w_{r p} \in\left(\widetilde{w}^{u}, \widehat{w}^{u}\right)$, such that:

- if $w \leq w_{r p}$, the unconstrained risk sharing solution is run proof $\left(c_{E} \leq c_{R}\right)$

- if $w>w_{r p}$, the unconstrained risk sharing solution is vulnerable to crises $\left(c_{E}>c_{R}\right)$.

where $w_{r p}=k_{r p}\left(1+\frac{\pi \gamma}{(1-\pi) \beta \gamma^{\sigma}}\right)$ and $h^{\prime}\left(k_{r p}\right)=\frac{1}{\gamma^{\sigma}}$

Proof. See Gaytan and Ranciere (2002a).

Impatient agents $(\sigma>1)$ have a stronger preference for liquidity insurance and demand higher early pay-off, making the first best contract vulnerable to runs. Patient agents $(\sigma \leq 1)$, on the other hand, prefer to enjoy higher payoffs on late withdrawals while the marginal returns are still high. However, as wealth increases and liquidity insurance improves, the economy reaches a point where the optimal risk sharing solution becomes necessarily vulnerable to runs. ${ }^{24}$

For $0<w \leq w_{r p}$ and $\sigma \leq 1$, the first best solution is the optimal covered bank contract and the optimal banking solution. For higher levels of income, the optimal contracts are subject to the optimality conditions that prevail for $\sigma>1$. Therefore, we can concentrate our attention on the results for high risk aversion $(\sigma>1)$.

\subsubsection{Covered Banking $(\eta=0)$.}

Before presenting the optimal covered contract, it is useful to notice that the autarkic solution is run proof $\left(c_{E}^{a}=w-k+\pi \gamma h(k)<w-k+\gamma h(k)\right)$. A covered bank could always replicate the autarkic solution by setting $\lambda=\pi, k=k^{a}$, and $i=(1-\pi)(w-k)$ and, therefore, optimal covered banking will necessarily dominate the autarkic outcome.

Proposition 4.2 The optimal covered banking contract for high risk aversion $(\sigma>1)$ is characterized in the following conditions ${ }^{25}$ :

\footnotetext{
${ }^{24}$ Improving insurance and the existence of a wealth level above which the economy is vulnerable to a run, represent a difference with respect to the original DD model. In their original framework of fixed returns to assets, low risk aversion $(\sigma \leq 1)$ implied that the optimal risk sharing contract was necessarily run proof.

${ }^{25}$ Figure 3 illustrates the optimal choice of capital and liquidity insurance for a simulation of the economy
} 


\begin{tabular}{||c|c|c|c|c|c||}
\hline \hline & $w$ & $\frac{u^{\prime}\left(c_{c}\right)}{u^{\prime}\left(c_{L}\right)}$ & $k^{c}$ & $\lambda^{c}$ & $i^{c}$ \\
\hline $\boldsymbol{A}$ & $0<w \leq \underline{k}$ & $\frac{1}{\gamma^{\sigma}}$ & $w$ & $\pi$ & 0 \\
\hline $\boldsymbol{B}$ & $\underline{k} \leq w \leq \widetilde{w}^{c}$ & $\frac{1}{\gamma^{\sigma}}$ & $\underline{k}$ & $\lambda^{c}(w)$ & 0 \\
\hline $\boldsymbol{C}$ & $\widetilde{w}^{c} \leq w \leq \hat{w}^{c}$ & $\frac{1}{\gamma^{\sigma}}$ & $k_{C}^{c}(w)$ & 0 & 0 \\
\hline $\boldsymbol{D}$ & $w \geq \hat{w}^{c}$ & $\frac{1-\pi}{\pi} \frac{\left[\left(\frac{1-\pi \gamma}{1-\pi}\right) h^{\prime}(k)-1\right]}{\left(1-\gamma h^{\prime}(k)\right)}$ & $k_{D}^{c}(w)$ & 0 & $(1-\pi)\left(w-k^{c}\right)-\pi \gamma h\left(k^{c}\right)$ \\
\hline \hline
\end{tabular}

where the thresholds $\widetilde{w}^{c}, \hat{w}^{c}$, liquidation policy $\lambda^{u}(w)$, and investment $k^{s}(w)$ are given by:

$$
\begin{aligned}
& \widetilde{w}^{c}= \underline{k}\left(1+\frac{\pi}{\beta(1-\pi)}\right) \\
& \hat{w}^{c}=\widehat{k}^{c}\left(1+\frac{\gamma \pi}{\beta(1-\pi)} h^{\prime}\left(\widehat{k}^{c}\right)\right) \text { Where }: h^{\prime}\left(\widehat{k}^{c}\right)=\frac{\pi+(1-\pi) \gamma^{\sigma}}{\pi \gamma+(1-\pi \gamma) \gamma^{\sigma}} \\
& \lambda^{c}(w)=\pi-(1-\pi) \beta \frac{w-\underline{k}}{\underline{k}}
\end{aligned}
$$

$k^{c}(w)$ is implicitly defined by the marginal rate of substitution $\frac{u^{\prime}\left(c_{E}\right)}{u^{\prime}\left(c_{L}\right)}$ and excess liquidity $i^{c}{ }^{26}$

The source of distortions in covered banking is the limit imposed in the degree of liquidity insurance. The unconstrained level of liquidity insurance violates the run preventive constraint, therefore, a covered bank will provide a strictly lower level of liquidity than the first best. The incentive to increase early consumption towards the first best level, makes that the run preventive constraint binds for all levels of wealth $c_{E}=w-k+\gamma h(k)$. This limit in early consumption forces the bank to provide a constant level of liquidity insurance over regions $\mathrm{A}, \mathrm{B}$ and $\mathrm{C}\left(c_{E}=\gamma c_{L}\right)$, below the efficient level. Lower liquidity insurance frees resources to provide higher late consumption either through reducing liquidation or increasing capital investment.

Over regions $\mathrm{A}$ and $\mathrm{B}$, since capital is determined by pure technological considerations ( $k=w$ and $k=\underline{k}$ ), a lower liquidity insurance implies a smaller liquidation of the long asset $\lambda^{c}(w)<$ $\lambda^{u}(w) .{ }^{27}$ The bank stops liquidating the long asset at lower levels of wealth $\left(\widetilde{w}^{c}<\widetilde{w}^{u}\right)$. This reduction in liquidation increases the marginal product of capital and has a positive effect on economic growth. Once the covered economy has stopped early liquidation of the long technology it starts increasing capital. However, over region C, the increase in capital is not accompanied by an increase in liquidity insurance. Over region $\mathrm{C}$ and the first part of $\mathrm{D}$, the bank "over-invest"

\footnotetext{
${ }^{26} k_{C}^{s}(w)$ and $k_{D}^{s}(w)$ are two continuous, strictly increasing and concave functions of $w$ (see Appendix).

${ }^{27}$ Over region $\mathrm{A}, \lambda=\pi$; the safe contract just replicates the autarkic solution.
} 
in capital with respect to the first best level to maintain a covered contract. In the second part of region D, there is underinvestment in capital relatively to the first best, as "excess liquidity" $i>0$ becomes a more efficient way to restrict liquidity insurance. The use of excess liquidity before fully exhausting the return on the long asset $\left(h^{\prime}(k)<1\right)$ is a technological inefficiency of covered banking. Over region D, the bank can maintain a covered contract and increase liquidity insurance, reducing the distortion generated by the run preventing constraint.

Making a banking system "safe" implies restricting both the banks' asset portfolio, and the provision of liquidity insurance offered by the deposit contact in a way that banks can always satisfy any claim by depositors. In the previous literature, a requirement of excessive liquid reserves can attain this objective. However, when returns are endogenous it is not necessarily the case. We find that, except for rich economies, it is more efficient to reduce the promises to early consumers rather than to hold more liquid assets. This reduction of liquidity insurance allows the bank to allocate more resources to long term projects, with positive consequences for economic growth.

\subsubsection{Exposed Banking $(\eta=q)$.}

Proposition 4.3 The optimal exposed banking for high risk aversion $(\sigma>1)$ is characterized in the following conditions ${ }^{28}$

\begin{tabular}{||c|c|c|c|c|c||}
\hline \hline & $w$ & $\frac{u^{\prime}\left(c_{E}\right)}{u^{\prime}\left(c_{L}\right)}$ & $k^{e}$ & $\lambda^{e}$ & $i^{e}$ \\
\hline $\mathbf{A}$ & $0<w \leq \underline{k}$ & $\frac{1}{\gamma}$ & $w$ & $\lambda^{*}$ & 0 \\
\hline $\mathbf{B}$ & $\underline{k} \leq w \leq \widetilde{w}^{u}$ & $\frac{1}{\gamma}=h^{\prime}(\underline{k})$ & $\underline{k}$ & $\lambda^{u}(w)$ & 0 \\
\hline $\mathbf{C}$ & $\widetilde{w}^{u} \leq w \leq \hat{w}^{e}$ & $h^{\prime}\left(k^{e}\right)-\frac{q}{1-q}\left(1-\gamma h^{\prime}\left(k^{e}\right)\right) \frac{u^{\prime}\left(c_{R}\right)}{u^{\prime}\left(c_{L}\right)}$ & $k_{C}^{e}(w)$ & 0 & 0 \\
\hline $\mathbf{D}$ & $w \geq \hat{w}^{e}$ & $h^{\prime}\left(k^{e}\right)-\frac{q}{1-q}\left(1-\gamma h^{\prime}\left(k^{e}\right)\right) \frac{u^{\prime}\left(c_{R}\right)}{u^{\prime}\left(c_{L}\right)}$ & $k_{D}^{e}(w)$ & 0 & $(1-\pi)\left(w-k^{e}\right)-\pi h\left(k^{e}\right)$ \\
\hline \hline
\end{tabular}

Where $\hat{w}^{e}$ is given by:

$$
\hat{w}^{e}=\widehat{k}^{e}\left(1+\frac{\pi h^{\prime}\left(\widehat{k}^{e}\right)}{\beta(1-\pi)}\right) \quad \text { where }: h^{\prime}\left(\widehat{k}^{e}\right)=\frac{q+(1-q)(\pi+(1-\pi) \gamma)^{\sigma}}{\gamma q+(1-q)(\pi+(1-\pi) \gamma)^{\sigma}}
$$

$k_{C}^{e}(w)$ is implicitly defined by the expression for the marginal rate of substitution $\frac{u^{\prime}\left(c_{E}\right)}{u^{\prime}\left(c_{L}\right)}$, and $k_{D}^{c}(w)$ is implicitly defined by the marginal rate of substitution and excess liquidity $i^{e}$.

\footnotetext{
${ }^{28}$ Figure 4 illustrates the optimal choice of capital and liquidity insurance for a simulation of the economy
} 
Regions $\mathrm{A}$ and $\mathrm{B}$ of the exposed contract are identical to the intra-generational first best solution. Since over these regions the level of investment is determined by technological efficiency, it is optimal to provide the first best level of liquidity insurance, because a reduction of liquidity insurance helps only if it makes the contract run proof (covered banking); otherwise, crises are still possible. As a consequence, for this range of wealth an optimizing bank will be restricted to maximize utility under the good state of no-crisis only.

Exposed banking introduces an important new element. Having crises with positive probability generates aggregate uncertainty in the payoff for both types of consumers. The bank will have incentives to smooth consumption over realizations of the aggregate state. This "banking selfinsurance" against crisis risk is done by increasing the payoff in the bad state, that is, by increasing the early liquidation value of the bank's portfolio. Since the early value of the portfolio increases with investment in the storage technology, the bank will invest less capital than the optimal risk sharing over regions $\mathrm{C}$ and D. ${ }^{29}$

There is no conflict for the exposed bank between increasing liquidity insurance and increasing crises self-insurance. A promise of higher early consumption adds extra liquidity, which can be used in case of a financial crisis. That is why over region $\mathrm{C}$ the bank provides excessive liquidity insurance $\left(\frac{c_{E}^{e}}{c_{L}^{e}}>\frac{c_{E}^{u}}{c_{L}^{u}}\right)$, and starts providing full liquidity insurance at a lower level of wealth $\left(\hat{w}^{e}<\hat{w}^{u}\right)$.

Excess liquidity $(i>0)$ is used to provide perfect insurance, although the marginal product of capital is not the same than that of storage. Since the marginal return on capital have not been completely exhausted $\left(h^{\prime}(k)>1\right)$, the bank will continue to increase capital as wealth increases over D. ${ }^{30}$

Therefore a maximizing bank that faces a positive probability of a run, will increase the level of liquidity and liquidity insurance beyond the first best solution increasing the vulnerability of

\footnotetext{
${ }^{29}$ In region $\mathrm{C}$ of the unconstrained problem, the marginal cost of increasing capital was just $u^{\prime}\left(c_{E}\right)$, the valuation in terms of utility of the marginal return of storage. When crises occur with positive probability the marginal cost increases to

$$
u^{\prime}\left(c_{E}\right)+\left(1-\gamma h^{\prime}(k)\right) \frac{q}{1-q} u^{\prime}\left(c_{R}\right)
$$

because investment in capital also reduces consumption in case of a total run.

${ }^{30} \mathrm{It}$ is interesting to notice that over region $\mathrm{D}\left(c_{E}=c_{L}=c=w-k+h(k)\right)$, the optimality condition can be written as:

$$
\text { region } D: \frac{u^{\prime}\left(c_{R}\right)}{u^{\prime}(c)}=\frac{(1-q)\left(h^{\prime}\left(k^{e}\right)-1\right)}{q\left(1-\gamma h^{\prime}\left(k^{e}\right)\right)}
$$

that is a similar expression to the autarkic condition for self-insurance against liquidity risk.
} 
the system and reducing the growth benefits. Although this "excessive risk" result resembles those coming from a moral hazard problem, the distortion is not a consequence of insurance received, but of insurance provided. In effect, by increasing liquidity the bank is providing crisis insurance. At the cost of lower returns, a more liquid system reduces the output loss in case of a crisis, because it increases the bankruptcy value of the bank.

An exposed bank never "over-invest". At low levels of wealth (regions A and B), capital and growth are the same as under the unconstrained solution. For higher levels of wealth, the risk of a run reduces the level of investment, with negative consequences for economic growth.

\subsubsection{The Optimal Banking System}

In this section we characterize the optimal risk sharing solution when there is an exogenous probability of pessimism that can drive a panic run on the bank as the choice between the optimal" covered" and "exposed" contracts. For any given level of wealth, the financial intermediary will choose the contract that maximizes expected utility. The bank's decision reflects the tension between crisis prevention and precautionary measures to minimize the costs of a possible crisis. The financial intermediary chooses $\eta=\arg \max \{V(\eta, w)\}$, where $V(\eta, w)=\operatorname{Max}\left\{V^{e}(q, w), V^{c}(w)\right\}$.

Since the distortions generated by the contracts vary with the level of wealth, the optimal choice between the contracts will depend on wealth, and on the probabilty of a bad realization of the sunspot. Expected utility of covered banking $\left(V^{c}(w)\right)$ is invariant to $q$, while expected utility of the exposed contract $\left(V^{e}(q, w)\right)$ is strictly decreasing in $q$. The choice between the two contracts will be determined by a wealth dependant cut-off probability $q^{*}(w)$. This threshold probability is defined in the following proposition.

\section{Proposition 4.4 The Optimal Banking System}

For any level of wealth for $\sigma>1$, and for $w>w_{r p}$ when $\sigma \leq 1$, there exists a unique cut-off probability $q^{*} \in(0, \pi]$ such that:

$$
\begin{aligned}
& q>q^{*}(w) \Leftrightarrow \text { a covered banking system is optimal } \\
& q<q^{*}(w) \Leftrightarrow \text { an exposed banking system is optimal }
\end{aligned}
$$

where $q^{*}(w)$ is a continuous function defined by:

$$
V^{e}\left(q^{*}(w), w\right)=V^{c}(w)
$$




\section{Proof. See Appendix A}

Over region A and B the optimal exposed contract replicates the first best contract; therefore, there are no distortions in the contract, and the only cost is the expected cost of a run. This cost increases with $q$ and therefore expected utility is decreasing in $q$. Over regions $\mathrm{C}$ and $\mathrm{D}$, a positive probability of a run $q$ increases the liquidation risk, reducing the expected marginal return of capital, and investment.

Lower capital investment has two effects on expected utility: a positive effect because it increases liquidity insurance, and a negative effect because it reduces the returns for late consumption. The overall effect is negative, because the bank is increasing the expected payoff in case of a run at the cost of reducing it when there is no run, exacerbating the distortion in the non-run case. ${ }^{31}$ Over regions $\mathrm{C}$ and $\mathrm{D}$, every dollar kept for crisis self-insurance pays less in terms of utility than a dollar invested to increase the payoff in the good equilibrium.

In Appendix B, we show that if the probability of the sunpot is higher than the probability of the idiosyncratic liquidity shock $(q>\pi)$, autarky dominates the exposed banking solution. Since covered banking weakly dominates the autarkic outcome, the cutoff probability $q^{*}(w)$ must be strictly lower than $\pi$.

The cutoff probability determines the bank's optimal choice of contract for any given level of wealth. However, it is useful to invert the problem and find, for a given probability of the sunspot, how does the decision between the two contracts changes with the level of wealth? This analysis sheds light over how the choice of the risk taken by an exposed bank varies over the development path, or equivalently it provides a broad picture of the cross sectional distribution of risk for countries with different levels of wealth.

\section{Proposition 4.5 Optimal Banking and the Level of Wealth.}

There exist two cutoff probabilities $q_{0}, q_{1}\left(0<q_{0}<q_{1}<\pi\right)$ such that:

(i) high probability of run: if $q>q_{1}$, a covered banking system is the optimal for all levels of wealth

\footnotetext{
${ }^{31}$ Using the envelope condition we can see that:

$$
\frac{d V^{e}(q, w)}{d q}=-\left[\pi u\left(c_{E}\right)+(1-\pi) u\left(c_{L}\right)\right]+u\left(c_{R}\right)<0 .
$$
}


(ii) intermediate probability of run: if $q_{0}<q<q_{1}$, there exist two levels of wealth $w_{l}<w_{h}$ such that an exposed banking system is optimal for middle income economies $\left(w_{l}<w<w_{h}\right)$ and a covered banking system is optimal for poor and rich economies $\left(w \in \mathbb{R}^{+}-\left[w_{l}, w_{h}\right]\right)$

(iii) low probability of run: if $q<q_{0}$, there exist one level of wealth $w_{h}$ such that an exposed banking system is optimal, except for rich economies $\left(w>w_{h}\right)$

$$
\begin{aligned}
& \text { where: } \\
& q_{0}=q_{o}^{*}=\frac{\left[\pi+(1-\pi) \gamma^{\frac{\sigma-1}{\sigma}}\right]^{\sigma}-\left[\pi+(1-\pi) \gamma^{\sigma-1}\right]}{\left[\pi+(1-\pi) \gamma^{\frac{\sigma-1}{\sigma}}\right]^{\sigma}-1} \\
& q_{1}=\operatorname{Max}\left\{q^{*}(w)\right\}<\pi \\
& \frac{\delta w_{l}}{\delta q}>0 ; \frac{\delta w_{h}}{\delta q}<0 \text { and } \lim _{q \rightarrow 0} w_{h}=0
\end{aligned}
$$

Proof. See Appendix A

Figure 5 illustrates the characterization of the optimal solution in proposition 4.5. For any probability of the pessimistic state ( $q$ in the horizontal axis), it shows the upper and lower wealth thresholds $\left(w_{h}\right.$ and $\left.w_{l}\right)$ that define the switch between the two contracts: 


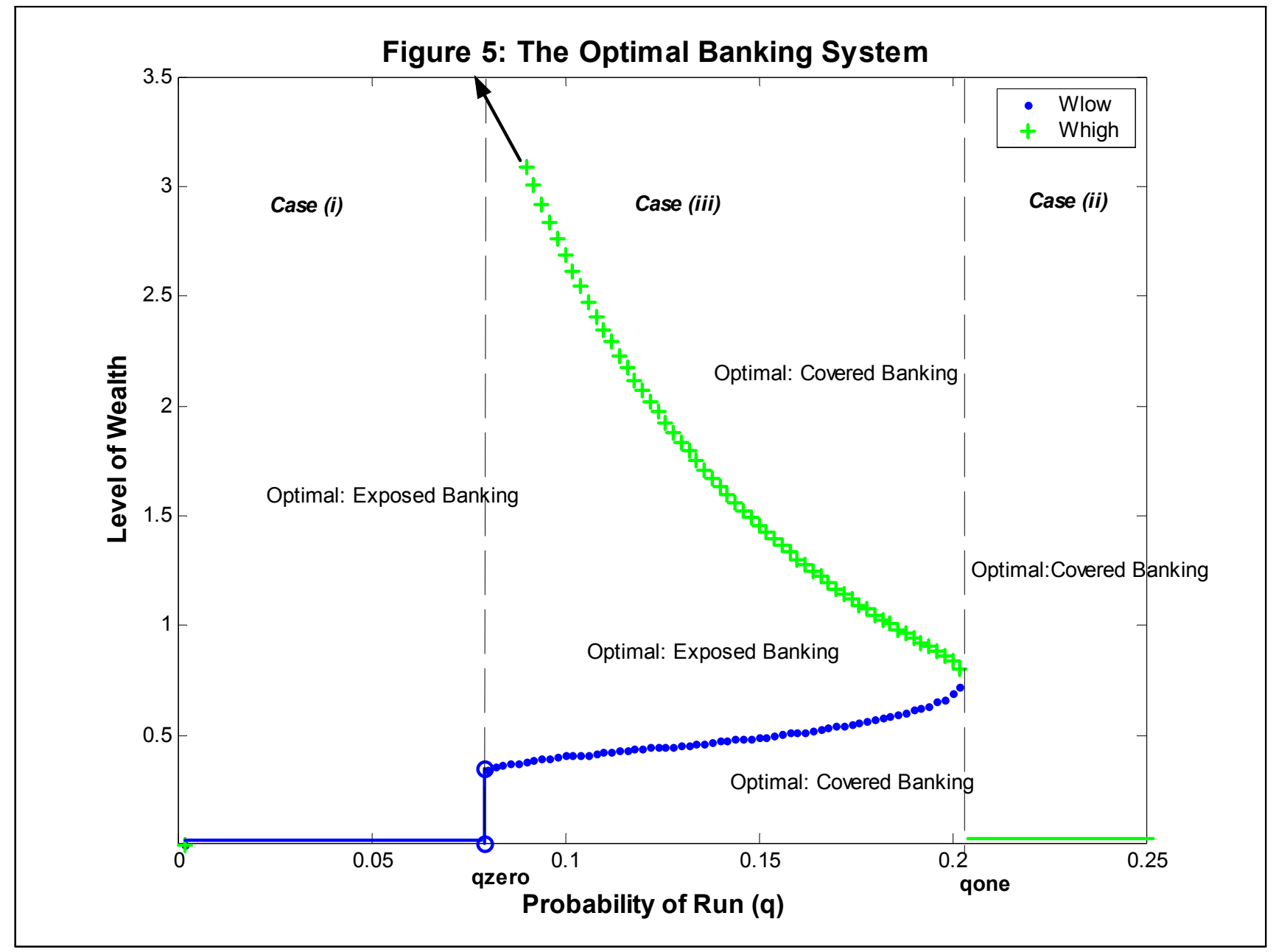

For poor economies, the cost of covered banking is the low liquidity insurance provided by the intermediary, however, the cost is partially compensated because lower liquidation increases late consumption. On the other hand, since the exposed banking replicates the unconstrained solution, the cost of exposed banking is the cost of a run. Therefore, poor economies will prefer a covered contract when the probability of the pessimistic state is high enough $\left(q>q_{0}\right)$.

The underinsurance distortion of covered banking becomes more pervasive for higher levels of wealth. Liquidity insurance is kept constant even when the return of the long asset is decreasing. In addition, the covered bank eventually uses excessive liquidity $(i>0)$ to satisfy the run preventive constraint although the returns to the long assets are not fully exhausted $\left(h^{\prime}(k)>1\right)$.

On the other hand, an exposed contract does increase insurance and crisis insurance, partially offsetting the loss of the run. Therefore, for intermediate levels of wealth, the exposed contract may prevail over the covered contract (if $q<q_{1}$ ). However, there is always a sufficiently high probability 
$q$ that can make the exposed banking suboptimal.

There is always a high level of wealth after which covered banking is the optimal contract. The distortions of covered banking tend to disappear as the bank increases liquidity insurance and increases investment towards the best maximum capital $(\bar{k})$; while the exposed banking always faces an uninsurable crisis risk that prevents capital investment to achieve the maximum efficient level. ${ }^{32}$

\section{Thee degree of exposure of the optimal banking system.}

Even though under exposed banking crises happen with fixed probability, it is illustrative to construct an indicator of the degree of exposure of the banking system. Total runs are triggered when the proportion of late consumers that misrepresent their type is enough to violate the incentive compatibility constraint. Therefore, we can define the maximum fraction of late consumers a bank can serve in the early sub-period without triggering a bank run ${ }^{33}$ :

$$
r=\frac{1}{(1-\gamma)(1-\pi)}\left[\frac{c_{R}}{c_{E}}-(\pi+(1-\pi) \gamma)\right]
$$

In this case $(1-r)$ is a measure of the degree of exposure of the banking system. ${ }^{34}$ A covered contract that does not exhibit any exposure $(1-r \leq 0)$ is run proof. This degree of exposure varies with the level of wealth. Since over regions A, B and $\mathrm{C} c_{R}=\pi c_{E}+\gamma(1-\pi) c_{L}$, we can express the degree of exposure as a function of liquidity insurance:

$$
1-r=1-\frac{\gamma}{1-\gamma}\left[\frac{1}{\frac{c_{E}}{c_{L}}}-1\right] \text { for regions A,B and } \mathrm{C}
$$

Exposed banking for low income economies (regions A and B) imply constant exposure. Over region $\mathrm{C}$, the increase in liquidity insurance leads to an increase in the degree of financial exposure. Over region $\mathrm{D}$, as $c_{E}=c_{L}=c, q-r$ can be expressed as:

$$
1-r=\frac{1}{(1-\gamma)(1-\pi)}\left[1-\frac{c_{R}}{c}\right] \text { for region } \mathrm{D}
$$

Over region D, $\frac{c_{R}}{c}$ increases, and this increase in self-insurance against crises decreases the degree of financial exposure. In summary:

\footnotetext{
${ }^{32}$ In the limit for infinite large wealth $k^{c}$ attains $\bar{k}$, while $k^{e}$ attains an upperbound given by

$$
h^{\prime}\left(k_{\max }^{e}\right)=\frac{1}{q \gamma+1-q}
$$

${ }^{33}$ See Appendix * for details on the derivation of $r$.

${ }^{34}$ An alternative interpretation of $(1-r)$ is the minimum trust a bank needs to remain solvent. The more expose is a bank, the higher the trust required.
} 


\begin{tabular}{||l||l||}
\hline \hline regions & degree of exposure of an exposed banking system \\
\hline \hline A-B & constant \\
\hline \hline C & increasing \\
\hline \hline D & decreasing \\
\hline \hline
\end{tabular}

\subsection{The Dynamics of Wealth, Capital and Consumption}

We characterize the dynamics of wealth implied by the optimal banking solution for high risk aversion $(\sigma>1){ }^{35}$ We assume an initial generation endowed with $w_{0}>0$. When the optimal contract is $j=\{c, e\}$, the dynamics of wealth can be represented as:

$$
\begin{aligned}
& w_{t}=\left\{\begin{array}{ccc}
F^{j}\left(w_{t-1}\right)= & (1-\beta)\left[\lambda\left(w_{t-1}\right) \gamma+1-\lambda\left(w_{t-1}\right)\right] f\left(k\left(w_{t-1}\right)\right) & \text { with probability } 1-\eta \\
F^{r u n}\left(w_{t-1}\right)= & (1-\beta) \gamma f\left(k\left(w_{t-1}\right)\right) & \text { with probability } \eta
\end{array}\right. \\
& k_{t}=k^{j}\left(w_{t-1}\right): \text { optimal capital choice } \\
& \lambda_{t}=\lambda^{j}\left(w_{t-1}\right): \text { optimal liquidation } \\
& \eta= \begin{cases}0 & \text { if } j=c \\
q & \text { if } j=e\end{cases}
\end{aligned}
$$

When the optimal banking solution is a covered banking system $(j=c)$, the dynamics of wealth are deterministic. By contrast, when the optimal banking solution is a exposed banking system $(j=e)$, the dynamics of wealth are stochastic. When a exposed bank experiences a run, the full liquidation of the bank porfolio will reduce the wealth and investment possibilities of the following generation. ${ }^{36}$

The following proposition characterizes the generic convergence properties of this economy:

\footnotetext{
${ }^{35}$ Early and late consumption $\left(c_{E}\right.$ and $\left.c_{L}\right)$ are monotonically increasing in wealth, therefore their dynamics follow the dynamics of wealth, and the level of liquidity insurance implied by the optimal contract.

${ }^{36}$ It is important to the notice that a higher probability of the sunspot does not necessarily imply lower growth under optimal banking, since the probability can affect the choice between the two contracts. Under exposed banking, an increase in $q$ would imply lower growth if exposed banking remains the optimal contract; however, since covered banking has a positive effect on growth, a switch to a covered contract, as a response to the increase in crisis risk, could have positive growth consequences.
} 
Proposition 4.6 For any initial wealth $w_{0}>0$, the economy with financial intermediaries converges toward a unique stable steady state $\bar{w}^{b}>0$ and $k^{s s}=k\left(\bar{w}^{b}\right)$. The steady state is defined by $F^{b}\left(\bar{w}^{b}\right)=\bar{w} \cdot{ }^{37}$

\section{Proof. See AppendixB}

Figure 6 illustrates the dynamics for a simulation of the economy. It presents the unique dynamic paths $\left(F\left(w_{t-1}\right)\right)$ for autarky, covered banking, and the unconstrained problem. By contrast, the stochastic growth dynamics for exposed banking is represented by two paths: $F^{e}\left(w_{t-1}\right)$ if there is no run, and $F^{\text {run }}\left(w_{t-1}\right)$ otherwise. The dynamics of the optimal banking solution is underlined. The steady state is determined by the intersection of the optimal path with the 45 degree line. ${ }^{38}$

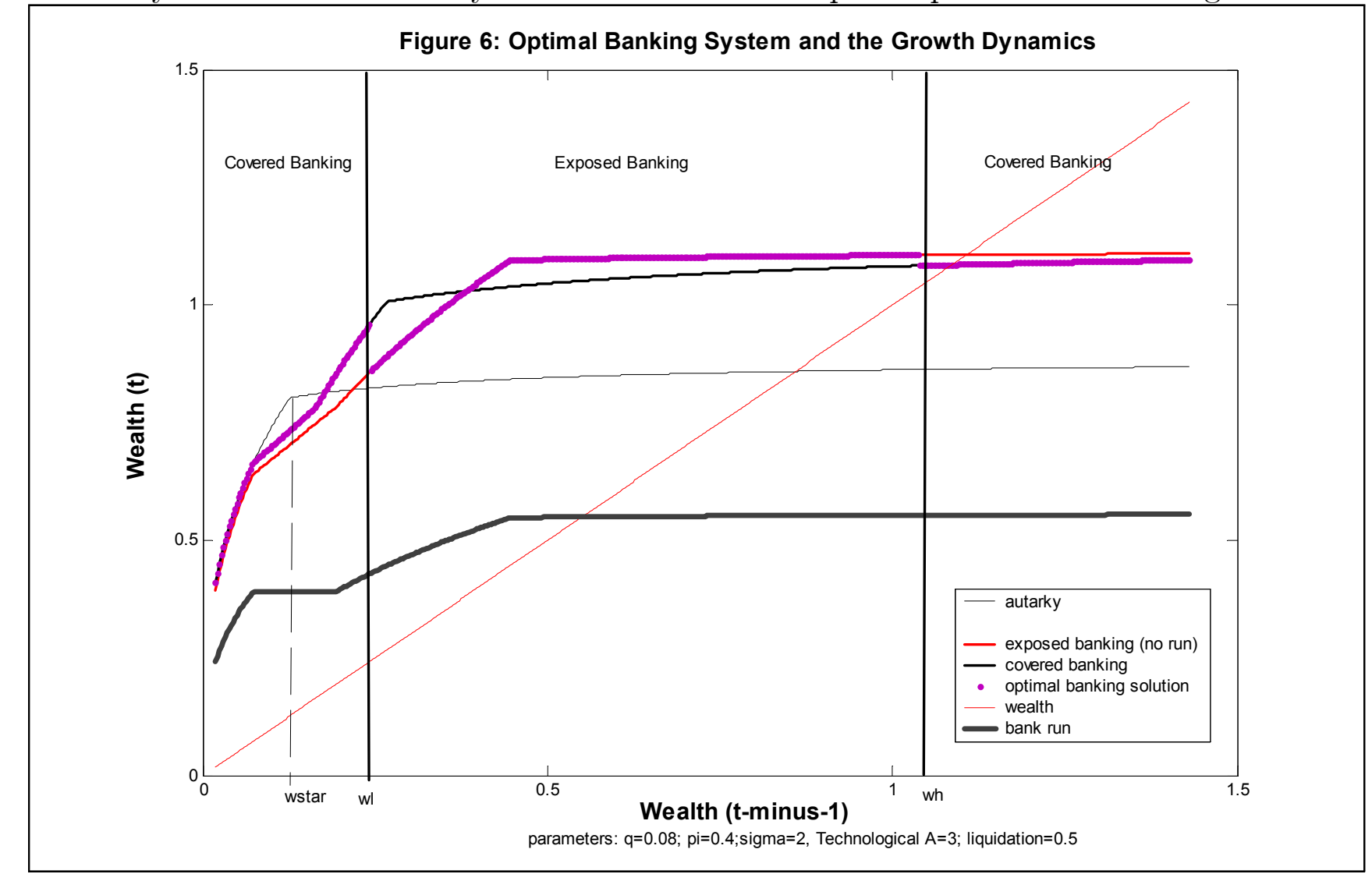

\footnotetext{
${ }^{37}$ When the optimal banking system at the steady state is an exposed bank, the economy remains in the steadystate conditional on no run. To be precise, an exposed banking economy converges to a limit distribution centered around this point.

${ }^{38}$ Under some special combination of parameters, the economy could converge to limit cycles centered around the thresholds $w_{l}$ or $w_{h}$, because at those points, the switch of contract generates a discontinuity in the dynamic path. These cases are clearly non generic.
} 
The simulation used in Figure 6 presents the case of an economy with an intermediate probability of the sunspot $\left(q_{0}<q<q_{1}\right) \cdot{ }^{39}$ Covered banking is the optimal contract both for low and high income, and attains a covered banking steady state. Starting with an initial low level of wealth, such an economy experiences the fast growth associated with covered banking, and then switch to an exposed contract, entering the region where crises happen with positive probability. Eventually, the economy will converge to a long run, financially safe steady state. The speed of convergence will depend on the realization of the sunspot. If the economy receives good draws it will "escape" rapidly to a run proof region. If the economy experiences bad draws, it will experience multiple crises, and yet, it remains optimal to take on the risk associated with an exposed banking system.

The optimality of covered banking for high levels of wealth is similar to the result of Acemoglu and Zilibotti [1997]. In their model growth and crises will depend on "luck" until the economy gets rich enough to afford full insurance through broader risk diversification. In our model, the economy is financially fragile and vulnerable to bank runs until it becomes rich enough to afford the cost of a full self-insurance against the risk of liquidity crises.

\section{The Consequences of a Banking System}

\subsection{Liquidity Insurance and the welfare of the current generation}

The fundamental source of inefficiency under financial autarky is the absence of a mechanism for pooling liquidity risk, making necessary that each agent insures herself against such risk. On the other hand, the bank pools resources and balances the assets' returns with the consumers' ex-ante preference for consumption smoothing between the two possible liquidity needs. Since the bank maximizes expected utility of a current depositor, welfare for the current generation is necessarily higher than under financial autarky. This result is independent of the probability $q$ because covered banking dominates autarky in terms of welfare of the current generation ${ }^{40}$.

Therefore, as optimal banking weakly dominates the best covered banking system, we have the following result:

Proposition 5.1 For any probability of a run and for any level of wealth, the optimal banking solution dominates autarky for the welfare of the current generation and strictly dominates autarky

\footnotetext{
${ }^{39}$ The parameters used in the simulation are presented in the Appendix.

${ }^{40}$ and stricly dominates for $w>\underline{k}$ [see Appendix A, property P6 for a formal proof]
} 
for $w>\underline{k}$

\subsection{Growth}

In this section, we compare the relative growth performance of financial autarky and financial intermediation. ${ }^{41}$ We concentrate on the financial intermediation growth performance conditional on the good state of no run, leaving the analysis of output losses caused by liquidity crises to the next section. The relative growth consequences of the two financial regimes can be analyzed using the ratio of wages for the following generation:

$$
\frac{F^{a}(w)}{F^{b}(w)}=\frac{1-\pi(1-\gamma)}{1-\lambda(w)(1-\gamma)}\left(\frac{k^{a}(w)}{k^{b}(w)}\right)^{\beta}
$$

where the indexes $\{a, b\}$ stand for financial autarky and the optimal banking system.

Equation (23) can be written in terms of growth rates as: ${ }^{42}$

$$
g^{a}(w)-g^{b}(w) \approx \underbrace{\ln (1-\pi(1-\gamma))-\ln (1-\lambda(w)(1-\gamma))}_{\text {Liquidation Effect }(\mathrm{A})}+\beta \underbrace{\left[\ln k^{a}(w)-\ln k^{b}(w)\right]}_{\text {Investment Effect }(\mathrm{B})}
$$

The relative growth performance depends on the combination of a liquidation effect (A), that reflects the different level of liquidation $(\lambda(w)$ vs $\pi)$, and an investment effect $(\mathrm{B})$, that reflects the difference in capital choice. In terms of growth accounting, the first effect reflects a "total factor productivity" gap and the second effect an "investment" gap.

\section{The Liquidation Effect.}

Under autarky, self-insurance imposes a constant aggregate liquidation equal to $\pi$. By contrast under optimal banking, whenever the marginal return of the short asset exceeds the early liquidation marginal return of the long asset, the bank sets liquidation to zero. This features represents a technological advantage of banking, its ability to avoid inefficient liquidation by pooling the liquidity

\footnotetext{
${ }^{41}$ for the simplicity of the exposition, we restrict here to the case $\sigma>1$. See Gaytan and Ranciere (2002) for a discussion on the relative growth performance for $\sigma \leq 1$.

${ }^{42}$ The growth rate of welath $g^{i}(w), i=\{a, b\}$ is given by
}

$$
g^{i}(w)=\frac{F^{i}(w)}{w}-1 \approx \ln F^{i}(w)-\ln w
$$


risk. Since the marginal returns, both of capital and labor, are inversely related with the level of liquidation, its suppression explains why financial intermediaries can attain a higher steady state level of wealth.

For lower levels of wealth, liquidation of the long technology is optimally chosen by the bank to distribute a fraction of the high returns of this asset to early consumers. When for low levels of wealth, a covered bank is optimal, liquidation in region A equals $\pi$-the level of autarkic aggregate liquidation-, and it is gradually reduced to zero. Therefore, the liquidation effect will favor growth under optimal banking. On the other hand, if for low wealth, exposed banking is optimal, the bank will liquidate, over region $\mathrm{A}$, a larger proportion of long term projects $\left(\lambda^{*}>\pi\right)$, and the liquidation effect will favor autarky, and as liquidation is reduced over region B, the liquidation effect will eventually favor the growth under banking.

\section{The Investment Effect.}

For some low levels of wealth $\left(w \in\left[\underline{k}, w^{*}\right]\right)$, autarkic agents overinvest in capital as a precautionary saving, while it would be efficient to start investing a fraction of wealth in the short asset, and reduce liquidation. This inefficiency is not present under banking, over region $\mathrm{B}$, a the banking level of investment is constant. Therefore, over this region, the investment effect will favor autarky.

Nevertheless, the cost of inefficient liquidation under autarky limits capital investment for larger levels of wealth, and the investment effect will eventually favor optimal banking. The reduction of liquidation under banking compensates the decline in the marginal product of capital due to increasing investment. In region D of the banking economy, investment in capital is strictly higher than under autarky. ${ }^{43}$ Therefore there exists a wealth threshold $m$ in region $\mathrm{C}$ at which capital investment in the banking economy and in the autarkic economy are identical, while for wealth levels higher than $m$, the investment effect favors the banking economy. At $m$, as capital investments are the same in both economies and liquidation is higher under autarky, growth is strictly higher in the banking economy. The same results necessarily hold for $w>m$. Therefore:

Proposition 5.2 There exist a level of wealth $w_{a} \in(\underline{k}, m)$ such that for $w>w_{a}$, growth under optimal banking is strictly higher than under financial autarky.

\footnotetext{
${ }^{43}$ To see that observe that in region $\mathrm{D}\left(w>\widetilde{w}^{c}>\widetilde{w}^{d}\right)$ : investment in exposed banking is higher than autarky if and only if $q<\pi$ (but, this is a necassary condition for exposed banking to be optimal); and, investment in covered banking is higher that under autarky (propositions (3.1) and (4.2))
} 


\section{Proof. see Appendix B}

The intra-generational optimal banking contract maximizes welfare of the current generation of depositors, without direct concerns on welfare of future generations or the growth rate of the economy. Risk-sharing is optimally done in an intra-generational sense, but it may be inter-generational inefficient, as the bank does not internalize the effect of its decisions on growth and wealth of future generations of depositors.

The simulation presented in Figure 6 shows an economy for which financial intermediaries has a lower rate of growth at early stages of economic development than the autarkic agents. After the economy has crossed the threshold $w_{a}$, financial intermediation has a strictly growth enhancing effect.

Figure 5 also illustrates the stage at which the development of a banking system starts to have crucial long run effects. When the economy has enough resources to keep an increasing number of long term projects until full maturity, financial intermediation has an increasing contribution to growth. This result replicates the empirical importance of financial intermediation for the growth perspectives of middle income, or emerging economies. This can explain why these economies are willing to undertake the risk of an exposed banking system and increase financial vulnerability by developing their financial systems.

\subsection{Liquidity crises and output losses}

An exposed bank is vulnerable to panic runs, and runs impose a cost on the present and following generations. The ultimate cost of a financial crises is the reduction in welfare it imposes on consumers of the current, and any subsequent generation that may bear the costs. The output forgone when there is a crisis is another possible indicator of its cost. However, both indicators are difficult to estimate empirically. The available empirical information on the costs of banking crises, reported by De Caprio and Klingebiel [1999], is the fiscal cost of those episodes.

The fiscal burden of banking crises does not distinguish which generation is paying for the rescue of the banking system. In that respect, the relevant variable in our model to compare with the empirical evidence is the output loss of exposed banking when there is a run. This variable considers the total cost of the crises, and it synthesizes both the loss of consumption of the current generation, 
and the reduction in investment (or wealth) of the next generation. Under the good state of no crisis, an exposed banking system produces:

$$
y=w-k^{e}+\left(1-\lambda^{e}(1-\gamma)\right) f\left(k^{e}\right) .
$$

When there is a bank run, liquidation of all long term assets imply an output: ${ }^{44}$

$$
y_{R}=w-k^{e}+\gamma f\left(k^{e}\right)
$$

To analyze how the output loss varies with the level of wealth, define the relative output loss by:

$$
\begin{aligned}
L_{Y} & =\frac{y-y_{R}}{y} \\
& =\frac{\left(1-\lambda^{e}\right)(1-\gamma)}{\beta \frac{\left(w-k^{e}\right)}{h\left(k^{e}\right)}+\left(1-\lambda^{e}(1-\gamma)\right)}
\end{aligned}
$$

The output forgone in case of a run is linked to the liquidity of the banking portfolio. The more liquid the portfolio, the lower the output cost in case of a crisis, because there is less inefficient

\begin{tabular}{|c|c|c|c|}
\hline Region & $\mathbf{w}-\mathbf{k}$ & $\lambda(\mathbf{w})$ & $\mathbf{L}_{\mathbf{Y}}$ \\
\hline A & 0 & $\lambda^{*}$ & $\frac{\left(1-\lambda^{*}\right)(1-\gamma)}{1-\lambda^{*}(1-\gamma)} \quad$ constant \\
\hline B & increasing & decreasing & $\frac{\beta(w-\underline{k})+\underline{k}}{\beta(w-\underline{k})+\underline{k}+\frac{\gamma}{\left(1-\lambda^{*}\right)(1-\gamma)}\left[\beta^{2}(w-\underline{k})+\underline{k}\right]} \quad$ increasing \\
\hline $\mathrm{C}$ & increasing & 0 & $\frac{(1-\gamma)}{1+\beta \frac{w-k}{h(k)}} \quad$ decreasing \\
\hline D & increasing & 0 & $\frac{(1-\gamma)}{1+\beta \frac{w-k}{h(k)}} \quad$ decreasing \\
\hline
\end{tabular}
liquidation of long term projects. The bank provides liquidity by investing in the short asset $(w-k)$ and by liquidating a proportion $\lambda$ of long term projects. The following table presents the relative output loss for the different regions of exposed banking:

The relative output loss $\mathbf{L}_{\mathbf{Y}}$ has a humped shape. Poor economies that offer a constant proportion of liquidity in the form of liquidation, exhibit a constant output loss. Over region B, there

${ }^{44}$ Let $w^{\prime}=$ wealth of the next generation.The distribution of income between consumption and investment is:

$$
\begin{gathered}
\left.y=\pi c_{E}+(1-\pi) c_{L}+w^{\prime} \quad \text { (if no run }\right) \\
y_{R}=c_{R}+w_{R}^{\prime} \\
\text { with } w_{R}^{\prime}=(1-\beta) \gamma f(k)
\end{gathered}
$$


is two effects: first, an exposed bank starts investing in the liquid asset which reduces the relative output lost, second, it decreases the optimal liquidation increasing the relative output lost. The latter effect dominates, and increases of wealth over this region increases the loss in case of a run. Once an exposed bank stops liquidating the long technology, any subsequent increase in wealth will be accompanied by an increase in investment in the liquid asset, reducing the output loss in case of a run. ${ }^{45}$

Figure 7 depicts the potential output loss for an exposed banking system, under different probabilities of the sunspot $q$. It provides further insight on why middle income economies may find optimal an exposed banking system, while covered banking is optimal for poor economies.

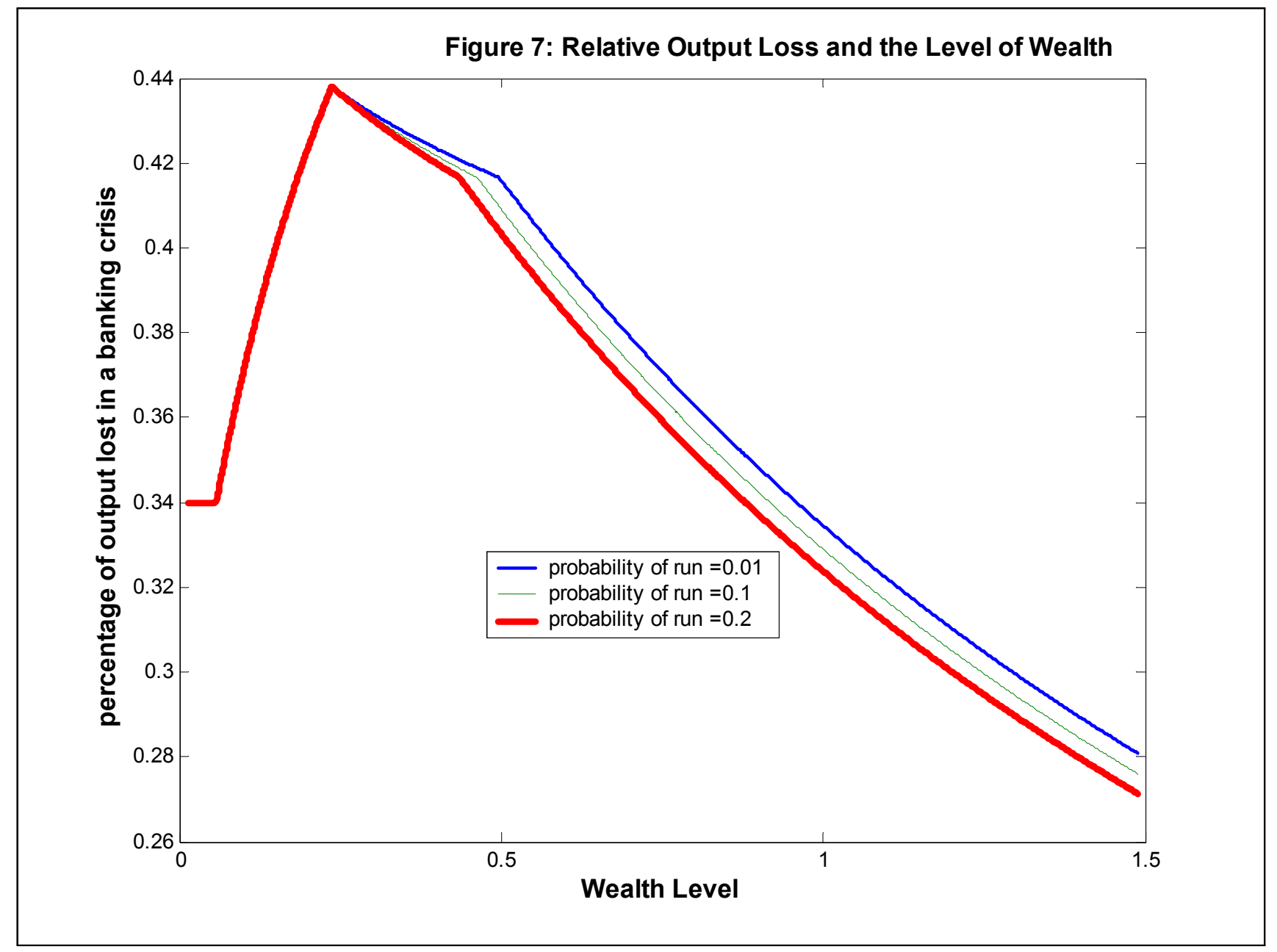

Over regions A and B, an exposed bank holds the same portfolio independently of a having a

\footnotetext{
${ }^{45}$ Except for region B, there is a negative relationship between the output loss and liquidity insurance, since early consumption is increased using liquid assets.
} 
higher probability of crises. An increase in $q$ does not increase liquidity as a crises self-insurance, and the only way to limit the consequences of a run is to be covered. By contrast, over regions $\mathrm{C}$ and D, an exposed bank does increase self-insurance through a more liquid portfolio as an optimal response to higher run risk, reducing the output loss. The humped shape of the output loss matches the empirical evidence: crises in middle income economies have higher costs than poor and rich economies.

\section{Conclusion}

In this paper, we developed an integrated framework to analyze the relationships between financial intermediation, financial fragility and growth. This framework is capable of replicating the observed relationship between financial development and economic growth, and between the recurrence and depth of financial crises and the level of economic development of the countries.

To summarize, poor economies have too much to loose in a banking crisis and tend to prefer to sacrifice liquidity insurance for crisis protection; middle income economies choose to be vulnerable to crises in exchange for higher liquidity insurance and returns; and finally rich economies need a smaller sacrifice of liquidity insurance to be fully protected against crises and avoid any liquidation of long term projects. By choosing to be vulnerable, middle income economies accept the risk of experiencing banking crises. As they get richer, they eventually converge to a long run financially safe steady state. Consequently, the uncertainty on their growth process introduced by the risk of crises as well as the cost of actual banking crises may be only transitory phenomena on the road of their development.

Consistently with the data, we find that the development of the banking system in middle income economies is associated both with a higher growth performance and a higher risk of banking crises. We also replicate the empirical evidence that the output costs of a banking crises are more severe for middle income economies than for poor and rich economies. Finally, it shows that although there can be short run growth costs of developing the financial system, there is a positive relationship in the long run between financial development and economic growth, replicating the results of Loayza and Ranciere [2001].

A important variable in our model is the probability of the bad realization of the sunspot, which in an exposed banking system becomes the actual probability of banking crises. Although 
it is difficult to assess empirically this probability, there are some estimations of the unconditional probability of banking crises. Gourinchas, Landerreche and Valdes (2001) using a 24 year-data set on banking crises, provide an estimate of the probability of banking crises following episodes of rapid financial development ranging between 9.5 and 14\%. By comparison, the most interesting case of intermediate probability in our model -where covered banking is optimal for poor and rich economies, and exposed banking for middle income economies- occurs within a range for the probability of run of $5 \%$ to $20 \%$.

\section{References}

[1] Acemoglu, D. and Zilibotti, F. (1997), "Was Prometheus Unbound by Chance? Risk, Diversification, and Growth", Journal of Political Economy, 105, 709-751.

[2] Aiyagari S.,"Uninsured Idyosynchratic Risk and Aggregate Saving", 1994,Quarterly Journal of Economics, 109(3), 659-684

[3] Angeletos G. and L. Calvet, 2001,"Incomplete Markets, Growth and the Business Cycle", unpublished

[4] Allen, F. and Gale, D. (2000), "Optimal Currency Crises", Journal of Monetary Economics, Carnegie-Rochester Conference on Public Policy, forthcoming.

[5] Allen, F. and Gale, D. (1998),"Optimal Financial Crises," Journal of Finance 53, 1245-1284.

[6] Benhabib,J. and M.Spiegel, 2000, "The Role of Financial Development in Growth and Investment ,"Journal of Economig Growth,5(4), 315-340

[7] Bhattachary S, A Boot and A.Thakor,1998,Journal-of-Money,-Credit,-and-Banking; 30(4), pages $745-70$.

[8] Bencivenga, V. and Smith, B.(1991),"Financial Intermediation and Endogenous Growth", Review of Economic Studies,58,195-209

[9] Beck T, R. Levine and N. Loayza, and , 2000, "Financial Intermediation and Growth: Causality and Causes," Journal of Monetary Economics, 46(1), 31-77. 
[10] Caprio G. and D. Klingbiel, 1999, "Episodes of Systemic and Borderline Financial Crises," mimeo World Bank

[11] Chang, R. and A. Velasco (2000), "Financial Fragility and the Exchange Rate Regime" Journal of Economic Theory; 92(1), 1-34.

[12] Cooper R and T. Ross, 1998,"Bank Runs: Liquidity Costs and Investment Distortions" Journalof-Monetary-Economics; 41(1), pages 27-38..

[13] Demirguc A. and G. Degatriache, 1998, The Determinants of Banking Crises in Developing and Developed Countries, International-Monetary-Fund-Staff-Papers;45 (1), 81-109.

[14] Demirguc A. and G. Degatriache, 2000, Banking Sector Fragility: A Multivariate Logit Approach, World Bank Economic Review, 14 (2), 287-307.

[15] Diamond, P.(1965),"National Debt in a Neoclassical Growth Model", American Economic Review, 55, 1126-1150.

[16] Diamond, D. and Dybvig, P.(1983), "Bank Runs, Deposit Insurance, and Liquidity", Journal of Political Economy, 91, 401-419.

[17] Fulghieri, P. and Rovelli, R, (1998), "Capital markets, financial intermediaries and liquidity supply" Journal of Banking and Finance, 22, 1157-1179.

[18] Gaytan A. and R.Ranciere, (2002a) "Liquidity, Financial Intermediation and Growth", unpublished.

[19] Gaytan A. and R.Ranciere, (2002b) "Banking Regulations and Growth", unpublished.

[20] Goldfajn I and R. Valdes,1997,"Capital Flows and the Twin Crises: The Role of Liquidity" International Monetary Fund Working Paper: WP/97/87

[21] Gourinchas P.O., O. Landerretche, and R. Valdes, 1999, "Lending Booms: Some Stylized Facts", unpublished.

[22] Greenwood, J. and Jovanovic, B.(1990)"Financial Development, Growth, and the Distribution of Income", Journal of Political Economy,98,1076-1107 
[23] Japelli T. and M.Pagano (1994), "Saving, Growth and Liquidity Constraints", Quarterly Journal of Economics, 109(1), 83-109

[24] Kaminsky G. and C Reinhart, 1999, "The Twin Crises: The Causes of Banking and Balance of Payments Problems,", American Economic Review, Vol. 89, No. 3, 473-500.

[25] King R. and R. Levine, 1993, "Finance and Growth: Schumpeter Might Be Right," Quarterly Journal of Economics, 153(3), 717-38.

[26] Loayza N and R. Ranciere (2001),"Financial Development, Financial Fragility and Growth", unpublished.

[27] Morris,-S. and H. Shin,1998" Unique Equilibrium in a Model of Self-Fulfilling Currency Attacks" American-Economic-Review; 88(3), pages 587-97..

[28] Postlewaite A. and X.Vives, 1987 "Bank Runs as an Equilibrium Phenomenon" Journal-ofPolitical-Economy; 95(3),485-91..

[29] Qi, J.(1994), "Bank liquidity and stability in an overlapping generations model", Review of Financial Studies, 7, 389-417

[30] Saint Paul, G. (1992), "Technological choice, Financial Markets, and Economic Development", European Economic Review, April 1992, 763-781 


\section{A The optimal banking system}

Properties of the Value Functions.

P1: $V^{e}(w, q)$ and $V^{c}(w)$ are continuous, differentiable, strictly increasing and strictly concave in $w$ and satisfy Inada Conditions.

P2: $V^{e}(w, q)$ is continuous, differentiable and strictly decreasing in $q$.

P3: $V^{c}(w)$ is invariant in $q$

P4: $V^{c}(w)<V^{u}(w)$ and $\lim _{w \rightarrow \infty} \frac{V^{c}(w)}{V^{u}(w)}=1$

P5: $q>0: V^{e}(w)<V^{u}(w) ; \lim _{w \rightarrow \infty} \frac{V^{e}(w, q)}{V^{u}(w)}<1$ and $\lim _{q \rightarrow 0} \frac{V^{e}(w, q)}{V^{u}(w)}=1 ;$ and $q=0: \Rightarrow V^{e}(w, 0)=V^{u}(w)$ :

P6 Covered Banking weakly dominates autarky $\left(V^{c}(w) \geq V^{a}(w)\right)$ and stricly dominates autarky for $w>k$

- By replicating the autarkic solution $\left(\lambda=\pi, k=k^{a}(w)\right)$, a bank is covered $\Rightarrow$ Covered Banking weakly dominates autarky

- The solution for the optimal covered bank is unique. Therefore, except when the autarkic and covered banking solution are identical $(w \leq \underline{k})$, the optimal covered banking solution stricly dominates autarky.

\section{A.1 The optimal banking system [proof of proposition (4.4)]}

The proof first proves existence by showing that for extreme values of $q(0$ and $\pi)$ the choice of the optimal contract differs. Uniqueness comes from a single crossing property given by the properties of the value functions.

- for $q=0: V^{e}(w, q)=V^{u}(w)>V^{c}(w)$

- for $q=\pi$ :covered banking weakly dominates exposed banking. 
Under autarky the function to be maximized is

$$
V^{a}(w)=\max \{\pi u(w-k+\gamma h(k))+(1-\pi) u(w-k+h(k))\}
$$

Under a exposed banking, the function to be maximized is

$$
\begin{aligned}
V^{e}(q=\pi, w) & =\max \left\{(1-\pi)\left[\pi u\left(c_{E}\right)+(1-\pi) u\left(c_{L}\right)\right]+\pi u(w-k+h(k))\right\} \\
\text { with } & : \quad \pi c_{E}+(1-\pi) c_{L} \leq w-k+h(k)
\end{aligned}
$$

$\Rightarrow$ Using Jensen inequality:

$$
\left[\pi u\left(c_{E}\right)+(1-\pi) u\left(c_{L}\right)\right] \leq u(w-k+h(k))
$$

the optimal solution for exposed bank and autarky for $q=\pi$, implies $k^{e}(w) \leq k^{a}(w)$ for any $w<\infty$, and

$$
\left.\lim _{w \rightarrow \infty} k^{e}(w)\right|_{q=\pi}=\lim _{w \rightarrow \infty} k^{a}(w)=\frac{1}{\pi \gamma+1-\pi}
$$

then:

$$
V^{e}(w) \leq V^{a}(w)
$$

Using $P 6$ :

$$
V^{e}(w, \pi) \leq V^{a}(w) \leq V^{c}(w)
$$

for $q>\pi$ by $P 2$ and $P 6: V^{e}(w)<V^{a}(w) \leq V^{e}(w)$

By $P 2$ and $P 3$ the cutoff probability $q^{*}(w)$ is unique, therefore:

$$
\begin{aligned}
& q<q^{*}(w): V^{e}>V^{c} \\
& q>q^{*}(w): V^{e}<V^{c} \\
& q=q^{*}(w): V^{e}=V^{c}
\end{aligned}
$$

- $q^{*}(w)$ is implicitly define by:

$$
V^{e}\left(w, q^{*}\right)=V^{c}(w)
$$

then as $V^{e}\left(w, q^{*}\right)$ and $V^{c}(w)$ are continuous in $w$ and $V^{e}(w, q)$ is continuous in $q$; hence $q^{*}(w)$ is continuous in $w$ 


\section{A.2 Optimal Banking and the level of wealth [proof of proposition (4.5)]}

The proof proceeds as follows. First we characterize two ranges of wealth: for the first range (poor economies) the cutoff probability is fixed, for some higher levels of wealth, the cutoff probability is strictly increasing. Second, we show that the two value functions can be at most crossing in two points (intersections with different slope). Hence, for a fixed $q$ there are three possible cases. No crossing, one crossing and two crossings. Third, we characterize the implications of the three cases. For any $q$ we show the corresponding case.

Prelimiaries ( $P 7-P 8$ are proved at the end of the proof)

$P 7$ : for $w \leq \widetilde{w}^{c}$ it exists a unique $q_{0}^{*}$ invariant in $w$ such that:

$$
\begin{aligned}
& q<q_{0}^{*}: V^{e}(w)<V^{c}(w) \\
& q>q_{0}^{*}: V^{e}(w)>V^{c}(w) \\
& q=q_{0}^{*}: V^{e}(w)=V^{c}(w) \\
& \text { with } q_{0}^{*}=\frac{\left[\pi+(1-\pi) \gamma^{\frac{\sigma-1}{\sigma}}\right]^{\sigma}-\left[\pi+(1-\pi) \gamma^{\sigma-1}\right]}{\left[\pi+(1-\pi) \gamma^{\frac{\sigma-1}{\sigma}}\right]^{\sigma}-1}
\end{aligned}
$$

$P 8$ for $\widetilde{w}^{c}<w<\min \left(\widetilde{w}^{e}, \widehat{w}^{c}\right): q^{*}(w)$ is stricly increasing. Let's $\widetilde{q}=q\left(\min \left(\widetilde{w}^{e}, \widehat{w}^{c}\right)\right)$

For the rest of the proof will will assume $q \neq q_{0}^{*}$ and describe at the end the special case $q=q_{0}^{*}$ $\Rightarrow$ By $P 1$ and $P 4-P 5$, the graphs of $V^{e}(w)$ and $V^{c}(w, q)$ can intersect in zero,one or two points

Let's first characterize the different possible cases and show then how they apply to different values of $q$ :

case a: one intersection

$\Rightarrow$ By $P 4-P 5$ at the unique intersection point $w_{h} \frac{\delta V^{c}(w, q)}{\delta w}<\frac{\delta V^{c}(w, q)}{\delta w}$

case $b$ :two intersections

Let's call $w_{l}$ and $w_{h}$, the two point of intersection where they intersect twice

$\Rightarrow$ By $P 4-P 5$, at $w_{h}, \frac{\delta V^{c}(w, q)}{\delta w}<\frac{\delta V^{c}(w, q)}{\delta w}$. Then at $w_{l}, \frac{\delta V^{c}(w, q)}{\delta w}>\frac{\delta V^{c}(w, q)}{\delta w}$. which implies:

$$
\begin{aligned}
& w<w_{l}: V^{e}<V^{c}: \text { covered banking is optimal } \\
& w_{l}<w<w_{h}: V^{e}>V^{c}: \text { exposed banking is optimal } \\
& w>w_{h}: V^{e}<V^{c}: \text { covered banking is optimal }
\end{aligned}
$$

case c: no intersection 
$\Rightarrow$ By $P 4-P 5, V^{e}>V^{c}$ for all level of $w$

Let's now consider how thoses cases apply for different value of $q$

$\Rightarrow$ By $P 7$ and $P 4-P 5$, when $q<q_{0}^{*}$, case $a$ applies

$\Rightarrow$ By $P 8$ and $P 4-P 5$ when $q_{0}^{*}<q<\widetilde{q}$ case $b$ applies

$\Rightarrow$ By Proposition (4.4), when $q>\pi$, case $c$ applies

Let's now use the $P 2$ to demonstrate by continuity which cases apply to the remaining range $q \in] \widetilde{q}, \pi]$.

When $q$ continuously decreases, the graph of $V^{b}(w, q)$ continuously shift up when the graph of $V^{c}(w)$, stays invariant.

Therefore by continuity $\exists$ ! $q_{1}$ such that:

$$
\begin{aligned}
q_{1} & <q<\pi: \text { case } c \text { applies } \\
\widetilde{q} & <q<q_{1}: \text { case } b \text { applies } \\
q & =q_{1}: V^{b}(w, q) \text { and } V^{c}(w) \text { are tangeant }
\end{aligned}
$$

By the same reasonning when there is two intersections points $w_{l}, w_{h}: \frac{\delta w_{l}}{\delta q}>0 ; \frac{\delta w_{h}}{\delta q}<0$.

$\Rightarrow \operatorname{By} P 7-P 8, \min \left(\widetilde{w}^{e}, \widehat{w}^{c}\right)<w_{l}<w_{h}$

special case: $q=q_{0}^{*}:$

By $P 7$ for $w<\widetilde{w}^{c}: V^{e}\left(w, q_{0}^{*}\right)=V^{c}(w)$

When $w \geq \widetilde{w}^{e}$ the analysis is as above and over $\left.] \widetilde{w}^{e}, \infty\right)$ and by $P 4-P 5$, case $b$ applies on ]$\left.\widetilde{w}^{e}, \infty\right)$

Having demonstrated the relative position of $V^{c}(w)$ and $V^{e}(w, q)$ for all values of $q$ and all value for $w$, the proof of proposition is now complete.

\section{Appendix: proofs of $P 7-P 8$}

Let : $\Delta(w, q)=V^{e}(w, q)-V^{c}(w)$

for $w \leq \underline{k}$ :

$$
\Delta(w, q)=V^{e}(w, q)-V^{c}(w)=\left[V^{e}(1, q)-V^{c}(1)\right] w^{1-\sigma}
$$

then:

$$
\Delta\left(q^{*}, w\right)=0 \Leftrightarrow\left[V^{e}(1, q)-V^{c}(1)\right]=0
$$

then $q^{*}=q_{0}^{*}$ is a constant independant of $w$ 
for $\underline{k}<w \leq \widetilde{w}^{c}$

$V^{c}(w)=\pi u\left(c_{E}\right)+(1-\pi) u\left(c_{L}\right)$ and as $c_{E}=w-\underline{k}+\gamma h(\underline{k})$ and $c_{L}=c_{E} / \gamma$ :

$$
V^{c}(w)=u(w-\underline{k}+\gamma h(\underline{k}))\left[\pi+(1-\pi) \gamma^{\sigma-1}\right]
$$

$V^{e}(w, q)=(1-q)\left(\pi u\left(c_{E}\right)+(1-\pi) u\left(c_{L}\right)\right)+q u(w-\underline{k}+\gamma h(\underline{k})$

and $c_{L}=c_{E} / \gamma^{1 / \sigma}$

then:

$$
V^{e}(w, q)=(1-q) u\left(c_{E}\right)\left[\left[\pi+(1-\pi) \gamma^{\frac{\sigma-1}{\sigma}}\right]+q u(w-\underline{k}+\gamma h(\underline{k})\right.
$$

but also:

$$
\begin{aligned}
c_{r u n} & =\pi c_{E}+(1-\pi) \gamma c_{L} \\
c_{r u n} & =c_{E}\left[\pi+(1-\pi) \gamma^{\frac{\sigma-1}{\sigma}}\right] \\
c_{E} & =\left[\pi+(1-\pi) \gamma^{\frac{\sigma-1}{\sigma}}\right]^{-1}(w-\underline{k}+\gamma h(\underline{k}))
\end{aligned}
$$

then:

$$
\begin{aligned}
V^{e}(w, q) & =\left((1-q)\left[\pi+(1-\pi) \gamma^{\frac{\sigma-1}{\sigma}}\right]\left[\pi+(1-\pi) \gamma^{\frac{\sigma-1}{\sigma}}\right]^{\sigma-1}+q\right) u(w-\underline{k}+\gamma h(\underline{k})) \\
& =\left((1-q)\left[\pi+(1-\pi) \gamma^{\frac{\sigma-1}{\sigma}}\right]^{\sigma}+q\right) u(w-\underline{k}+\gamma h(\underline{k}))
\end{aligned}
$$

And at $q=q^{*}$

$$
V^{e}(w, q)=V^{c}(w)
$$

then subsituting it appears clearly that $q^{*}$ does not depend on $w$ :

$$
\left(\left(1-q^{*}\right)\left[\pi+(1-\pi) \gamma^{\frac{\sigma-1}{\sigma}}\right]^{\sigma}+q^{*}\right) u(w-\underline{k}+\gamma h(\underline{k}))=\left[\pi+(1-\pi) \gamma^{\sigma-1}\right]
$$

then:

$$
q_{0}^{*}=\frac{\left[\pi+(1-\pi) \gamma^{\frac{\sigma-1}{\sigma}}\right]^{\sigma}-\left[\pi+(1-\pi) \gamma^{\sigma-1}\right]}{\left[\pi+(1-\pi) \gamma^{\frac{\sigma-1}{\sigma}}\right]^{\sigma}-1}
$$

for $\underline{\widetilde{w}^{c}<w \leq \min \left(\widetilde{w}, \widehat{w}^{c}\right)}$

$$
\begin{aligned}
& V^{c}(w)=u(w-k+\gamma h(k))\left[\pi+(1-\pi) \gamma^{\sigma-1}\right] \\
& V^{e}(w, q)=\left((1-q)\left[\pi+(1-\pi) \gamma^{\frac{\sigma-1}{\sigma}}\right]\left(\pi+(1-\pi) \gamma^{1-1 / \sigma}\right)^{\sigma-1}+q\right) u(w-\underline{k}+\gamma h(\underline{k}))
\end{aligned}
$$


SO $q^{*}$ :

$$
\begin{aligned}
u(w-k+\gamma h(k))\left[\pi+(1-\pi) \gamma^{\sigma-1}\right] & =\left(\left(1-q^{*}\right)\left[\pi+(1-\pi) \gamma^{\frac{\sigma-1}{\sigma}}\right]^{\sigma}+q^{*}\right) u(w-\underline{k}+\gamma h(\underline{k})) \\
\frac{u(w-k+\gamma h(k))}{u(w-\underline{k}+\gamma h(\underline{k}))} & =\frac{\left(-q^{*}\left(\left[\pi+(1-\pi) \gamma^{\frac{\sigma-1}{\sigma}}\right]^{\sigma}-1\right)+\left[\pi+(1-\pi) \gamma^{\frac{\sigma-1}{\sigma}}\right]^{\sigma}\right)}{\left[\pi+(1-\pi) \gamma^{\sigma-1}\right]}
\end{aligned}
$$

with $\left[\pi+(1-\pi) \gamma^{\frac{\sigma-1}{\sigma}}\right]^{\sigma}>1$

As $w$ increases, $k$ increases in the SBG solution but stay steady in the CWR solution, $u(w-$ $k+\gamma h(k))$ increase by less than $u(w-\underline{k}+\gamma h(\underline{k}))$

because $\left.\left(\gamma h^{\prime}(k)-1\right)<0\right)$.

Then the LHS will go down so to restore equality the RHS will have to down as well which implies $q$ to go up

$$
\frac{\delta q^{*}}{\delta w}>0
$$

\section{B The dynamics of wealth of a banking economy [proof of proposition (4.6)]}

We prove that the growth rate of the economy with the optimal banking system is stricly decreasing in two steps, first within banking systems and then between banking systems when there is a switch in the optimal banking regime.

Step A: we prove that the growth rates with a covered banking system and with an exposed banking system are stricly decreasing

growth rate under covered banking

- region A-B: $g^{\prime}(w)<0$ cf proof of proposition 4.2 in Gaytan-Ranciere (2002a) in the special case where $\sigma=1$

- region $\mathrm{C}: 1+g(w)=\frac{(1-\beta) h(k) / \beta}{w}$

which combined with f.o.c and after some algebra gives: $g^{\prime}(w)=\frac{k^{\prime}(w) h^{\prime \prime}(k(w))(1-\beta)\left(\frac{1-\pi}{\beta \pi}\right)^{2}}{\left(\frac{1-\pi}{\pi} \frac{h^{\prime}(k)}{\beta}+1\right)}$ As $h^{\prime \prime}(k(w))<0$ and $k^{\prime}(w)>0 \Longrightarrow g^{\prime}(w)<0$ 
- region D: $g^{\prime}(w)<0$ identical to the proof of proposition 3.2 in Gaytan-Ranciere (2002a)

growth rate under exposed banking

- region A-B: $g^{\prime}(w)<0$ cf proof of proposition 4.2 in Gaytan-Ranciere (2002a) as $\left\{k^{e}(w), \lambda^{e}(w)\right\}=$ $\left\{k^{u}(w), \lambda^{u}(w)\right\}$

- region $\mathrm{C}: g^{\prime}(w)<0 \Leftrightarrow \beta w k^{\prime}(w)<k \Leftrightarrow \beta w \frac{k^{\prime}(w)}{k}<1$

Let show that $\beta w \frac{k^{\prime}(w)}{k}<1$

$\beta w \frac{k^{\prime}(w)}{k}=\frac{\beta \frac{1-\pi}{\pi} \frac{w}{h(k)}}{\frac{1-\pi}{\pi} \beta\left(\frac{1}{h^{\prime}(k)}+\frac{w-k}{h(k)}\right)+k B}$ with $B=\frac{(1-\beta) h^{\prime}(k)}{k}\left(\frac{(1-\gamma) h^{\prime}(k)+1-u^{\prime}(x)}{1-\gamma h^{\prime}(k)}\right)\left(\frac{x(\pi x+(1-\pi) \gamma)}{u^{\prime}(x) \gamma(1-\pi)+\pi x h^{\prime}(k)}\right)$

and $\left(\frac{1}{h^{\prime}(k)}+\frac{w-k}{h(k)}\right)=\left(\frac{w+k\left(\beta^{-1}-1\right)}{h(k)}\right)>\left(\frac{w-k}{h(k)}\right) \Rightarrow \beta w \frac{k^{\prime}(w)}{k}<1 \Leftrightarrow g^{\prime}(w)<0$

- region D: indentical to the proof of proposition 3.2 in Gaytan-Ranciere (2002a)

Step B: we prove that when there is a change in banking regime at $w_{l}$ and $w_{h}: g\left(w_{l}\right)^{+}<g\left(w_{l}\right)^{-}$ and $g\left(w_{h}\right)^{+}<g\left(w_{h}\right)^{-}$

- at $w_{h}$ there is a switch from an exposed system to an covered system then:

$g\left(w_{h}\right)^{+}<g\left(w_{h}\right)^{-} \Leftrightarrow k^{e}\left(w_{h}\right)>k^{c}\left(w_{h}\right)$

$k^{e}\left(w_{h}\right)>\left.k^{c}\left(w_{h}\right) \Leftrightarrow \frac{\delta V^{c}}{\delta k}\right|_{k=k^{e}\left(w_{h}\right)}>0$

After some algebra: $\left.\frac{\delta V^{c}}{\delta k}\right|_{k=k^{e}\left(w_{h}\right)}>0 \Leftrightarrow q<\pi$ which is true as $q=q^{*}\left(w_{h}\right)<\pi$

$=>k^{e}\left(w_{h}\right)>k^{c}\left(w_{h}\right) \Leftrightarrow g\left(w_{h}\right)^{+}<g\left(w_{h}\right)^{-}$

- at $w_{l}$, by a similar argument, $g\left(w_{l}\right)^{+}<g\left(w_{l}\right)^{-}$

\section{The Consequences of a Banking System [proof of propo- sition (5.2)]}

- Let prove first the existence of a wealth threshold $m$ in region $\mathrm{C}$ such that $k^{a}(m)=k^{b}(m)$ and $w>m \Rightarrow k^{a}(w)<k^{b}(w)$ 
In region D: $k^{e}(w)>k^{a}(w) \Leftrightarrow q<\pi$ which is verified if an exposed banking system is optimal

In region D: $V^{c}(w)>V^{a}(w) \Rightarrow k^{c}(w)>k^{a}(w)$

In region $\mathrm{B}: k^{a}(w)>\underline{k}=k^{e}(w)=k^{c}(w)$

Then there exists a threshold $m$ in region $\mathrm{C}$ such that $k^{a}(m)=k^{b}(m)$ and $w>m \Rightarrow k^{a}(w)<$ $k^{b}(w)$

- Let know compare growth in both regimes

In region $\mathrm{C}$ and $\mathrm{D}, \lambda^{b}(w)=0<\lambda^{a}(w)=\pi$ then $w \geq m \Rightarrow g^{b}(w)>g^{a}(w)$

In region A: for $\sigma>1: k^{a}(w)=k^{b}(w)=w$ and $\lambda^{a}(w)=\pi=\lambda^{c}(w)>\lambda^{e}(w) \Rightarrow g^{a}(w) \geq g^{b}(w)$

Then there exists a threshold $w_{a} \in(\underline{k}, m)$ such that $w>w_{a} \Rightarrow g^{b}(w)>g^{a}(w)$

\section{Parameters}

The parameters used for simulations are:

\begin{tabular}{|l|l|}
\hline Factor productivity & $A=3$ \\
\hline Capital share & $\beta=.4$ \\
\hline Liquidity needs & $\pi=.4$ \\
\hline Liquidation value & $\gamma=.5$ \\
\hline Risk Aversion & $\sigma=2$ \\
\hline
\end{tabular}




\section{Figure 2. Marginal Returns}

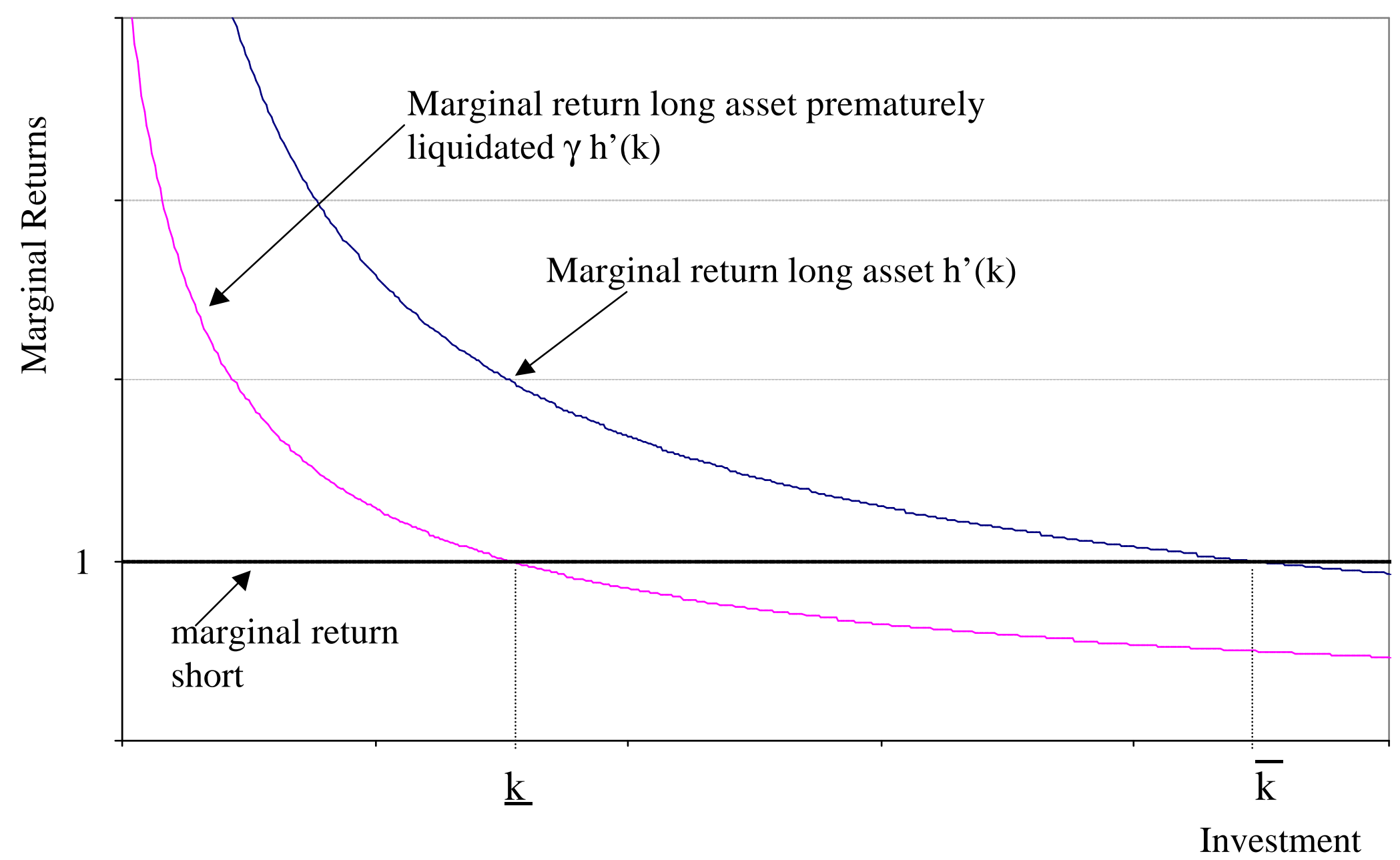


Figure 3 :THE BEST COVERED BANKING SYSTEM

Optimal Capital Choice (k)

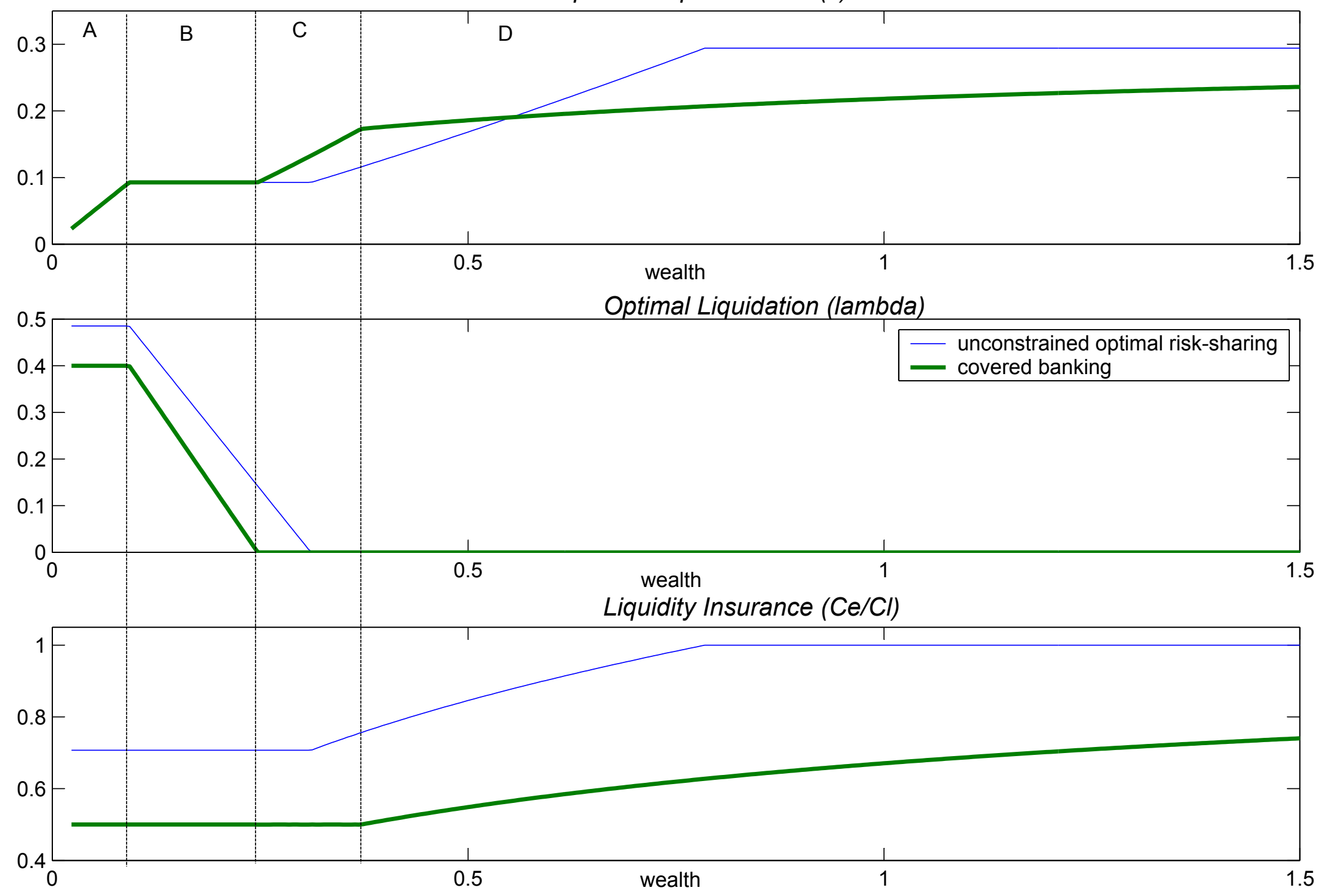


Figure 4 :THE BEST EXPOSED BANKING SYSTEM

Optimal Capital Choice (k)

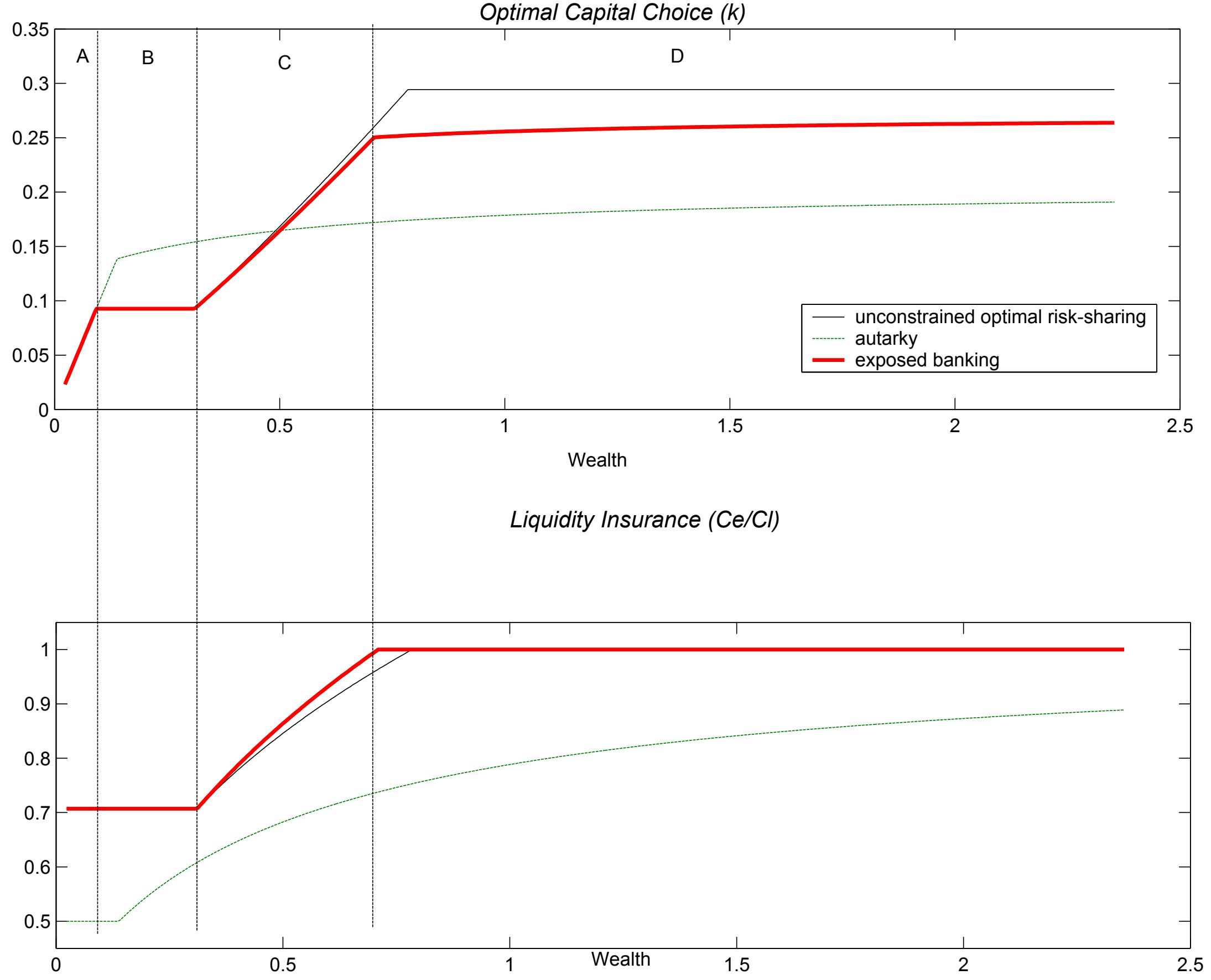




\title{
FinANCIAL DEVELOPMENT, FinANCIAL Fragility, AND GROWTH*
}

\author{
Norman Loayza \\ World Bank
}

\author{
Romain Ranciere \\ NYU and CERAS
}

First draft: October 2000

This draft: February 2002

\begin{abstract}
This paper attempts to reconcile the apparent contradiction between two strands of the literature on the effects of financial intermediation on economic activity. On the one hand, the empirical growth literature finds a positive effect of financial depth as measured by, for instance, private domestic credit and liquid liabilities (e.g., Levine, Loayza, and Beck 2000). On the other hand, the banking and currency crisis literature finds that monetary aggregates, such as domestic credit, are among the best predictors of crises and their related economic downturns (e.g., Kaminski and Reinhart 1999). This paper starts by illustrating these opposing effects by, first, analyzing the dynamics of output growth and financial intermediation around systemic banking crises and, second, showing that the growth enhancing effects of financial depth are weaker in countries that experienced such crises. After these illustrative exercises, the paper attempts an empirical explanation of the apparently opposing effects of financial intermediation. This explanation is based on a distinction between transitory and trend effects of domestic credit aggregates on economic growth. Working with a panel of cross-country and time-series observations, the paper estimates an encompassing model of long- and short-run effects, following Pesaran, Shin, and Smith (1999)'s Pooled Mean Group Estimator. The main result of the paper is that a positive long-run relationship between financial intermediation and output growth co-exists with a, mostly, negative short-run relationship.
\end{abstract}

\footnotetext{
This paper was written while Loayza and Ranciere worked in the research department of the Central Bank of Chile. We are grateful for the comments and advice from J. Benhabib, J. Cummings, F. Gallego, P.O. Gourinchas, O. Jeanne, P. Martin, K. Schmidt-Hebbel, A. Rose, A. Tornell, and R. Soto. Correspondence: nloayza@worldbank.org.
} 


\section{FINANCIAL DEVELOPMENT, FINANCIAL FRAGILITY AND GROWTH}

\section{INTRODUCTION}

This paper attempts to reconcile the apparent contradiction between two strands of the literature on the effects of financial intermediation on economic activity. On the one hand, the empirical growth literature finds a positive effect of measures of private domestic credit and liquid liabilities on per capita GDP growth. This is interpreted as the growth enhancing effect of financial development (e.g., King and Levine, 1993; Levine, Loayza, and Beck, 2000). On the other hand, the banking and currency crisis literature finds that monetary aggregates, such as domestic credit, are among the best predictors for crises (e.g., Demirguc-Kunt and Degatriache, 1998 and 2000; Gourinchas, Landerretche, and Valdes, 1999; Kaminsky and Reinhart, 1999). Since banking crises usually lead to recessions, an expansion of domestic credit would then be associated to growth slowdowns.

A similar divide exists at the theoretical level. According to the endogenous growth literature, financial deepening leads to a more efficient allocation of savings to productive investment projects (see Greenwood and Jovanovic, 1990; Bencivenga and Smith, 1991). Conversely, the financial crisis literature points to the destabilizing effect of financial liberalization as it leads to overlending. Overlending would occur through a combination of channels, including a limited monitoring capacity of regulatory agencies, the inability of banks to discriminate good projects during investment booms, and the existence of an explicit or implicit insurance against banking failures (Shneider and Tornell, 2000; Aghion, Bacchetta and Banerjee, 1999). Not surprisingly, each strand of the literature has produced its own set of policy implications. Thus, researchers that emphasize the findings of the endogenous growth literature advocate financial liberalization and deepening (e.g., Roubini and Sala-i-Martin, 1992), while those that concentrate on crises caution against "excesive" financial liberalization (e.g., Balino and Sundarajan, 1991; Gavin and Hausman, 1995).

This paper seeks to contribute to the debate from an empirical perspective. In section II we examine how the relationship between measures of financial depth and economic growth is affected by the presence of financial crises. For this purpose, we first 
describe the behavior of financial intermediation and output growth around episodes of banking crises. We then reconsider the evidence on the positive growth effect of financial deepening by analyzing whether this effect is weaker in countries afflicted by financial crises.

In section III the paper attempts an empirical explanation of the apparently contradictory effects of financial intermediation on economic activity. This explanation is based on the distinction between cycle and trend changes of financial intermediation and their corresponding effects on output growth. Working with a panel of cross-country and time-series observations, we estimate an encompassing model of long- and short-run effects. Section IV concludes.

\section{The Relationship between Financial DePth and Growth in the Presence of FinANCIAL CRISES}

In this section we examine how the relationship between measures of financial depth and economic growth is affected by the presence of financial crises. First, we describe the behavior over time of financial intermediation and output growth around banking crises. We do it by using an event-study methodology applied to a panel of countries that have experienced such crises, as identified by Caprio and Klingbiel (1999). Second, we revisit the evidence on the positive growth effect of financial deepening by testing whether this effect is weaker in countries that have experienced banking crises. For this purpose, we follow the GMM cross-country panel-data approach to growth empirics in Levine, Loayza and Beck (2000). ${ }^{1}$

\section{A. The behavior of financial intermediation and economic activity around episodes of financial crises}

Here we describe the behavior of financial intermediation and economic activity in a typical country before and after the start of a banking crisis. We use total liquid liabilities and domestic credit to the private sector, both as ratios to GDP, as the measures of financial intermediation. Economic activity is measured with total and per capita GDP growth rates.

\footnotetext{
${ }^{1}$ See also Caselli, Esquivel, and Lefort (1996), Easterly, Loayza, and Montiel (1997), and Beck, Levine, and Loayza (2000).
} 
We first identify the episodes of banking crises for a large sample of countries following Caprio and Klingbiel (1999). According to the Caprio and Klingbiel classification, a systemic banking crisis is a situation where all or most of the capital of the banking system is eroded. In this situation, even if some banks stay solvent, the net worth of the banking system as a whole is negative. A banking crisis is almost always associated with a ratio of non-performing assets larger than $10 \%$ and a rescue cost higher than $2 \%$ of annual GDP. The list of countries and time periods where systemic banking crises occurred is given in Appendix A.

Second, applying an event-study methodology, we make country experiences comparable by re-scaling calendar time into crisis-centered time for each country. Moreover, to eliminate country-specific effects, we demean each observation with the corresponding country average.

We focus the analysis on the 12-year widow centered on the start of the banking crisis. Figure 1 presents the behavior of the typical country-year observation, which is given by the median across countries in a particular year for each measure of financial intermediation and output growth. Table 1 presents Students' t-tests for the significance of level and correlation changes over the 12-year period.

Both liquid liabilities and private credit rise rapidly before the crisis then drop drastically once it starts. They recover partially in the following years but remain far below their pre-crisis levels. On the other hand, total and per capita GDP growth rates fall in the years prior to the banking crisis, reach the bottom at the onset of the crisis, and recover gradually afterwards. The correlation between the measures of financial intermediation and economic activity depend on the period where the correlation is computed. In general, however, the correlation between growth and financial intermediation is negative in the years prior to and after the crisis. In the case of private credit, its correlation with growth is strongly negative prior to the crisis, and it becomes close to neutral in the aftermath.

In summary, this first exercise shows that credit booms do precede banking crisis and that the relationship between financial intermediation and growth is negative in the years surrounding banking crises. 


\section{B. Revisiting the evidence on the growth effects of financial deepening}

Working with a large cross-section of countries, King and Levine (1993a, 1993b) find a positive relationship between initial financial intermediation depth and subsequent long-run growth performance. In these and related studies, the long-run growth rate is estimated as the average rate over periods of time as long as 25-30 years. King and Levine use initial measures of financial intermediation (rather than, say, period averages) to be able to conclude that more developed financial systems lead to higher growth. Levine, Loayza, and Beck (2000) address directly the issue of joint endogeneity of financial development through the use of instrumental variables in their growth regressions. They use the countries' legal origin as the "external" instrument for financial depth in their cross-sectional regressions and the lagged observations of all explanatory variables as "internal" instruments in their pooled (cross-country and timeseries) regressions. The data panels used by Levine et al. consist of about 74 countries and, for each of them, non-overlapping five-year averages covering the period 1960-95. They use five-year averages, rather than annual observations, to smooth out transitory or business-cycle fluctuations. Confirming previous results, Levine et al. find robust evidence that financial development and depth lead to an improved growth performance.

It is arguable that in most cases, using low-frequency data (such as averages over five or more years) allows the researcher to concentrate on long-run effects. However, in cases of prolonged or deep recessions, such as those associated with financial crises, even averages over long periods may be contaminated by cycle effects. Developing this argument, De Gregorio and Guidotti (1995) present evidence that while in cross-sectional regressions involving a worldwide sample of countries financial intermediation is positively linked with growth, in panel regressions for only Latin American countries, the relationship is negative. They suggest that their results for Latin America may reflect the lasting impact of the repeated financial crises (and associated overlending) that the region has suffered. However, De Gregorio and Guidotti do not offer direct evidence on the role of financial crises in distorting the financial intermediation and growth relationship. Moreover, it is possible that their contrasting results between the worldwide and Latin American samples are actually due to the use of cross-sectional vs. panel-data estimators. 
We now analyze how the presence of financial crises modifies the estimated link between measures of financial intermediation and economic growth. For this purpose, we work with the same data and methodology as in Levine, Loayza, and Beck (2000) but allow for, respectively, a banking-crisis and a Latin America effect.

\section{Data and Methodology}

We work with a pooled data set consisting of 74 countries and, for each of them, at most 7 non-overlapping five-year periods spanning the years 1960-95. The resulting panel of country and time-period observations is unbalanced. Appendix B lists the countries included in the sample, and Appendix $\mathrm{C}$ presents the definitions and sources of the variables included in our empirical model.

We estimate a growth regression using panel data. As standard in the literature, the regression equation is dynamic given that it includes the initial level of per capita output as an explanatory variable. Apart from the measure of financial intermediation, the regression equation considers a set of control variables, including initial per capita output, average secondary school attainment of the adult population, the average ratio of government consumption to GDP, the average inflation rate, and the average black market premium on foreign exchange.

The regression equation to be estimated is the following,

$$
y_{i, t}-y_{i, t-1}=(\alpha-1) y_{i, t-1}+\beta^{\prime} C V_{i, t}+\delta F D_{i, t}+\mu_{t}+\eta_{i}+\varepsilon_{i, t}
$$

where, $y$ is the logarithm of real per capita output, $C V$ is a set of control variables, $F D$ is an indicator of financial depth, $\mu_{t}$ is a time-specific effect, $\eta_{i}$ is an unobserved countryspecific effect, and $\varepsilon$ is the error term. The subscripts $i, t$ represent country and timeperiod, respectively. We assess the banking-crisis and the Latin-America effects by introducing a slope dummy on the financial depth indicator.

The proposed growth regression poses some challenges for estimation. The first is the presence of unobserved period- and country-specific effects. While the inclusion of period-specific dummy variables can account for the time effects, the common methods

to deal with country-specific effects ("within" or differences estimators) are inappropriate given the dynamic nature of the regression. The second challenge is that most 
explanatory variables are likely to be jointly endogenous with economic growth. Then we need to control for the biases resulting from simultaneous or reverse causation. In the following paragraphs we outline the econometric methodology we use to control for unobserved country-specific effects and joint endogeneity in a dynamic model of panel data.

\section{Econometric methodology}

We use the Generalized-Method-of-Moments (GMM) estimators developed for dynamic models of panel data that were introduced by Holtz-Eakin, Newey, and Rosen (1988), Arellano and Bond (1991), and Arellano and Bover (1995). Taking advantage of the panel nature of the data, these estimators are based on, first, differencing regressions and/or instruments to control for unobserved effects, and, second, using previous observations of the explanatory variables as instruments (which are called "internal" instruments).

After accounting for the time-specific effects and grouping all explanatory variables in a vector $X$, we can rewrite equation (1) as follows,

$$
y_{i, t}=\alpha y_{i, t-1}+\beta^{\prime} X_{i, t}+\eta_{i}+\varepsilon_{i, t}
$$

In order to eliminate the country-specific effect, we take first-differences of equation (2),

$$
y_{i, t}-y_{i, t-1}=\alpha\left(y_{i, t-1}-y_{i, t-2}\right)+\beta^{\prime}\left(X_{i, t}-X_{i, t-1}\right)+\left(\varepsilon_{i, t}-\varepsilon_{i, t-1}\right)
$$

The use of instruments is required to deal with (i) the likely endogeneity of the explanatory variables, and, (ii) the problem that, by construction, the new error term, $\varepsilon_{i, t}-\varepsilon_{i, t-1}$, is correlated with the lagged dependent variable, $y_{i, t-1}-y_{i, t-2}$. Taking advantage of the panel nature of the data set, the instruments consist of previous observations of the explanatory and lagged dependent variables. Given that it relies on past values as instruments, this method only allows current and future values of the explanatory variables to be affected by the error term. Therefore, while relaxing the 
common assumption of strict exogeneity, our instrumental-variable method does not allow the $X$ variables to be fully endogenous.

Under the assumptions that (a) the error term, $\varepsilon$, is not serially correlated, and (b) the explanatory variables, $X$, are weakly exogenous (i.e., the explanatory variables are assumed to be uncorrelated with future realizations of the error term), the GMM dynamic panel estimator uses the following moment conditions.

$$
\begin{aligned}
& E\left[y_{i, t-s} \cdot\left(\varepsilon_{i, t}-\varepsilon_{i, t-1}\right)\right]=0 \quad \text { for } s \geq 2 ; t=3, \ldots, T \\
& E\left[X_{i, t-s} \cdot\left(\varepsilon_{i, t}-\varepsilon_{i, t-1}\right)\right]=0 \quad \text { for } s \geq 2 ; t=3, \ldots, T
\end{aligned}
$$

The GMM estimator based on these conditions is known as the difference estimator. Notwithstanding its advantages with respect to simpler panel data estimators, there are important statistical shortcomings with the difference estimator. AlonsoBorrego and Arellano (1999) and Blundell and Bond (1998) show that when the explanatory variables are persistent over time, lagged levels of these variables are weak instruments for the regression equation in differences. Instrument weakness influences the asymptotic and small-sample performance of the difference estimator. Asymptotically, the variance of the coefficients rises. In small samples, Monte Carlo experiments show that the weakness of the instruments can produce biased coefficients. ${ }^{2}$

To reduce the potential biases and imprecision associated with the usual difference estimator, we use a new estimator that combines in a system the regression in differences with the regression in levels (developed in Arellano and Bover 1995 and Blundell and Bond 1997). The instruments for the regression in differences are the same as above. The instruments for the regression in levels are the lagged differences of the corresponding variables. These are appropriate instruments under the following additional assumption: there should be no correlation between the change in the righthand-side variables and the country-specific effect (which does not preclude from

\footnotetext{
${ }^{2}$ An additional problem with the simple difference estimator relates to measurement error: differencing may exacerbate the bias due to errors in variables by decreasing the signal-to-noise ratio (see Griliches and Hausman, 1986).
} 
correlation between the levels of these variables and the country-specific effect). This assumption results from the following stationarity property,

$E\left[y_{i, t+p} \cdot \eta_{i}\right\rfloor=E\left[y_{i, t+q} \cdot \eta_{i}\right\rfloor$ and

$E\left[X_{i, t+p} \cdot \eta_{i}\right]=E\left[X_{i, t+q} \cdot \eta_{i}\right]$ for all $p$ and $q$

The additional moment conditions for the second part of the system (the regression in levels) are: ${ }^{3}$

$E\left\lfloor\left(y_{i, t-1}-y_{i, t-2}\right) \cdot\left(\eta_{i}+\varepsilon_{i, t}\right)\right\rfloor=0$

$E\left[\left(X_{i, t-1}-X_{i, t-2}\right) \cdot\left(\eta_{i}+\varepsilon_{i, t}\right)\right]=0$

Thus, we use the moment conditions presented in equations (4), (5), (7), and (8) and employ a GMM procedure to generate consistent and efficient parameter estimates.

Using the moment conditions presented in equations (4), (5), (7), and (8), we employ a Generalized Method of Moments (GMM) procedure to generate consistent estimates of the parameters of interest and their asymptotic variance-covariance (Arellano and Bond 1991, and Arellano and Bover 1995). These are given by the following formulas:

$$
\begin{aligned}
& \hat{\theta}=\left(\bar{X}^{\prime} Z \hat{\Omega}^{-1} Z^{\prime} \bar{X}\right)^{-1} \bar{X}^{\prime} Z \hat{\Omega}^{-1} Z^{\prime} \bar{y} \\
& A \operatorname{VAR}(\hat{\theta})=\left(\bar{X}^{\prime} Z \hat{\Omega}^{-1} Z^{\prime} \bar{X}\right)^{-1}
\end{aligned}
$$

where $\theta$ is the vector of parameters of interest $(\alpha, \beta), \bar{y}$ is the dependent variable stacked first in differences and then in levels, $\bar{X}$ is the explanatory-variable matrix (including the lagged dependent variable, that is, $\left.\left[y_{t-1}, X\right]\right)$ stacked first in differences and then in levels,

\footnotetext{
${ }^{3}$ Given that lagged levels are used as instruments in the differences specification, only the most recent difference is used as instrument in the levels specification. Using other lagged differences would result in redundant moment conditions. (see Arellano and Bover 1995).
} 
$Z$ is the matrix of instruments derived from the moment conditions, and $\hat{\Omega}$ is a consistent estimate of the variance-covariance matrix of the moment conditions. ${ }^{4}$

The consistency of the GMM estimators depends on whether lagged values of the explanatory variables are valid instruments in the growth regression. We address this issue by considering two specification tests suggested by Arellano and Bond (1991) and Arellano and Bover (1995). The first is a Sargan test of over-identifying restrictions, which tests the overall validity of the instruments by analyzing the sample analog of the moment conditions used in the estimation process. Failure to reject the null hypothesis gives support to the model. The second test examines the null hypothesis that the error term $\mathcal{E}_{i, t}$ is not serially correlated. As in the case of the Sargan test, the model specification is supported when the null hypothesis is not rejected. In the system specification we test whether the differenced error term (that is, the residual of the regression in differences) is second-order serially correlated. First-order serial correlation of the differenced error term is expected even if the original error term (in levels) is uncorrelated, unless the latter follows a random walk. Second-order serial correlation of the differenced residual indicates that the original error term is serially correlated and follows a moving average process at least of order one. This would reject the appropriateness of the proposed instruments (and would call for higher-order lags to be used as instruments).

\section{Results}

Tables 2 and 3 report the growth regression results. We study how the effect of financial intermediation on growth varies in the presence of financial turmoil by including a slope dummy for countries that have suffered a banking crisis (Table 2). Furthermore, in order to reconsider De Gregorio and Guidotti's findings, we also assess the effect of a slope dummy for Latin American and Caribbean countries (Table 3). Of the 74 countries in the sample, 31 experienced at least one banking crisis and 20 belonged

\footnotetext{
${ }^{4}$ In practice, Arellano and Bond (1991) suggest the following two-step procedure to obtain consistent and efficient GMM estimates. First, assume that the residuals, $\varepsilon_{i, t}$, are independent and homoskedastic both across countries and over time. This assumption corresponds to a specific weighting matrix that is used to produce first-step coefficient estimates. Then, construct a consistent estimate of the variance-covariance matrix of the moment conditions with the residuals obtained in the first step, and use this matrix to re-estimate the parameters of interest (i.e. second-step
} 
to Latin America and the Caribbean (LAC). All but 3 countries in LAC suffered a banking crisis (see Appendix B for further details). In each case, we work with two indicators of financial intermediation, namely, the ratio of liquid liabilities to GDP and the ratio of domestic credit to the private sector to GDP.

The GMM regression results are presented in Tables 2 and 3. Note that according to both specification tests, Sargan and $2^{\text {nd }}$-order serial correlation, the null hypothesis of the validity of the moment conditions cannot be rejected.

The estimation results confirm the positive growth effect of larger financial depth. As Table 2 indicates, this effect is significantly positive for the samples of non-crisis and crisis countries. However, as the size and significance of the slope dummy coefficient reveals, the positive growth effect is statistically smaller for crisis than for non-crisis countries. This is true for both indicators of financial intermediation (i.e., liquid liabilities and private domestic credit). In Table 3, we reconsider De Gregorio and Guidotti's results. We agree with them that the growth effect of financial deepening is smaller in Latin American countries than in the rest. However, we find that even for Latin American countries an expansion of financial intermediation, as measured in the frequencies of five-year averages, leads to higher growth rates. Qualitatively, the results obtained with the slope dummies for crisis and LAC countries are similar. Quantitatively, the coefficient on the interactive term for crisis countries is larger than that for LAC countries, which may be due to the fact that Latin America accounts for only about half of all crisis countries.

In summary, the estimated growth effect of financial deepening is smaller, but still positive, in countries that have faced financial crisis, and particularly those in Latin America. $^{5}$

estimates). Asymptotically, the second-step estimates are superior to the first-step ones in so far as efficiency is concerned.

${ }^{5}$ The results reported above are obtained using only the closest appropriate lag for each variable in the regression. We could use only one instrument per variable because if we used more, we would run into an overfitting problem (reflected on implausibly large Sargan test statistics with p-values close to 1). Overfitting would occur because the number of instrumental variables is too large compared to the number of available cross-sectional units. In order to assess the robustness of our basic results to the lag structure of the instruments, we need to restrict the set of explanatory variables (to avoid the overfitting problem). We then consider two lags for each variable as instruments, using alternatively the two closest lags to the regression period and the two lags separated by one period from the regression. The results of this exercise are presented in Appendix E. They confirm our basic results, that is, the effect of financial deepening on growth is always positive but significantly smaller in crisis-countries. 


\section{SHORT- AND LONG-RUN GROWTH EFFECTS OF FINANCIAL DEEPENING}

In this section we attempt an empirical explanation of the apparently contradictory effects of financial intermediation on economic activity. This explanation is based on the distinction between cycle and trend changes of financial intermediation and their corresponding effects on output growth. Instead of averaging the data to isolate trend effects, we estimate both long- and short-run effects using annual data in a panel containing a large sample of countries. Our method can be summarized as a panel, errorcorrection model, where long- and short-run effects are estimated jointly from a general autoregressive distributed-lag (ARDL) model.

We propose this panel error-correction method as an alternative to the traditional method of time averaging for the following reasons. First, while averaging clearly induces a loss of information, it is not obvious that averaging over fixed-length intervals effectively eliminates business-cycle fluctuations. Second, averaging eliminates information that may be used to estimate a more flexible model that allows for some parameter heterogeneity across countries. Third, and most importantly for our purposes, averaging hides the dynamic relationship between financial intermediation and economic activity, particularly the presence of opposite effects at different time frequencies. ${ }^{6}$

\section{A. Methodology}

Empirical estimation poses two issues. The first is the need to separate and estimate short- and long-run effects without being able to decompose directly trend and transitory components of growth, financial intermediation, and the other explanatory variables. We treat this issue below in the context of single-country estimation. The second issue is the likely possibility that the parameters in the relationship between financial intermediation and economic activity be different across countries. It can be argued that country heterogeneity is particularly relevant in short-run relationships, given that countries are affected by overlending and financial crises to widely different degrees. On the other hand, we can expect that long-run relationships would be more

\footnotetext{
${ }^{6}$ Similar arguments are made by Attanasio, Scorcu, and Picci (2000) in their cross-country study on the dynamic relationship between saving, investment, and growth.
} 
homogeneous across countries. We discuss below the issue of heterogeneity in the context of multi-country estimation.

\section{Single-country estimation}

As said above, we face the challenge to estimate long- and short-run relationships without being able to observe the long- and short-run components of the variables involved. Over the last decade or so, a booming cointegration literature has focused on the estimation of long-run relationships among I(1) variables (Johanssen 1995, Phillips and Hansen 1990). From this literature, two common misconceptions have been derived. The first one is that long-run relationships exist only in the context of cointegration of integrated variables. The second one is that standard methods of estimation and inference are incorrect. Pesaran and Smith (1995) and Pesaran and Shin (1999) have argued against both misconceptions, showing how small modifications to standard methods can render consistent and efficient estimates of the parameters in a long-run relationship between both integrated and stationary variables. Furthermore, the methods proposed by Pesaran and co-authors avoid the need for pre-testing and order-of-integration conformability given that they are valid whether or not the variables of interest are $\mathrm{I}(0)$ or I(1). The main requirements for the validity of this methodology are that, first, there exist a long-run relationship among the variables of interest and, second, the dynamic specification of the model be augmented such that the regressors are strictly exogenous and the resulting residual is not serially correlated. For reasons that will become apparent shortly, Pesaran and co-authors call their method "an autoregressive distributed lag (ARDL) approach" to long-run modelling.

As an illustration, consider the following simple bivariate model:

$$
\begin{aligned}
& y_{t}=a+b y_{t-1}+c X_{t-1}+v_{t} \\
& X_{t}=\gamma+\rho X_{t-1}+\varepsilon_{t}
\end{aligned}
$$

where $y_{t}$, the decision variable, is the per capita GDP growth rate in year $t$; and $X$, the forcing variable, represents a set of growth determinants including financial depth and control variables. Furthermore, assume that the residuals (or shocks) have the following distributional properties: 


$$
\left(\begin{array}{l}
v_{t} \\
\varepsilon_{t}
\end{array}\right) \text { iid }(0, \Sigma), \quad \Sigma=\left(\begin{array}{ll}
\sigma_{v v} & \sigma_{v \varepsilon} \\
\sigma_{v \varepsilon} & \sigma_{\varepsilon \varepsilon}
\end{array}\right)
$$

The first point to note is that $X$ does not depend on past values of $y$ (beyond its dependence on previous values of $X$ ). If a more general process for $X$ were allowed, the long-run relationship between the two variables would not be unique. That is, both variables would be endogenous and additional identification assumptions would be needed to discern between various long-run relationships. ${ }^{7}$ Since multiple long-run relationships are beyond the scope of this paper, we restrict the dynamic process for $X$ to be purely autoregressive.

The second point to note is that the existence of a long-run relationship requires the process for $y$ to be stable, which in this simple example entails that $|b|<1$. Notice that once we have restricted the process of $X$ to be purely autoregressive, the existence of a long-run relationship does not rely on whether $X$ is $\mathrm{I}(0)$ or $\mathrm{I}(1)$; that is, there is no restriction on whether $\rho=1$. Pesaran, Shin, and Smith (2000) present a test for the null hypothesis that there is no long-run relationship when it is not known a priori whether $X$ is $\mathrm{I}(0)$ or $\mathrm{I}(1)$. The test consists on examining the null that $b=1$ against the alternative that $|b|<1$.

In order to be able to derive the long-run relationship between $y$ and $X$, we must obtain a dynamic regression equation in which, first, the regression residual is serially uncorrelated and, second, the regressors, $X$, are strictly exogenous (that is, independent of the residuals at all leads and lags.) Given the assumptions on the distributional properties of the residuals $v$ and $\varepsilon$ (equation 13), the requisite that the residuals be serially uncorrelated is met in our simple example. If this were not the case, we would need to augment the lag order in (11) and (12) until the residuals become serially independent (Pesaran and Shin 1999). The second pre-requisite to derive a long-run relationship is, however, not met in our simple example $-X$ is not strictly exogenous given that the nonzero correlation between the shocks entails a contemporaneous feedback between $y$ and $X$. As explained by Pesaran and Shin (1999), the way to control for this contemporaneous feedback is also to augment the dynamic specification in (16). The

\footnotetext{
${ }^{7}$ See Hsiao (1997) and Pesaran and Shin (1999).
} 
purpose of augmenting the regression equation is to replace the (correlated) residual $v$ with a linear predictor based on leads and lags of $X$ and a new residual that by construction is independent of $X$. In our simple example, we model the contemporaneous correlation between $v_{t}$ and $\varepsilon_{t}$ by a linear regression of $v_{t}$ on $\varepsilon_{t}$ as follows,

$v_{t}=\left(\frac{\sigma_{v \varepsilon}}{\sigma_{\varepsilon \varepsilon}}\right) \varepsilon_{t}+\eta_{t}$

where $\left(\sigma_{v \varepsilon} \sigma_{\varepsilon \varepsilon}\right)$ represents the population coefficient of the regression, and $\eta_{t}$ is distributed independently from $\varepsilon_{t}$.

Substitute the above expression for $v_{t}$ into equation (11). Then, using the AR model for $X$, express $\varepsilon_{t}$ in terms of $X_{t}$ and $X_{t-1}$. The ensuing regression equation is an auto-regressive distributed lag model (ARDL) for $y$ from which a long-run relationship can be derived. The resulting ARDL $(1,1)$ for $y$ is given by,

$$
y_{t}=\left(a-\gamma \frac{\sigma_{v \varepsilon}}{\sigma_{\varepsilon \varepsilon}}\right)+b y_{t-1}+\left(\frac{\sigma_{v \varepsilon}}{\sigma_{\varepsilon \varepsilon}}\right) X_{t}+\left(c-\rho \frac{\sigma_{v \varepsilon}}{\sigma_{\varepsilon \varepsilon}}\right) X_{t-1}+\eta_{t}
$$

Note that the original process for $y$ (equation 1) is now augmented by the inclusion of the additional regressor $X_{t}$.

The error-correction model (ECM) implied by the ARDL $(1,1)$ given above can be expressed as,

$$
\Delta y_{t}=-(1-b)\left[y_{t-1}-\left(\frac{a-\gamma \frac{\sigma_{v \varepsilon}}{\sigma_{\varepsilon \varepsilon}}}{1-b}\right)-\left(\frac{c+\frac{\sigma_{v \varepsilon}}{\sigma_{\varepsilon \varepsilon}}(1-\rho)}{1-b}\right) X_{t-1}\right]+\left(\frac{\sigma_{v \varepsilon}}{\sigma_{\varepsilon \varepsilon}}\right) \Delta X_{t}+\eta_{t}
$$

Where the expression in brackets is the error-correction term and $(1-b)$ is the speed of adjustment.

Therefore, the long-run (steady-state) relationship implied by the dynamic system in equations (11)-(14) is given by,

$$
y^{*}=\left(\frac{a-\gamma \frac{\sigma_{v \varepsilon}}{\sigma_{\varepsilon \varepsilon}}}{1-b}\right)+\left(\frac{c+\frac{\sigma_{v \varepsilon}}{\sigma_{\varepsilon \varepsilon}}(1-\rho)}{1-b}\right) X^{*}+\eta^{*}
$$

or, $y^{*}=\alpha+\beta x^{*}+\eta^{*}$. 
The presentation of this simple empirical model serves to highlight the assumptions and properties of the ARDL method proposed by Pesaran and Smith (1995), Pesaran (1997), and Pesaran and Shin (1999) for the estimation of a long-run relationship. The advantage of the method is that standard estimation and inference can be used regardless of whether the regressors are stationary or integrated. The main assumption is that there exist a single long-run relationship between the endogenous and forcing variables. ${ }^{8}$ The pre-requisites for consistent and efficient estimation are that the shocks in the dynamic specification be serially uncorrelated and that the forcing variables be strictly exogenous. As we illustrated, the pre-requisites can be met by augmenting sufficiently the lag order of the dynamic regression equation. The resulting equation will generally be an ARDL(p, q) model of sufficiently large lag order.

\section{Multi-country estimation}

Our empirical samples below are characterized by time-series (T) and crosssection $(\mathrm{N})$ dimensions of relatively large size. In such conditions, there are a number of alternative methods for multi-country estimation, which allow for different degrees of parameter heterogeneity across countries. At one extreme, the fully heterogeneouscoefficient model imposes no cross-country parameter restrictions and can be estimated on a country-by-country basis -- provided the time-series dimension of the data is sufficiently large. When, in addition, the cross-country dimension is large, the mean of long- and short-run coefficients across countries can be estimated consistently by the unweighted average of the individual country coefficients. This is the "mean group" (MG) estimator introduced by Pesaran, Smith, and Im (1996). At the other extreme, the fully homogeneous-coefficient model requires that all slope and intercept coefficients be equal across countries. This is the simple "pooled" estimator.

In between the two extremes, there are a variety of estimators. The "dynamic fixed effects" estimator restricts all slope coefficients to be equal across countries but allows for different country intercepts. The "pooled mean group" (PMG) estimator, introduced by Pesaran, Shin, and Smith (1999), restricts the long-run coefficients to be

\footnotetext{
${ }^{8}$ It is worth noting that this assumption underlies implicitly the various single-equation based estimators of long-run relationships commonly found in the cointegration literature. Without such assumption, these estimators would at best identify some linear combination of all the long-run relationships present in the data.
} 
the same across countries but allows the short-run coefficients (including the speed of adjustment) to be country specific. The PMG estimator also generates consistent estimates of the mean of short-run coefficients across countries by taking the unweighted average of the individual country coefficients (provided that the cross-sectional dimension is large).

The choice among these estimators faces a general trade-off between consistency and efficiency. Estimators that impose cross-country constraints dominate the heterogeneous estimators in terms of efficiency if the restrictions are valid. If they are false, however, the restricted estimators are inconsistent. In particular, imposing invalid parameter homogeneity in dynamic models typically leads to downward-biased estimates of the speed of adjustment (Robertson and Symons 1992, Pesaran and Smith 1995).

For our purposes, the pooled mean group estimator offers the best available compromise in the search for consistency and efficiency. This estimator is particularly useful when the long run is given by conditions expected to be homogeneous across countries while the short-run adjustment depends on country characteristics such as financial development, institutional quality, and relative price flexibility. Furthermore, the PMG estimator is sufficiently flexible to allow for long-run coefficient homogeneity over only a subset of variables and/or countries.

In view of these considerations, we use the PMG method to estimate a long-run relationship that is common across countries while allowing for unrestricted country heterogeneity in the adjustment dynamics. The interested reader is referred to Pesaran, Shin, and Smith (1999) where the PMG estimator is developed and compared with the MG estimator. Briefly, the PMG estimator proceeds as follows. The estimation of the long-run coefficients is done jointly across countries through a (concentrated) maximum likelihood procedure. Then the estimation of short-run coefficients (including the speed of adjustment), country-specific intercepts, and country-specific error variances is done on a country-by-country basis, also through maximum likelihood and using the estimates of the long-run coefficients previously obtained. ${ }^{9}$

\footnotetext{
${ }^{9}$ The comparison of the asymptotic properties of PMG and MG estimates can be put also in terms of the general trade-off between consistency and efficiency noted in the text. If the long-run coefficients are in fact equal across countries, then the PMG estimates will be consistent and efficient, whereas the MG estimates will only be consistent. If, on the other hand, the long-run coefficients are not equal across
} 
An important assumption for the consistency of our PMG estimates is the independence of the regression residuals across countries. In practice, non-zero error covariances usually arise from omitted common factors that influence the countries' ARDL processes. We seek to eliminate these common factors and, thus, ensure the independence condition by allowing for time-specific effects in the estimated regression; this is equivalent to a regression in which each variable enters as deviations with respect to the cross-sectional mean in a particular year.

\section{B. Data and Results}

The sample consists of 49 countries with annual data for the period 1960-97 (see Appendix B for the list of countries included in the sample). Given the procedure's requirements on the time-series dimension of the data, we include only countries that have at least 20 consecutive observations. The dependent variable is the growth rate of GDP per capita. The measures of financial intermediation are liquid liabilities and private domestic credit, both as ratios to GDP. The control variables are the initial level of GDP per capita, government consumption (as ratio to GDP), the volume of trade (as ratio to GDP), and the inflation rate.

Tables 4 and 5 present the results on specification tests and the estimation of longand short-run parameters linking per capita GDP growth, financial intermediation, and other growth determinants. In Table 4 the measure of financial intermediation is the ratio of private domestic credit to GDP, and in Table 5 it is the ratio of liquid liabilities to GDP. In both tables, we present the results obtained using the pooled mean group (PMG) estimator, which we prefer given its gains in consistency and efficiency over other panel error-correction estimators. For comparison purposes, we also present the results obtained with the mean group (MG) and the dynamic fixed-effects (DFE) estimators.

countries, then the PMG estimates will be inconsistent, whereas the MG estimator will still provide a consistent estimate of the mean of long-run coefficients across countries. The long-run homogeneity restrictions can be tested using Hausman or likelihood ratio tests to compare the PMG and MG estimates of the long run coefficients. In turn, comparison of the small sample properties of these estimators relies on their sensitivity to outliers. In small samples (low $\mathrm{T}$ and $\mathrm{N}$ ), the MG estimator, being an unweighted average, is excessively sensitive to the inclusion of outlying country estimates (for instance those obtained with small T). The PMG estimator performs better in this regard because it produces estimates that are similar to weighted averages of the respective country-specific estimates, where the weights are given according to their precision (that is, the inverse of their corresponding variance-covariance matrix). 
As outlined in the previous section, the consistency and efficiency of the PMG estimates relies on several specification conditions. The first are that the regression residuals be serially uncorrelated and that the explanatory variables can be treated as exogenous. We seek to fulfill these conditions by including in the ARDL model, three lags of the growth rate, 3 lags of the measure of finance intermediation, and one lag of each control variable. We could not expand the lag structure any further because we would run into problems of lack of degrees of freedom. We chose to use a richer (longer) lag structure for the dependent variable (growth) and the variable of interest (financial intermediation) because our main concern was to characterize their long- and short-run relationships.

The second specification condition is that both country-specific effects and crosscountry common factors be accounted for. We control for country-specific effects by allowing for an intercept for each country, and we attempt to eliminate cross-country common factors by demeaning the data using the corresponding cross-sectional means for every period (which is algebraically the same as allowing for year-specific intercepts).

The third condition refers to the existence of a long-run relationship (dynamic stability) and requires that the coefficient on the error-correction term be negative. In the second panel of Tables 4 and 5, we report the estimates for the pooled error-correction coefficient and its corresponding standard error. This coefficient is significantly negative in the PMG estimator (and in dynamic fixed effects), which is evidence that supports the dynamic stability of the model.

The fourth condition is that the long-run parameters be the same across countries. As explained in the econometric methodology section, we can test the null hypothesis of homogeneity through a Hausman-type test; this is based on the comparison between the Pooled Mean Group and the Mean Group estimators. In Tables 4 and 5, we present the Hausman test statistic and the corresponding p-values for the coefficients on each of the explanatory variables and for all of them jointly. When the proxy for financial intermediation is private credit (Table 4), the homogeneity restriction is never rejected, either for individual parameters or jointly. When we use instead liquid liabilities (Table 5 ), the homogeneity of long-run parameters is not rejected except in the case of the coefficient on the inflation rate. 
Regarding the estimated parameters, our analysis focuses on those obtained with the PMG estimator. In the long run, the growth rate of GDP per capita is negatively related to initial income, the size of government, and the inflation rate, and positively related to international trade openness. These are standard results from the empirical growth literature, and it is reassuring that we are able to reproduce them with our methodology.

Most importantly for our purposes, we find that economic growth is positively and significantly linked to the measures of financial intermediation in the long run. On the other hand, the short-run coefficients tell a different story. As explained in the methodology section, short-run coefficients are not restricted to be the same across countries, so that we do not have a single pooled estimate for each coefficient. Nevertheless, we can still analyze the average short-run effect by considering the mean of the corresponding coefficients across countries. We find that the short-run average relationship between the growth rate of GDP per capita and the measures of financial intermediation appears to be strongly negative in the case of private credit and mildly so in the case of liquid liabilities. Thus, comparing the long- and short-run estimates, we can conclude that the sign of the relationship between economic growth and financial intermediation depends on whether their movements are cyclical or permanent.

Finally, we consider the question as to whether the negative short-run relationship between growth and financial intermediation can be linked to the occurrence of systemic banking crisis. We address this question by examining the short-run coefficients on financial intermediation for each country in the sample. We separate the countries with significant short-run effects in two groups: those that experienced a systemic banking crisis and those that did not. Figure $2 \mathrm{a}$ plots the short-run coefficients for the crisis countries and Figure $2 b$, for the non-crisis ones. We can see that seventy-five percent of the crisis countries present a negative short-run relationship between growth and financial intermediation, while only forty-four percent of the non-crisis countries do. Therefore, boom-bust credit cycles appear to explain in part the average negative effect of short-run 
financial intermediation. However, this negative effect appears to occur more generally and can be also linked to experiences of soft-landing after credit booms. ${ }^{10}$

\section{CONCLUSIONS}

The results in this paper can be summarized as follows.

- The dynamic relationship between economic growth and financial intermediation is negative around financial crises. Furthermore, the positive link between "long-run" economic growth and financial deepening is smaller in countries that have suffered banking crises than in the rest.

- Using recent econometric methods for the estimation of dynamic models using panel data, we find that a positive long-run relationship between financial intermediation and output growth co-exists with a, mostly, negative short-run relationship. We propose this result as an empirical explanation for the apparent contradiction between the crisis literature and the endogenous-growth literature on the effects of financial deepening.

\footnotetext{
${ }^{10}$ See Tornell and Westermann (2001) for a model that explains the cycles of credit expansions and contractions by focusing on the dynamics of credit constraints in the non-tradable sector. They conclude that a short-run negative correlation between financial intermediation and growth can reflect not only financial crises but also episodes where lending booms end gradually.
} 


\section{REFERENCES}

Aghion P., P. Bacchetta, and A. Banerjee, 1999, "Capital Markets and the Instability of Open Economies," unpublished.

Alonso-Borrego C. and M. Arellano, 1999, "Symmetrically Normalized Instrumental-Variable Estimation Using Panel Data", Journal of Business \& Economic Statistics, 17, 36-49.

Arellano M. and S. Bond, 1991, "Some Tests of Specification for Panel Data:

Monte Carlo Evidence and an Application to Employment Equations," Review of Economic Studies, 58, 277-297.

Arellano M. and O. Bover, 1995, “Another Look at the Instrumental-Variable Estimation of Error-Components Models," Journal of Econometrics, 68, 29-51.

Attanasio O., L. Picci, and A. Scorcu, 2000, "Saving, Growth and Investment: A Macroeconomic Analysis using a panel of countries," Review of Economics and Statistics, 82(2), 182-211.

Balino T. and V. Sundarajan, editors, 1991, Banking Crises: Cases and Issues, Washington: International Monetary Fund.

Barro R., 1991, "Economic Growth in a Cross Section of Countries," Quarterly Journal of Economics, 106(2), 407-443.

Beck T, A. Demirguc-Kunt, and R. Levine, 2000, “A New Database on Financial Development and Structure," World Bank Economic Review, 14 (3), pp.597-605.

Beck, T., R. Levine, and N. Loayza, 2000, "Financial Development and the Sources of Growth," Journal of Financial Economics, 58 (1-2), 261-300.

Bencivenga, V. and B. Smith, 1991, "Financial Intermediation and Endogenous Growth", Review of Economic Studies, 58, 195-209.

Blundell R, and S. Bond, 1998, "Initial conditions and Moment Conditions in Dynamic Panel Data Models", Journal of Econometrics, 87, 115-143.

Caprio G. and D. Klingbiel, 1996, "Bank Insolvencies: Cross-country Experience," World Bank policy research working paper 1620.

Caprio G. and D. Klingbiel, 1999, "Episodes of Systemic and Borderline Financial Crises," mimeo World Bank. 
Caselli A., G.Esquivel and G. Lefort, "Reopening the Convergence Debate: a new look at the Cross-Country Growth Empirics, Journal of Economic Growth, 1 (3), 363389.

Demirguc A. and G. Degatriache, 2000, Banking Sector Fragility: A Multivariate Logit Approach, World Bank Economic Review, 14 (2), 287-307.

Demirguc A. and G. Degatriache, 1998, The Determinants of Banking Crises in Developing and Developed Countries, International-Monetary-Fund-Staff-Papers;45 (1), 81-109.

De Gregorio J. and P. Guidotti, 1995, "Financial Development and Economic Growth," World Development, 23(3), 433-448.

Eichengreen, B and A. Rose, 1998, "Staying Afloat When the Wind Shifts: External Factors and Emerging-Market Banking Crises," NBER working paper W6370.

Gavin M., and R. Hausman, 1996, "The roots of banking crises: The macroeconomic context," in Banking crises in Latin America, Ricardo Hausmann and Liliana Rojas-Suarez, editors, Washington: Interamerican Development Bank.

Gourinchas P.O., O. Landerretche, and R. Valdes, 1999, “Lending Booms: Some Stylized Facts", unpublished.

Greenwood J. and B. Jovanovic, 1990, "Financial Development, Growth, and the Distribution of Income", Journal of Political Economy, 98,1076-1107

Griliches Z. and J. Hausman. 1986. "Errors in Variables in Panel Data." Journal of Econometrics ,31, 93-118.

Holtz-Eakin D., Newey N, and Harvey S. Rosen, 1988, "Estimating Vector Autoregressions with Panel Data”, Econometrica, 56 (6), 1371-1395

King R. and R. Levine, 1993, "Finance and Growth: Schumpeter Might Be Right," Quarterly Journal of Economics, 153(3), 717-38.

Kaminsky G. and C Reinhart, 1999,"The Twin Crises: The Causes of Banking and Balance of Payments Problems," American Economic Review, Vol. 89, No. 3, 473500 .

King R. and R. Levine, 1993, "Finance, Entrepreneurship, and Growth: Theory and Evidence", Journal of Monetary Economics, 32(3), 513-542. 
Levine R., N. Loayza, and T. Beck, 2000, "Financial Intermediation and Growth: Causality and Causes," Journal of Monetary Economics, 46(1), 31-77.

Pesaran H and R.P. Smith, 1995, Estimating Long-Run Relationships from Dynamic Heterogeneous Panels, Journal of Econometrics,68, 79-113.

Pesaran H, R. Smith, and K. Im, 1996, "Dynamic Linear Models for Heterogenous Panels"in The Econometrics of Panel Data, L. Matyas and P. Sevestre, editors, 145-195, Dordrecht: Kluwer Academic Publishers.

Pesaran H. and Y. Shin, 1999, “An Autoregressive Distributed Lag Modelling Approach to Cointegration" chapter 11. in Econometrics and Economic Theory in the 20th Century: The Ragnar Frisch Centennial Symposium. Cambridge University Press.

Pesaran H., Y. Shin, and R. Smith, 1999, "Pooled Mean Group Estimation of Dynamic Heterogeneous Panels," Journal of the American Statistical Association, 94, 621-634.

Robertson D and J. Symons,"Some Strange Properties of Panel Data Estimators", Journal of Applied Econometrics, 7, 175-189.

Roubini N. and X. Sala-y-Martin 1992, "Financial Repression and Economic Growth”, Journal Of Development Economics, Vol. 39 (1) pp. 5-30

Sachs J., A. Tornell, and A. Velasco, 1996, "Financial Crises in Emerging Markets: The Lessons from 1995," Brookings Papers on Economic Activity, 147-98.

Tornell A. and M. Schneider, 2000, "Boom-Bust Cycles and the Balance Sheet Effect",unpublished.

Tornell A. and F. Westermann, 2001, "Boom-Bust Cycles: Facts and Explanations", unpublished. 
Table 1 Descriptive Statistics for Countries with Crisis Experience

\begin{tabular}{|c|c|c|c|}
\hline & ANTE CRISIS PERIOD & CRISIS PERIOD & T-test P-Value \\
\hline Liquid Liabilities /GDP & $\mathrm{t}-5$ to the starting year of crisis, $\mathrm{t}$ & $\mathrm{t}+1$ to $\mathrm{t}+6$ & Ho: ante=crisis \\
\hline OBS & 0.047578843 & 0.007509945 & 0.07 \\
\hline Private Credit/ GDP & 48 & 50 & 0.06 \\
\hline OBS & 0.066891752 & 0.027435856 & \\
\hline Real Per Capita Growth & 48 & 49 & 0.0157 \\
\hline OBS & -0.269641648 & 0.780450416 & \\
\hline Correlation (Liquid Liabilities, Growth) & 56 & 53 & 0.35 \\
\hline OBS & -0.1072 & -0.1208 & \\
\hline OBS & 42 & 40 & 0.18 \\
\hline
\end{tabular}


TABLE 2: Financial Intermediation, Crisis Experience and Growth; system estimator

\begin{tabular}{lcccc}
\hline \hline Regressors & Coefficient & Std Error & Coefficient & Std Error \\
\hline Constant & 0.751883 & 1.0316 & 3.06879 & 0.9624 \\
Log of Initial Income per Capita & -0.204635 & 0.1096 & 0.10722 & 0.1226 \\
Average year of secondary schooling & 0.477162 & 0.1463 & 0.14471 & 0.1519 \\
Liquid Liabilities & 2.086862 & 0.1837 & & \\
Liquid Liabilities*Crisis Experience & -0.379457 & 0.0414 & & \\
Private Credit & & & 1.43412 & 0.0634 \\
Private Credit*Crisis Experience & & & -0.26059 & 0.0411 \\
Government size & -1.187689 & 0.2865 & -1.90475 & 0.2665 \\
Inflation Rate & 0.325441 & 0.3941 & -0.39897 & 0.3056 \\
Black Market Premium & -1.980017 & 0.09 & -1.18752 & 0.0859 \\
Dummy 71-75 & -0.833267 & 0.08 & -0.98195 & 0.0642 \\
Dummy 76-80 & -0.882677 & 0.1251 & -0.96971 & 0.1158 \\
Dummy 81-85 & -3.043068 & 0.1322 & -2.96185 & 0.1672 \\
Dummy 86-90 & -2.074279 & 0.1594 & -2.01945 & 0.1674 \\
Dummy 91-95 & -2.867901 & 0.1776 & -2.77716 & 0.1637 \\
\hline Sargan Test (P-value) & 0.467 & & 0.41 & \\
2nd Order Serial Correlation (P-Value) & 0.836 & & 0.642 & \\
\hline Number of Countries & 74 & & 359 & \\
Number of Obsevations & 359 & & & \\
\hline \hline
\end{tabular}


TABLE 3: Financial Intermediation,Latin America and Growth; system estimator

\begin{tabular}{lcccc}
\hline \hline Regressors & Coefficient & Std Error & Coefficient & Std Error \\
\hline Constant & 2.074185 & 0.9213 & 5.379823 & 0.9257 \\
Log of Initial Income per Capita & -0.181326 & 0.0955 & -0.036462 & 0.1106 \\
Average year of secondary schooling & 0.592854 & 0.1141 & 0.434511 & 0.1289 \\
Liquid Liabilities & 2.098478 & 0.1586 & & \\
Liquid Liabilities*Latin America & -0.203884 & 0.0498 & & \\
Private Credit & & & 1.557448 & 0.073 \\
Private Credit*Latin America & & & -0.199361 & 0.053 \\
Government size & -1.946623 & 0.1978 & -2.665188 & 0.2506 \\
Inflation Rate & 0.363155 & 0.357 & -0.287723 & 0.2191 \\
Black Market Premium & -1.741312 & 0.0957 & -1.111259 & 0.0933 \\
Dummy 71-75 & -0.923225 & 0.0941 & -1.03786 & 0.129 \\
Dummy 76-80 & -1.070274 & 0.1002 & -1.146228 & 0.1307 \\
Dummy 81-85 & -3.103926 & 0.1268 & -3.131746 & 0.19 \\
Dummy 86-90 & -2.271343 & 0.1176 & -2.261626 & 0.1375 \\
Dummy 91-95 & -3.18211 & 0.1357 & -3.154942 & 0.1465 \\
\hline Sargan Test (P-value) & 0.467 & & 0.461 & \\
2nd Order Serial Correlation (P-Value) & 0.836 & & 0.655 & 74 \\
\hline Number of Countries & 74 & & 359 & \\
Number of Obsevations & 359 & & & \\
\hline \hline
\end{tabular}


Table 4: ARDL(3,3,1,1,1,1); Dependant Variable: Growth; Financial Indicator: Private Credit/GDP Pooled Mean Group, Mean Group estimators and Dynamic Fixed Effect, controlling for country and time effects Sample: All Countries 1961-1997

\begin{tabular}{|c|c|c|c|c|c|c|c|c|}
\hline \multirow[b]{2}{*}{ Variabels } & \multicolumn{2}{|c|}{ Pooled Mean Group } & \multicolumn{2}{|c|}{ Mean Group } & \multicolumn{2}{|c|}{ Hausman Tests } & \multicolumn{2}{|c|}{ Dynamic Fixed Effect } \\
\hline & Coef. & St.Er. & Coef. & St.Er. & h-test & p-val & Coef. & St.Er. \\
\hline \multicolumn{9}{|c|}{ Long-Run Coefficients } \\
\hline Private Credit & 0.741 & 0.349 & 0.032 & 7.235 & 0.01 & 0.92 & 1.6063 & 0.9594 \\
\hline Initial Income & -7.042 & 0.738 & -23.06 & 15.493 & 1.07 & 0.3 & -3.717 & 0.9322 \\
\hline Governement Size & -5.359 & 0.545 & -1.76 & 3.423 & 1.13 & 0.29 & -2.6075 & 0.7248 \\
\hline Trade Openness & 3.614 & 0.352 & 0.966 & 4.127 & 0.41 & 0.52 & 3.9511 & 0.6987 \\
\hline \multirow[t]{2}{*}{ Inflation Rate } & -3.383 & 0.411 & -3.141 & 3.805 & 0 & 0.95 & -2.9602 & 0.4325 \\
\hline & & \multicolumn{3}{|c|}{ Joint Hausman Test } & 6.78 & 0.24 & & \\
\hline \multicolumn{9}{|c|}{ Error Correction Coefficients } \\
\hline Phi & -0.964 & 0.099 & -2.159 & 0.149 & & & -0.8538 & 0.0484 \\
\hline \multicolumn{9}{|c|}{ Short-Run Coefficients } \\
\hline$\Delta$ growth $(-1)$ & 0.127 & 0.067 & 1.878 & 0.734 & & & 0.043 & 1.6642 \\
\hline$\Delta$ growth $(-2)$ & -0.071 & 0.04 & -1.773 & 0.232 & & & 0.0417 & -1.8276 \\
\hline$\Delta$ Private Credit & -15.236 & 8.54 & -1.784 & -8.908 & & & 1.6453 & -2.1842 \\
\hline$\Delta$ Private Credit $(-1)$ & 6.332 & 5.768 & 1.098 & -3.827 & & & 1.1872 & -1.1897 \\
\hline$\Delta$ Private Credit $(-2)$ & -7.553 & 6.975 & -1.083 & -12.859 & & & 1.7477 & -2.7131 \\
\hline$\Delta$ Initial Income & -8.889 & 3.099 & -2.869 & -3.764 & & & 2.7932 & -1.449 \\
\hline$\Delta$ governement & -14.503 & 2.526 & -8.685 & 3.134 & & & -1.916 & 1.11 \\
\hline$\Delta$ trade & -3.055 & 1.672 & -1.827 & -7.938 & & & 2.7932 & -1.449 \\
\hline$\Delta$ inflation & -5.06 & 1.641 & -3.084 & 3.824 & & & 1.4129 & -2.6074 \\
\hline Inpt & 0.022 & 1.425 & 0.015 & 16.332 & & & & \\
\hline No. Countries & 48 & & 48 & & & & 48 & \\
\hline No.Observations & 1211 & & 1211 & & & & 1211 & \\
\hline Avg RBarSq & 0.65 & & 0.68 & & & & 0.68 & \\
\hline
\end{tabular}


Table 5: ARDL(3,3,1,1,1,1); Dependant Variable: Growth; Financial Indicator: Liquid Liabilities/GDP Pooled Mean Group, Mean Group estimators and Dynamic Fixed Effect, controlling for country and time effects Sample: All Countries 1961-1997

\begin{tabular}{|c|c|c|c|c|c|c|c|c|}
\hline \multicolumn{3}{|c|}{ Pooled Mean Group } & \multicolumn{2}{|c|}{ Mean Group } & Hausman Tests & \multicolumn{3}{|c|}{ Dynamic Fixed Effect } \\
\hline Variables & Coef. & St.Er. & Coef. & St.Er. & h-test & p-val & Coef. & St.Er. \\
\hline Long-Run Coefficients & & & & & & & & \\
\hline Liquid Liabilities & 1.677 & 0.526 & -4.506 & 26.511 & 0.05 & 0.82 & 0.3226 & 1.5346 \\
\hline Initial Income & -8.119 & 0.529 & 1.447 & 11.629 & 0.68 & 0.41 & -3.1004 & 0.8602 \\
\hline Governement Size & -0.751 & 0.502 & -6.541 & 5.889 & 0.97 & 0.32 & -2.3901 & 0.7706 \\
\hline Trade Openness & 1.077 & 0.456 & 10.051 & 4.393 & 4.23 & 0.04 & 3.9237 & 0.6802 \\
\hline \multirow[t]{2}{*}{ Inflation Rate } & -3.362 & 0.486 & -5.979 & 13.038 & 0.04 & 0.84 & -3.1331 & 0.4465 \\
\hline & & \multicolumn{3}{|c|}{ Joint Hausman Test } & 9.5 & 0.11 & & \\
\hline \multicolumn{2}{|c|}{ Error Correction Coefficients } & & & & & & & \\
\hline Phi & -0.861 & 0.084 & -1.788 & 0.149 & & & -0.8406 & 0.0472 \\
\hline \multicolumn{2}{|l|}{ Short-Run Coefficients } & & & & & & & \\
\hline$\Delta$ growth $(-1)$ & 0.076 & 0.054 & 0.467 & 0.106 & & & 0.0984 & 0.0379 \\
\hline$\Delta$ growth $(-2)$ & -0.053 & 0.039 & 0.097 & 0.063 & & & -0.0542 & 0.028 \\
\hline$\Delta$ liquid_Liabilities & -22.177 & 8.048 & -7.626 & 25.191 & & & -15.7766 & 2.8192 \\
\hline$\Delta$ liquid_Liabilities(-1) & 17.716 & 7.11 & 4.199 & 21.24 & & & 12.16 & 2.9951 \\
\hline$\Delta$ liquid_Liabilities(-2) & -2.588 & 4.84 & -12.56 & 17.576 & & & -5.7187 & 2.8335 \\
\hline$\Delta$ Initial Income & -8.043 & 3.008 & -7.236 & 4.025 & & & -4.6441 & 2.2555 \\
\hline$\Delta$ governement & -13.242 & 2.868 & -5.8 & 2.862 & & & -1.6355 & 0.9049 \\
\hline$\Delta$ trade & -0.747 & 2.152 & -8.657 & 2.327 & & & -2.4328 & 0.938 \\
\hline$\Delta$ inflation & -6.19 & 4.176 & 15.862 & 5.394 & & & -2.4466 & 0.5318 \\
\hline$\Delta$ inflation $(-1)$ & 60.921 & 6.114 & 119.028 & 52.686 & & & 0.7388 & 0.8909 \\
\hline Inpt & 57.06 & 5.992 & 104.47 & 50.76 & & & & \\
\hline No. Countries & 49 & & 49 & & & & 49 & \\
\hline No.Observations & 1235 & & 1235 & & & & 1235 & \\
\hline Avg RBarSq & 0.64 & & 0.68 & & & & 0.44 & \\
\hline
\end{tabular}


Figure 1a: Financial Intermediation

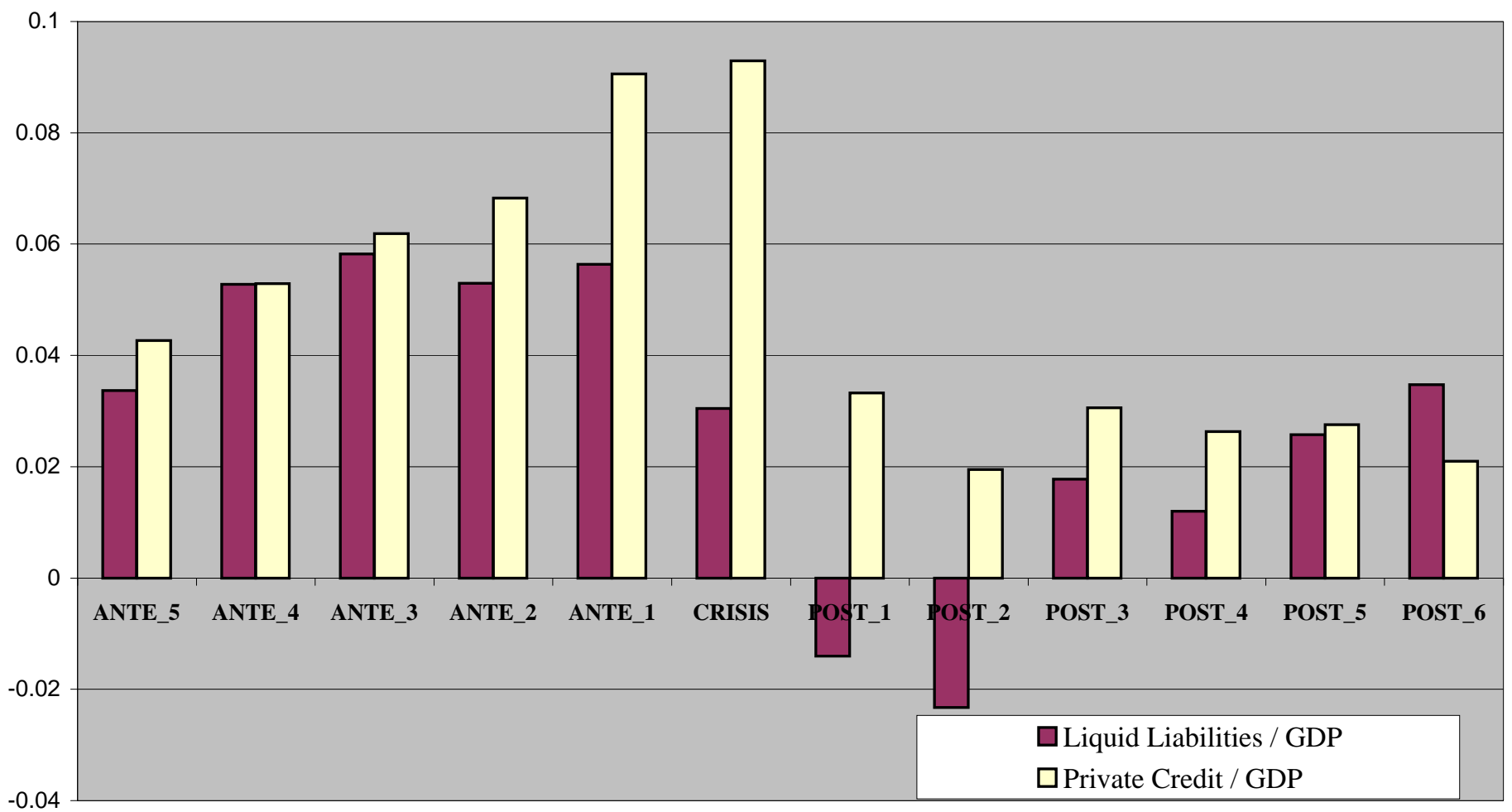

Figure 1b: Growth

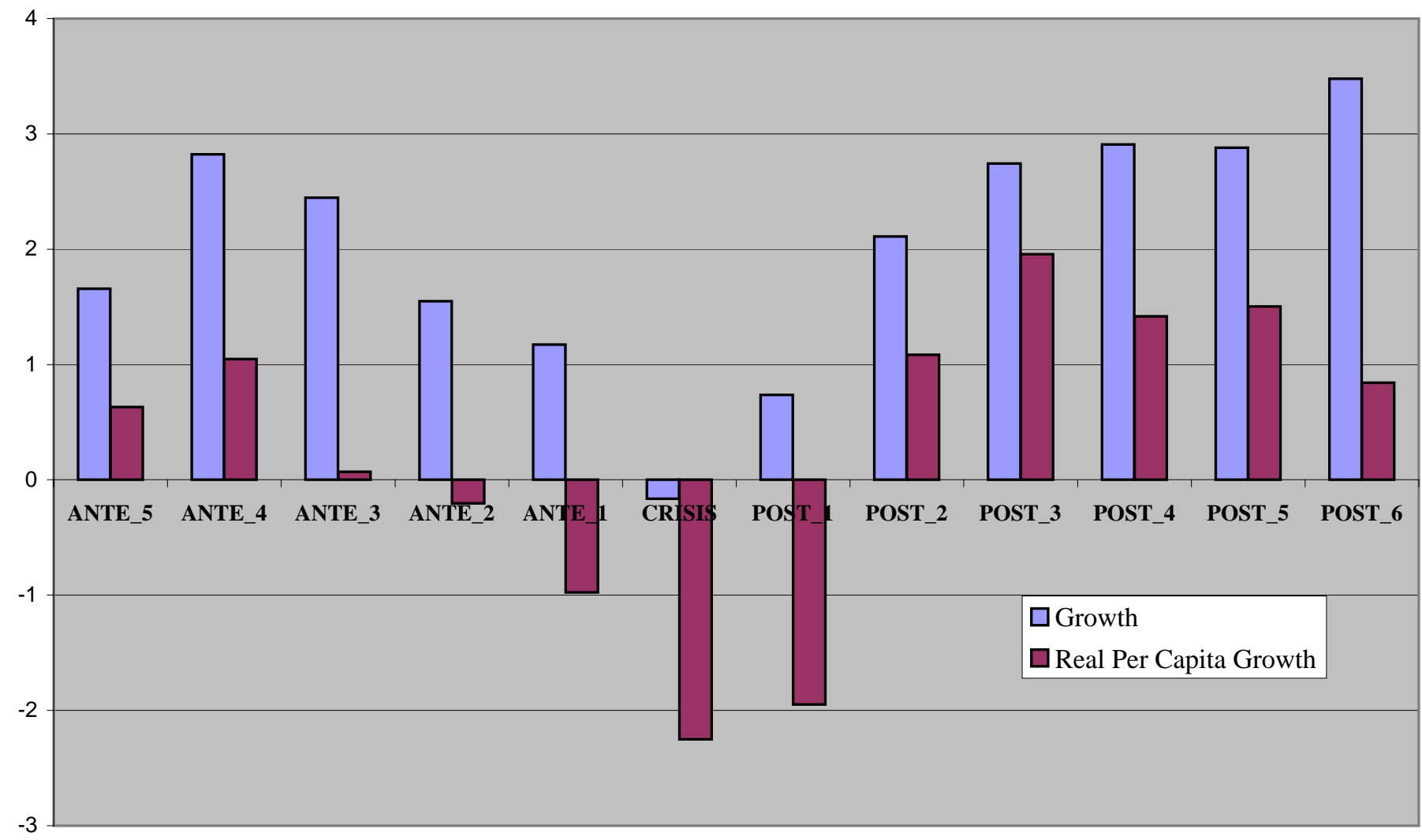


Figure 2a :Short Run Growth Effects of Financial Development

Countries with systemic crisis experience

Liquid Liabilities/GDP

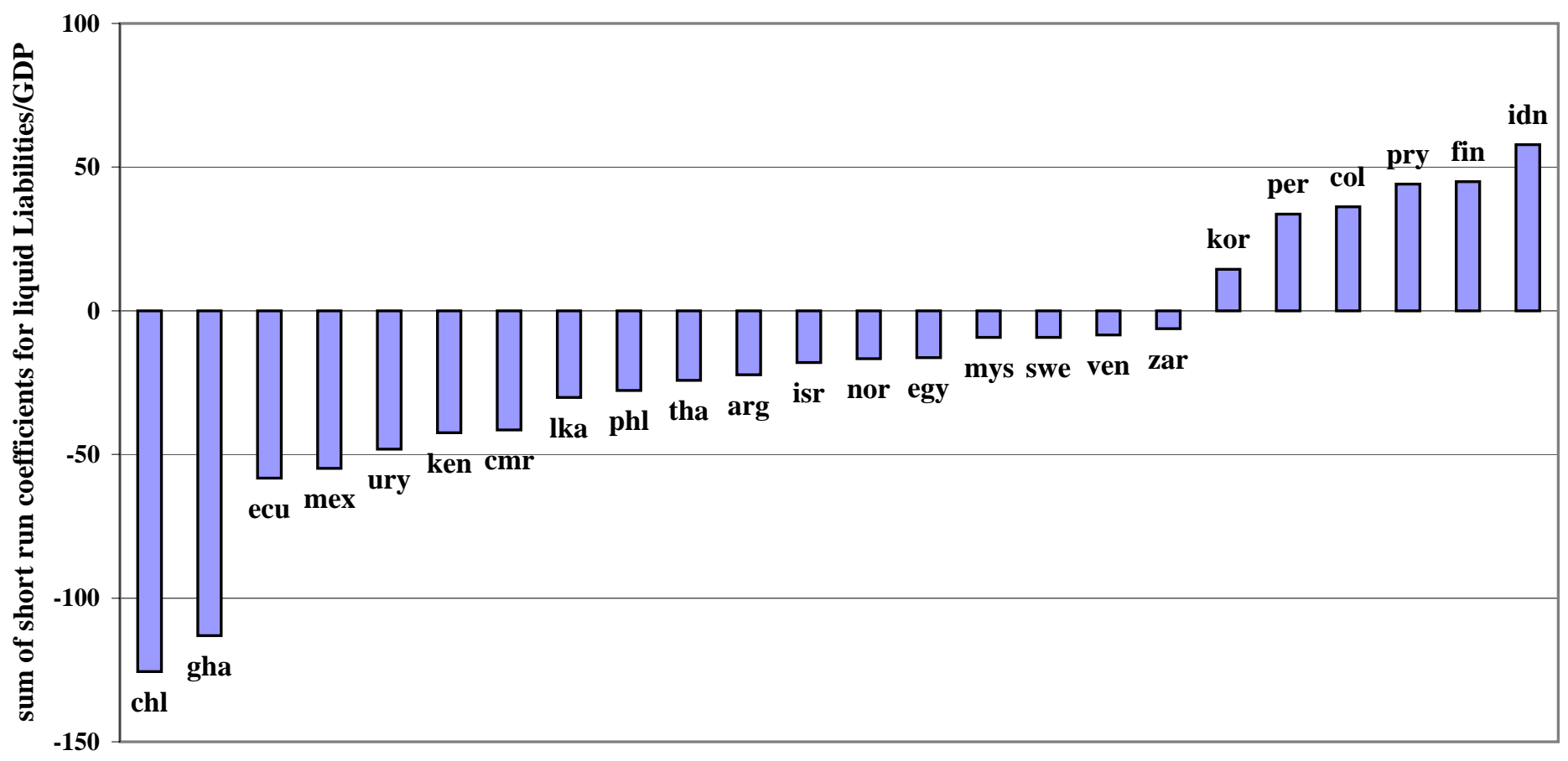

Figure 2b: Short Run Growth Effects of Financial Development

Countries with no systemic crisis experience

Liquid Liabilities/GDP

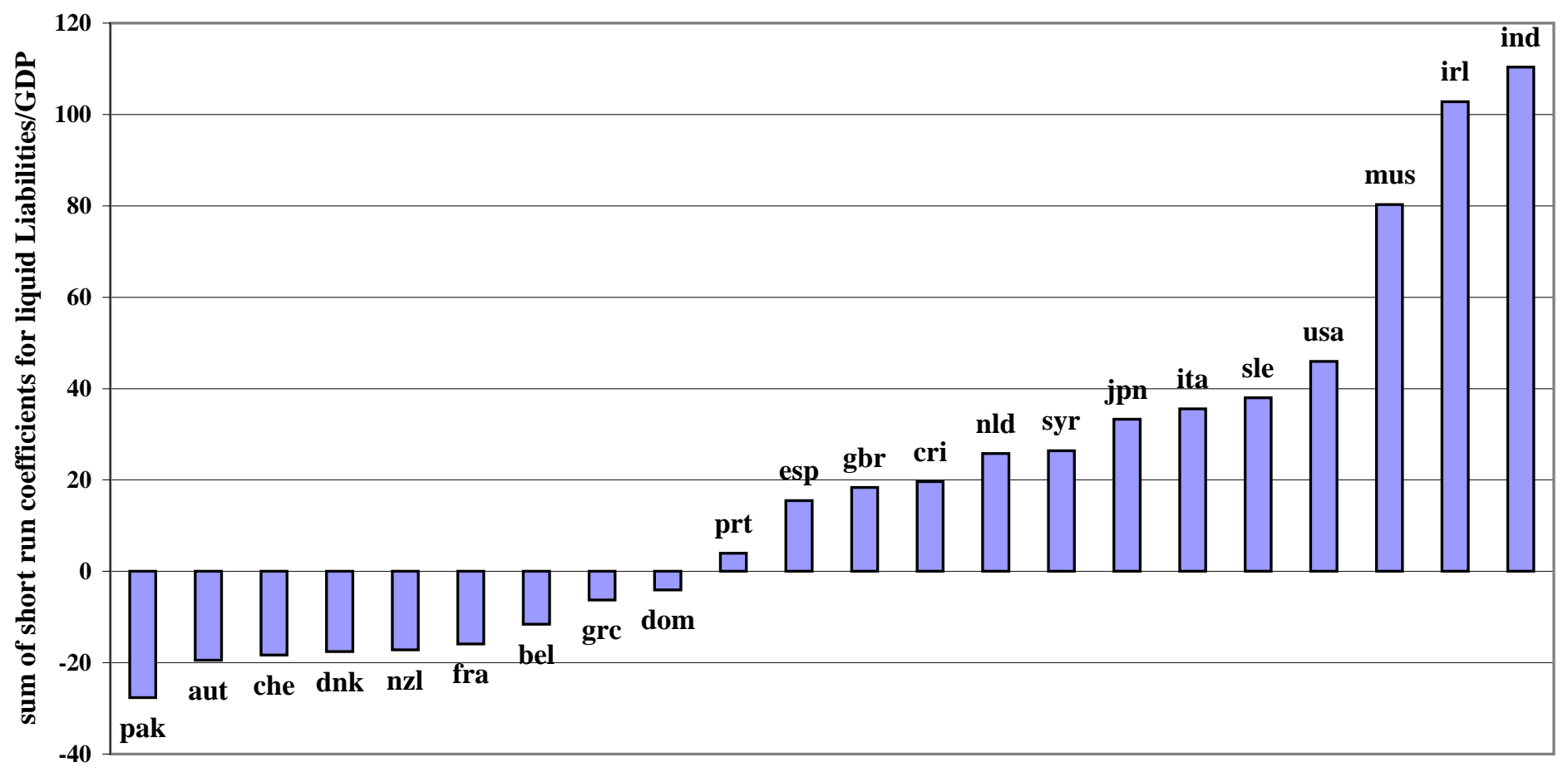


APPENDIX A:LIST OF SYTEMIC BANKING CRISES*

\begin{tabular}{|c|c|c|c|c|c|c|}
\hline Country Name & Start & End & Start & End & Start & End \\
\hline Algeria & 1990 & 1992 & & & & \\
\hline Argentina & 1980 & 1982 & 1989 & 1990 & 1995 & 1995 \\
\hline Benin & 1988 & 1990 & & & & \\
\hline Bolivia & 1986 & 1987 & 1994 & 2000 & & \\
\hline Brazil & 1990 & 1990 & 1994 & 1996 & & \\
\hline Burkina Faso & 1988 & 1994 & & & & \\
\hline Cameroon & 1987 & 1993 & 1995 & 1998 & & \\
\hline Central African Republic & 1988 & 1999 & & & & \\
\hline Chad & 1992 & 1992 & & & & \\
\hline Chile & 1976 & 1976 & 1981 & 1983 & & \\
\hline Colombia & 1982 & 1987 & & & & \\
\hline Congo, Rep. & 1992 & 2000 & & & & \\
\hline Cote d'Ivoire & 1988 & 1991 & & & & \\
\hline Czech Republic & 1989 & 1991 & & & & \\
\hline Ecuador & 1996 & 2000 & & & & \\
\hline Egypt, Arab Rep. & 1977 & 1985 & & & & \\
\hline El Salvador & 1989 & 1989 & & & & \\
\hline Estonia & 1992 & 1995 & & & & \\
\hline Finland & 1991 & 1994 & & & & \\
\hline Ghana & 1982 & 1989 & & & & \\
\hline Guinea & 1985 & 1985 & 1993 & 1994 & & \\
\hline Hungary & 1991 & 1995 & & & & \\
\hline Indonesia & 1987 & 2000 & & & & \\
\hline Israel & 1977 & 1983 & & & & \\
\hline Kenya & 1985 & 1989 & 1992 & 1992 & 1993 & 1995 \\
\hline Korea, Rep. & 1997 & 2000 & & & & \\
\hline Kuwait & 1988 & 1990 & & & & \\
\hline Latvia & 1995 & 1996 & & & & \\
\hline Lebanon & 1988 & 1990 & & & & \\
\hline Lithuania & 1995 & 1996 & & & & \\
\hline Madagascar & 1988 & 1988 & 1992 & 1992 & & \\
\hline Malaysia & 1997 & 2000 & & & & \\
\hline Mali & 1987 & 1989 & & & & \\
\hline Mauritania & 1984 & 1993 & & & & \\
\hline Mexico & 1995 & 2000 & & & & \\
\hline Nepal & 1988 & 1988 & & & & \\
\hline Niger & 1987 & 1993 & & & & \\
\hline Norway & 1988 & 1998 & & & & \\
\hline Paraguay & 1995 & 2000 & & & & \\
\hline Peru & 1983 & 1990 & & & & \\
\hline Philippines & 1998 & 2000 & & & & \\
\hline Russian Federation & 1995 & 1995 & 1998 & 1998 & & \\
\hline Senegal & 1988 & 1991 & & & & \\
\hline Slovak Republic & 1991 & 2000 & & & & \\
\hline Slovenia & 1992 & 1994 & & & & \\
\hline Spain & 1977 & 1985 & & & & \\
\hline Sri Lanka & 1989 & 1993 & & & & \\
\hline Sweden & 1991 & 1994 & & & & \\
\hline Thailand & 1997 & 2000 & & & & \\
\hline Ukraine & 1997 & 1997 & & & & \\
\hline Uruguay & 1981 & 1984 & & & & \\
\hline Venezuela & 1994 & 2000 & & & & \\
\hline Zaire & 1991 & 1992 & 1994 & 2000 & & \\
\hline Zimbabwe & 1995 & 1995 & & & & \\
\hline
\end{tabular}

Source: Caprio and Klingbiel (1999)

* Here are only listed countries for which we get a precise time period for Banking Crises. 
Appendix B

systemic banking crisis Latin American and Carribean GMM Sample Pooled Mean Group Sample

Algeria

Argentina

Australia

Austria

Belgium

Bolivia

Brazil

Cameroun

Canada

Central African Republic

Chile

Colombia

Costa Rica

Cyprus

Denmark

Dominican Republic

Ecuador

Egypt

El Salvador

Finland

France

Gambia

Germany

Ghana

Great Britain

Greece

Guatemala

Haiti

Honduras

India

Indonesia

Iran

Ireland

Israel

Italy

Jamaica

Japan

Kenya

Korea

Lesotho

Malawi

Malaysia

Mauritius

Mexico

Netherlands

New Zealand

Nicaragua

Niger

Norway

Pakistan

Panama

Papua New Guinea

Paraguay

Peru

Philippines

Portugal

Rwanda

Senegal

Sierra Leone

South Africa

Spain

Sri Lanka

Sudan

Sweden

Switzerland

Syria

Taiwan

Thailand

Togo

Trinidad and Tobago

United States of America

Uruguay

Venezuela

Zaire

Zimbabwe
$\mathrm{X}$

$X$
$X$

$\mathrm{X}$

$\mathrm{X}$

$\mathrm{X}$

$\mathrm{X}$

$\mathrm{X}$

$\mathrm{X}$

X

X

X

X

X

X

X

X

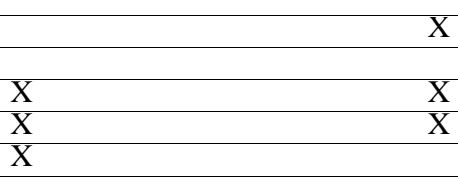

X

X

X

X

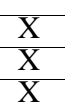

$\mathrm{X}$
$\mathrm{X}$
$\mathrm{X}$

X

X

X

$\mathrm{X}$

X
X
X

X
X

X

X

X
X

$\mathrm{X}$

$X$
$X$
$X$
$X$
$X$

$\mathrm{X}$
$\mathrm{X}$

X

X

X

$X$
$X$
$X$

$\mathrm{X}$

$\mathrm{X}$

X

X

X

$\mathrm{X}$
$\mathrm{X}$
$\mathrm{X}$
$\mathrm{X}$

$\mathrm{X}$

$X$
$X$

$\mathrm{X}$
$\mathrm{X}$
$\mathrm{X}$

X

$X$
$X$
$X$

X

X

$\mathrm{X}$
$\mathrm{x}$
$\mathrm{x}$
$\mathrm{x}$
$\mathrm{X}$
$\mathrm{X}$
$\mathrm{X}$
$\mathrm{X}$

$\mathrm{X}$
$\mathrm{X}$
$\mathrm{X}$

$\mathrm{X}$

$\mathrm{X}$ 


\section{Appendix C: Variables and Sources}

\begin{tabular}{|c|c|c|c|}
\hline Variable & Definition & Original source & Secondary source \\
\hline \multirow[t]{2}{*}{ Level and growth rate of GDP } & Real per capita GDP & World Development Indicators & Loayza et al. (1998) \\
\hline & $\begin{array}{l}\text { Real per capita GDP (for initial GDP in cross-section } \\
\text { regressions) }\end{array}$ & Penn World Tables & \\
\hline Government size & Government expenditure as share of GDP & World Development Indicators & Loayza et al. (1998) \\
\hline Openness to trade & Sum of real exports and imports as share of real GDP & World Development Indicators & Loayza et al. (1998) \\
\hline Inflation rate & Log difference of Consumer Price Index & $\begin{array}{l}\text { International Financial } \\
\text { Statistics (IFS), line } 64\end{array}$ & \\
\hline Average years of schooling & Average years of schooling in the population over 25 & Barro and Lee (1996) & \\
\hline $\begin{array}{l}\text { Average years of secondary } \\
\text { schooling }\end{array}$ & $\begin{array}{l}\text { Average years of secondary schooling in the population } \\
\text { over } 15\end{array}$ & Barro and Lee (1996) & \\
\hline Commercial-Central Bank & $\begin{array}{l}\mathrm{DBA}(\mathrm{t}) /(\mathrm{DBA}(\mathrm{t})+\mathrm{CBA}(\mathrm{t})) \text {, where } \mathrm{DBA} \text { is assets of } \\
\text { deposit money banks (lines 22a-d) and CBA is central } \\
\text { bank assets (lines } 12 \mathrm{a}-\mathrm{d}) \text {. }\end{array}$ & IFS & \\
\hline Private Credit & $\begin{array}{l}\left\{(0.5)^{*}\left[F(t) / P \_e(t)+F(t-1) / P \_e(t-1)\right]\right\} /\left[G D P(t) / P \_a(t)\right], \\
\text { where } F \text { is credit by deposit money banks and other } \\
\text { financial institutions to the private sector (lines } 22 d+ \\
42 d), G D P \text { is line } 99 b, P \_e \text { is end-of period } C P I(\text { line } 64) \\
\text { and } P \_a \text { is the average } C P I \text { for the year. }\end{array}$ & IFS & \\
\hline
\end{tabular}


Appendix D : 1960-1997 ANNUAL DATA CORRELATIONS (five year average data correlation in parenthesis)

\begin{tabular}{|c|c|c|c|c|c|c|c|c|c|c|}
\hline & com & lly & pc & growth & inf & gov & school & trade & bmp & initial \\
\hline com & 1.00 & & & & & & & & & \\
\hline lly & $0.47(0.51)$ & 1.00 & & & & & & & & \\
\hline pc & $0.55(0.6)$ & $0.84(0.84)$ & 1.00 & & & & & & & \\
\hline growth & $0.21 \quad(0.33)$ & $0.15(0.22)$ & $0.14(0.2)$ & 1.00 & & & & & & \\
\hline inf & $-0.2(0.6)$ & $-0.2(-0.26)$ & $-0.1(-0.26)$ & $-0.2(-0.29)$ & 1.00 & & & & & \\
\hline gov & $0.24(0.6)$ & $0.37(0.21)$ & $0.27(0.24)$ & $-0.0(-0.04)$ & -0.11 & 1.00 & & & & \\
\hline school & 0.31 & 0.56 & 0.56 & $0.09(0.13)$ & 0.03 & 0.41 & 1.00 & & & \\
\hline trade & $0.26(0.6)$ & $0.16(0.13)$ & $0.08(0.09)$ & $0.05(0.13)$ & -0.16 & 0.48 & 0.05 & 1.00 & & \\
\hline bmp & $-0.3(0.6)$ & $-0.1(-0.03)$ & $-0.2(0.22)$ & $-0.1(-0.2)$ & 0.26 & -0.13 & -0.10 & -0.21 & 1.00 & \\
\hline initial income & $0.52(0.6)$ & $0.62(0.61)$ & $0.55(0.76)$ & $0.14(-0.14)$ & -0.11 & 0.43 & 0.80 & 0.08 & -0.23 & 1.00 \\
\hline OBS & 2656.00 & 2509.00 & 2521.00 & 2612.00 & 2577.00 & 1551.00 & 2484.00 & 2620.00 & 2576.00 & 2766.00 \\
\hline 5 year avg OBS & 359.00 & 359.00 & 359.00 & 359.00 & 359.00 & 359.00 & 359.00 & 359.00 & 359.00 & 359.00 \\
\hline
\end{tabular}

\section{VARIABLES}

com $=$ Commercial Banks Assets /(Central Banks + Commercial Banks Assets $)$

lly = Liquid Liabilities / GDP

$\mathrm{pc}=$ Private Credit/ GDP

growth= real per capita Growth

inf $=$ inflation rate

gov= governement expenditures / GDP

school $=$ average year of secondary education

trade $=$ trade openess

bmp=black market premium

initial income $=$ beginning of the period real per capita income 
APPENDIX E : Robustness Check for GMM system estimation in Section II.B

Financial Intermediation, Crisis Experience and Growth

\begin{tabular}{|c|c|c|c|c|c|c|}
\hline \multirow[b]{2}{*}{ Regressors } & \multicolumn{2}{|c|}{$\begin{array}{l}\text { GMM sytem estimator } \\
4 \text { instruments: } t-2\end{array}$} & \multicolumn{2}{|c|}{$\begin{array}{l}\text { GMM sytem estimator } \\
8 \text { instruments: } t-2, t-3\end{array}$} & \multicolumn{2}{|c|}{$\begin{array}{l}\text { GMM sytem estimator } \\
8 \text { instruments: } t-3, t-4\end{array}$} \\
\hline & coef & std error & coef & std error & coef & std error \\
\hline Inititial Income & 0.15 & 0.23 & 0.02 & 0.185 & 0.09 & 0.14 \\
\hline private credit & 1.89 & 0.38 & 2.11 & 0.29 & 1.86 & 0.23 \\
\hline private credit* ${ }^{*}$ crisis & -0.23 & 0.09 & -0.29 & 0.05 & -0.2 & 0.05 \\
\hline governement size & -3.04 & 0.67 & -3.87 & 0.49 & -2.76 & 0.45 \\
\hline \multicolumn{7}{|l|}{ Sargan Test } \\
\hline degree of freedom & 29 & & 41 & & 41 & \\
\hline P-Value & 0.198 & & 0.25 & & 0.48 & \\
\hline \multicolumn{7}{|c|}{ Second Order correlation } \\
\hline P-Value & 0.12 & & 0.12 & & 0.125 & \\
\hline Number of Countries & 74 & & 74 & & 74 & \\
\hline Number of Observation & 359 & & 359 & & 359 & \\
\hline
\end{tabular}

